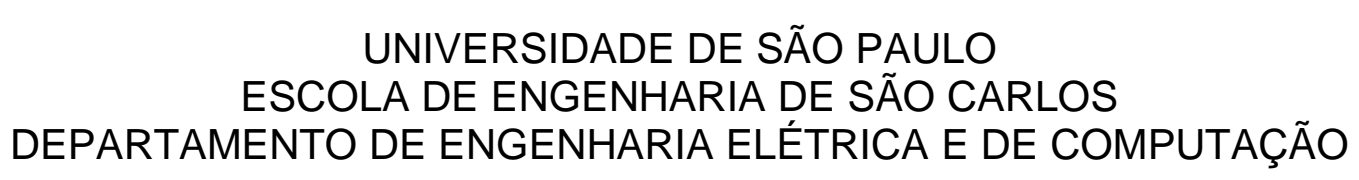

ALINE FLÁVIA NONATO DA COSTA

\title{
Sistema de MEdiçÃo FasoRIAL SinCRONIZADA Aplicado à Proteção de Retaguarda de GRANDES ÁrEAS
}

São Carlos

2015 



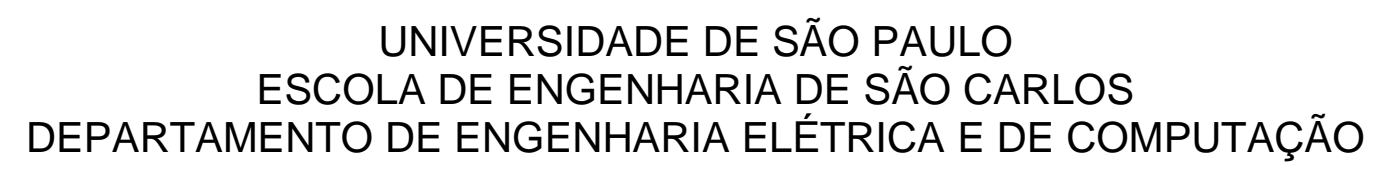

ALINE FLÁVIA NONATO DA COSTA

\section{Sistema de MEdiçÃo FasoRIAL SinCRONIZADA Aplicado à Proteção de Retaguarda de GRANDES ÁREAS}

Dissertação apresentada à Escola de Engenharia de São Carlos, da Universidade de São Paulo como parte dos requisitos para obtenção do título de Mestre em Ciências, Programa de Engenharia Elétrica.

Área de Concentração: Sistemas Elétricos de Potência

Orientador: Prof. Dr. Mário Oleskovicz

\section{São Carlos}

2015 
AUTORIZO A REPRODUÇÃO TOTAL OU PARCIAL DESTE TRABALHO, POR QUALQUER MEIO CONVENCIONAL OU ELETRÔNICO, PARA FINS DE ESTUDO E PESQUISA, DESDE QUE CITADA A FONTE.

N837s Nonato da Costa, Aline Flávia

SISTEMA DE MEDIÇÃO FASORIAL SINCRONIZADA APLICADO

À PROTEÇÃO DE RETAGUARDA DE GRANDES ÁREAS / Aline

Flávia Nonato da Costa; orientador Mário Oleskovicz. São Carlos, 2015.

Dissertação (Mestrado) - Programa de Pós-Graduação em Engenharia Elétrica e Área de Concentração em Sistemas Elétricos de Potência -- Escola de Engenharia de São Carlos da Universidade de São Paulo, 2015.

1. Linhas de transmissão. 2. Proteção de retaguarda. 3. Sistema de Medição Fasorial Sinconizada. 4. Sistema de Proteção de Grandes Áreas. I. Título. 


\section{FOLHA DE JULGAMENTO}

Candidato: Engenheiru ALINE FLAVIA NONATO DA COSTA.

Milulo da dissentaçäo: "Sistema do mediçâo fosorial sincronizada aplicado d̀ proteçāo de retaguarco de grandes àecs".

Dota da de [esa: 29/10/2015

Comissčo Julgadora:

Prof. Dr. Mario Oleskovicz (Orientador)

(Escola de Engenhoria de São Corlos/EESC)

Prof. Dr. Joss Carlos de Melo Vleira Junior

'Escola de Engenhario de São Corlos/FESC;

Prof, Dr. Kleber Melo e Silva

[Universidace de Erasilia/UnB]

\section{Resullado:}
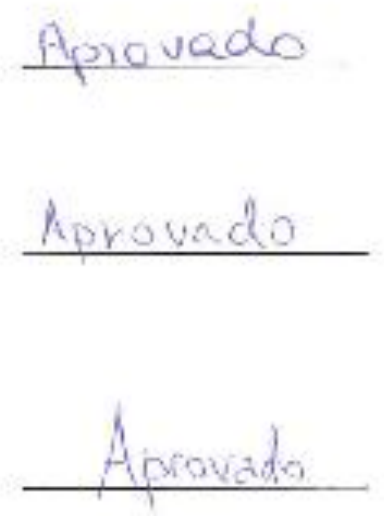

Coordenador do Programa de Pós-Grocucçōo em Engenharia Elélrica: Prof. Associodo Luis Fernando Costa Alberto

Presidente da Comissōo de Pós-Graduaçōo:

Prot. Associoco Paulo César Lima Seganiline 



\section{Agradecimentos}

Sair da minha cidade natal para vir até São Carlos fazer o Mestrado, foi uma decisão difícil, e devo confessar que não era um plano, mas sim, um sonho. Deixar meus pais, viver dois anos longe da minha família e amigos, parecia algo desafiador.

Hoje, dois anos depois de tomar a decisão de vir, eu tenho muito que agradecer a Deus por apontar o caminho certo. O Mestrado me fez evoluir, não apenas como profissional, mas como pessoa também. Devo isso também a minha família, que em nenhum momento deixou de me apoiar. Agradeço aos meus pais, João Batista e Ana Maria, e aos meus irmãos, Cássia, Willian e Daiana.

Em São Carlos eu pude construir uma família de amigos. E foi justamente esta família que me deu um grande apoio para continuar aqui. Eles estiveram sempre dispostos a me ouvir, aconselhar, distrair, e estudar. Obrigada do fundo do meu coração Marcelo Santana, Rafael Jales, Marina Carvalho, Camila Vieira, Fabio Arcamenel, Renan Carmurça, Anna Cecília e Thais Kempner. Outras três pessoas em especial, que construíram essa família junto comigo, foram três irmãos de coração que trouxe comigo lá de Cuiabá, e estão junto comigo desde a graduação. Camila Fantin, Jullian Zan e Elian Agnoleto, obrigada por mais essa caminhada juntos. A todos vocês, eu tenho um recado: que essa família não se desfaça, e que os laços construídos até aqui, permaneçam bem apertados.

Agradeço também aos meus amigos de Cuiabá Amanda Peres, Mayara Sales, Luiz Augusto, Alan Sales, Tisciane Perpétuo e Thiago Mengatti, que mesmo longe, oraram por mim, torceram e estão esperando pelo meu retorno.

Quero agradecer também aos meus colegas de laboratório, que me fizeram companhia durante muitos cafés, churrascos, e me ajudaram imensamente a 
concluir a pesquisa, seja com palavras de apoio, ou me ensinando alguma técnica. Obrigada Fabricio Mourinho, Athila Quaresma, Guacira Costa, Eduardo Augusto, Rodolfo Rocha, Douglas Gomes, Vinicius Albernaz, Rui Bertho, Ricardo Scarcelli, Júlio, Jáder Breda, Luiz Henrique, Rogerio Lima, Luciano Carli, Fernando Bottura, Juliano, Daniel Motter, Rodrigo Pavanello e Lázaro Eduardo.

Durante os últimos meses do Mestrado, recebi o apoio incondicional de uma pessoa que se tornou especial em minha vida. Agradeço imensamente ao apoio profissional e sentimental de Vinícius Moro, que não mediu esforços para me ajudar a concluir a pesquisa. Esse suporte também me foi dado por Juarez, Vera e Natália, que foram uma família quando eu fiquei tantos meses longe de casa. Muito obrigada!

À Coordenação de Aperfeiçoamento Pessoal de Nível Superior (CAPES), agradeço pelo apoio financeiro concedido.

Por último, e não menos importante, gostaria de agradecer aos docentes e funcionários da Escola de Engenharia de São Carlos (EESC-USP), que me acolheram, aconselharam e me ajudaram a iniciar a caminhada para construir a profissional que serei daqui pra frente. Meu muito obrigado em especial aos professores Dr. Mário Oleskovicz, Dr. José Carlos de Melo Vieira Júnior e Dr. Denis Vinicius Coury.

Hoje, concluo com alegria, graças a todos vocês, uma fase que foi de extrema importância em minha vida. Não apenas pelo título que receberei, mas também pela pessoa que me tornei. Tenho orgulho de todos vocês, e sentirei muita saudade dos quais a convivência diária se encerra aqui. Espero que a vida, algum dia, faça com que a gente volte a se cruzar em muitos momentos felizes. 


\section{Resumo}

COSTA, A. F. N. Sistema de Medição Fasorial Sincronizada Aplicado à Proteção de Retaguarda de Grandes Áreas. 2015. 120 p. Dissertação (Mestrado) - Escola de Engenharia de São Carlos, Universidade de São Paulo, São Carlos, 2015.

Este trabalho tem o objetivo de apresentar o desenvolvimento de uma metodologia para a proteção de retaguarda de linhas de transmissão de grandes áreas, utilizando dados de um Sistema de Medição Fasorial Sincronizada. O estudo se justifica devido à contínua expansão dos Sistemas de Transmissão, tais como os que fazem parte do Sistema Interligado Nacional. Vale esclarecer que esta expansão pode vir a dificultar a operação e controle do mesmo, o que faz com que seja necessário, um sistema de proteção cada vez mais confiável, que diminua o impacto de eventos danosos de grande porte, e que atenda aos requisitos de um sistema de proteção de grandes áreas. Neste contexto, o modelo do sistema elétrico de potência em análise foi implementado computacionalmente a partir do RSCAD, ambiente computacional e interface gráfica do RTDS® (Real Time Digital Simulator). Como principal passo, o algoritmo desenvolvido verifica a variação da potência ativa em todos os barramentos monitorados do sistema de transmissão e, de acordo com tal variação, associada ao estado dos dois extremos da linha, detecta e aponta a localização de uma situação de falta. Pelos resultados obtidos, a metodologia se mostrou eficiente na detecção e localização da falta em linhas de transmissão para sistemas de grandes áreas. Toda a metodologia desenvolvida, considerações adotadas e os promissores resultados observados serão reportados neste documento.

Palavras Chave: Linhas de transmissão, Proteção de retaguarda, Sistema de Medição Fasorial Sincronizada, Sistema de Proteção de Grandes Áreas. 



\section{Abstract}

COSTA, A. F. N. Synchronized Phasor Measurement System Applied to Wide Area Protection of Transmission Systems. 2015.120 p. Dissertation (Master Degree) - Engineering School of São Carlos, University of São Paulo, São Carlos, 2015.

This work aims to present the development of a methodology for wide area transmission line backup protection, using Synchronized Phasor Measurement Systems. This study is justified due to continuous expansion of Transmission Systems, such as those which are part of the National Interconnected System. It is worth clarifying that this expansion might difficult system operation and control, which makes necessary to have an increasingly reliable protection system, that minimizes the impact of large dangerous events, and, at the same time, supplies the requirements of a wide area protection system. Within this context, the electrical system model under analysis was implemented through RSCAD, which is a RTDS® (Real Time Digital Simulator) computing environment and graphical interface. As main step, the developed algorithm verifies the active power variation in all monitored buses of the transmission system and then, according to such variation, associated with the communication of the variation state of both line sides, detects and indicates the localization of a faulting condition. According to the results obtained, the methodology has shown its efficiency in transmission line faults detection and localization for wide areas of electrical power systems. The entire developed methodology, considerations adopted and promising outcomes will be reported along this document.

Keywords: Transmission lines, Backup protection, Synchronized Phasor Measurement System, Wide Area Protection System. 



\section{Lista de Figuras}

Figura 1.1 - Sistema Interligado Nacional. Fonte: ONS, 2014 .............................24

Figura 1.2 - Etapas de desenvolvimento da pesquisa.........................................29

Figura 2.1 - Representação do relé de distância tipo mho. Adaptado: IEEE,

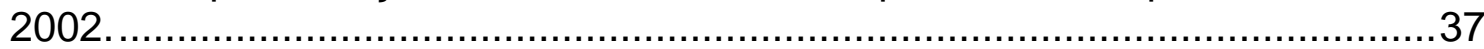

Figura 2.2 - Representação da proteção diferencial. Adaptado: MOLAS; SILVA, 2012 .

Figura 2.3 - Proteção de retaguarda. Adaptado: (COURY; OLESKOVICZ; GIOVANINI, 2007).

Figura 2.4 - Representação da proteção diferencial de potência. Fonte: DARWISH et al. (2009).

Figura 3.1 - Representação de um sinal senoidal puro.

Figura 3.2 - Figura 3.3 - Representação fasorial de X. Adaptado: PHADKE; THORP (2008).

Figura 3.4 - Representação de um SMFS. Adaptado: MENEZES (2012) . .56

Figura 3.5 - Hardware básico de uma PMU. Adaptado: PHADKE; THORP (2008).

Figura 3.6 - Formato das mensagens da PMU. Fonte: IEEE POWER AND ENERGY SOCIETY (2011).

Figura 4.1 - Uma das janelas propiciadas pela interface do RTDS $\AA$.......................75

Figura 4.2 - O rack contendo a configuração do RTDS $\AA$ em uso no LSEE...............76

Figura 4.3 - Sistema teste simulado. Fonte: SANTOS et al. (2015) .......................78

Figura 4.4 - Desenho da torre de transmissão do modelo simulado no RTDS $\circledast$

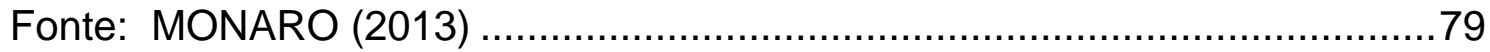

Figura 4.5 - Sentido adotado para a medição e cálculo das potências. ....................84

Figura 4.6 - Fluxograma da metodologia desenvolvida para a PDPL......................86

Figura 4.7 - Diagrama de blocos da implementação do algoritmo PDPL. ................87

Figura 4.8 - Representação do comportamento da potência em condições normais (a) e em condições de falta interna (b) ...............................................8 
Figura 4.9 - Fluxograma da metodologia desenvolvida para a PDP.

Figura 4.10 - Diagrama de blocos da implementação do algoritmo PDP.

Figura 4.11 - Exemplificação do sistema em três condições: Condições normais de operação sem variação de carga (a); Condições de falta (b); Condições normais de operação sem variação de carga(c).

Figura 5.1 - Potência ativa trifásica $P_{25}$ para o sistema em condições normais (LT3).

Figura 5.2 - Potência ativa trifásica $P_{52}$ para o sistema em condições normais (LT3).

Figura 5.3 - Potência ativa trifásica $P_{25}$ para uma falta na LT3..........................100

Figura 5.4 - Potência ativa trifásica $P_{52}$ para uma falta na LT3............................101

Figura 5.5 - Potência ativa trifásica $P_{46}$ para uma falta na LT3............................102

Figura 5.6 - Potência ativa trifásica $P_{64}$ para uma falta na LT3.............................102

Figura 5.7 - Potência ativa trifásica $P_{54}$ para o sistema em condições normais (LT5).

Figura 5.8 - Potência ativa trifásica $P_{45}$ para o sistema em condições normais (LT5).

Figura .5 .9 - Potência ativa trifásica $P_{54}$ para o sistema em condições normais com variação de carga (LT5).

Figura 5.10 - Potência ativa trifásica $P_{45}$ para o sistema em condições normais com variação de carga (LT5).

Figura 5.11 - Desempenho da metodologia da PDPL frente a baixos valores de resistência de falta.

Figura 5.12 - Desempenho da metodologia da PDPL frente a valores altos de resistência de falta.

Figura .5.13 - Desempenho da metodologia da PDPL de acordo com o tipo de falta.

Figura 5.14 - Desempenho da metodologia da PDPL de acordo com a distância próxima à barra 2 .

Figura 5.15 - Desempenho da metodologia da PDPL de acordo com a distância próxima à barra 5 .

Figura 5.16 - Desempenho da metodologia da PDP para baixas resistências de falta. 
Figura 5.17 - Desempenho da metodologia da PDP para altas resistências de falta.

Figura 5.18 - Desempenho da metodologia da PDP de acordo com o tipo de falta.

Figura 5.19 - Desempenho da metodologia da PDP de acordo com a distância de aplicação da falta.

Figura 5.20 - Desempenho da metodologia da PDP de acordo com a distância de aplicação da falta. 



\section{Lista de Tabelas}

Tabela 3.1 - Causas da alta latência do SMFS. Fonte: IEEE POWER AND

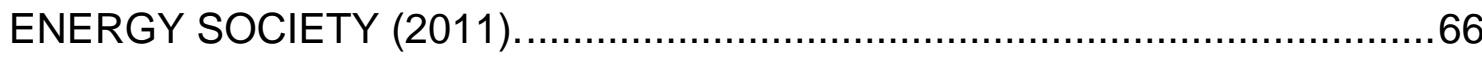

Tabela 4.1 - Dados das linhas de transmissão......................................................79

Tabela 4.2 - Dados construtivos das linhas de transmissão simuladas no RTDS $\AA$





Tabela 5.1 - Banco de dados formado via as simulações dispondo do RTDS..........97

Tabela 5.2 - Desempenho da PDPL em relação à resistência de falta. …...............108

Tabela 5.3 - Desempenho da PDPL em relação ao tipo de falta considerado. .......110

Tabela 5.4 - Desempenho da PDPL em relação à localização. …………………...112

Tabela 5.5 - Desempenho da PDPL em relação ao ângulo de inserção da falta. ...112

Tabela 5.6 - Desempenho da PDPL em relação à linha de transmissão onde ocorreu a falta.

Tabela 5.7 - Desempenho da PDP em relação à resistência de falta. …................115

Tabela 5.8 - Desempenho da PDP em relação ao tipo de falta...............................116

Tabela 5.9 - Desempenho da PDP em relação à distância de aplicação da falta. ..118

Tabela 5.10 - Desempenho da PDP em relação ao ângulo de inserção da falta. ...118

Tabela 5.11 - Desempenho da PDP em relação à linha de transmissão onde ocorreu a falta. 



\section{Lista de Siglas e Abreviaturas}

$\begin{array}{ll}\text { GPS } & \text { Global Positioning System } \\ \text { IEC } & \text { International Electrotechnical Commission } \\ \text { IED } & \text { Intelligent Electronic Device } \\ \text { IEEE } & \text { Institute of Electric and Electronics Engineering } \\ \text { LT } & \text { Linha de Transmissão } \\ \text { ONS } & \text { Operador Nacional do Sistema } \\ \text { PDC } & \text { Phasor Data Concentrator } \\ \text { PDP } & \text { Proteção Diferencial de Potência } \\ \text { PDPL } & \text { Proteção Diferencial de Potência Local } \\ \text { PMU } & \text { Phasor Measurement Unit } \\ \text { PPS } & \text { Pulso Por Segundo } \\ \text { RTDS® } & \text { Real Time Digital Simulator } \\ \text { SEP } & \text { Sistema Elétrico de Potência } \\ \text { SIN } & \text { Sistema Interligado Nacional } \\ \text { SMFS } & \text { Sistema de Medição Fasorial Sincronizada } \\ \text { TDF } & \text { Transformada Discreta de Fourier } \\ \text { UTC } & \text { Universal Time Coordinated } \\ \text { WAMS } & \text { Wide Area Measurement System }\end{array}$





\section{SUMÁRIO}

1 Introdução

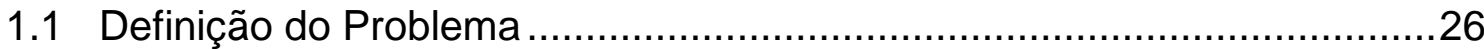

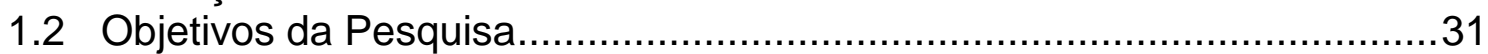



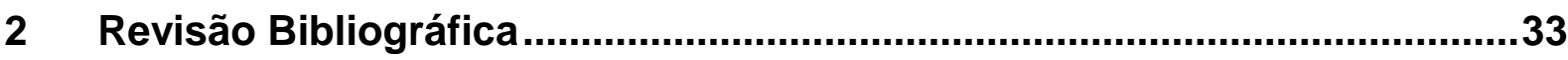

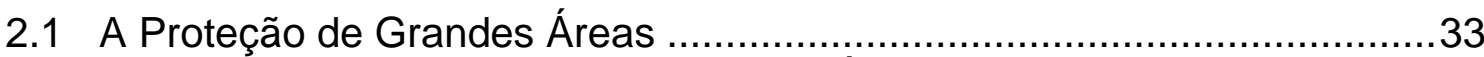

2.2 A Proteção de Retaguarda de Grandes Áreas .......................................42

2.3 O Sistema de Medição Fasorial Sincronizado........................................44

2.4 O Sistema de Medição Fasorial Sincronizado Aplicado na Proteção de Retaguarda de Linhas de Transmissão...............................................46

2.5 A Proteção Diferencial de Potência como Proteção de Retaguarda de

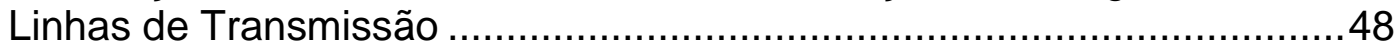

3 Sistema de Medição Fasorial Sincronizado ...............................................53

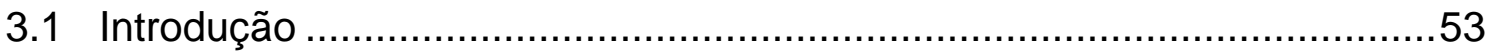

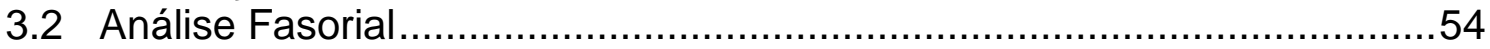

Componentes do Sistema de Medição Fasorial Sincronizada ..................55

3.355

3.3.1 Global Positioning System....................................................56

3.3.2 Unidades de Medição Fasorial ...............................................58

3.3.3 A Transformada Discreta de Fourier ........................................61

3.3.4 O Concentrador de Dados Fasoriais .........................................62

3.3.5 Sistema de Comunicação e Transferência de Dados......................63

3.3.6 Aplicações de PMU ...................................................................67

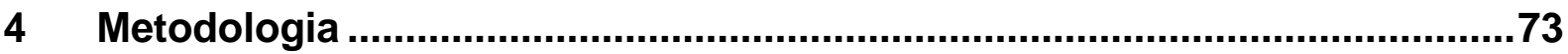

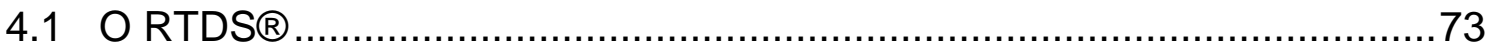

4.2 Descrição do Sistema Elétrico Simulado ...............................................77

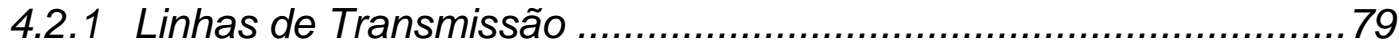

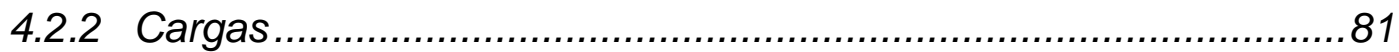

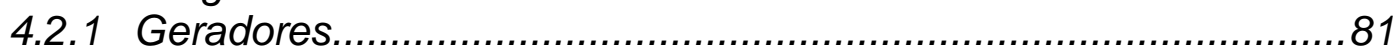

4.3 Algoritmo Desenvolvido............................................................. 82

4.3.1 Proteção Diferencial de Potência Local - PDPL ...........................83

4.3.2 Proteção Diferencial de Potência .............................................87

4.4 Exemplificação das Metodologias ......................................................90

4.4.1 Proteção Diferencial de Potência Local ........................................90

4.4.1 Proteção Diferencial de Potência .............................................. 91

4.5 Limiares de Atuação para as Proteções.....................................................92

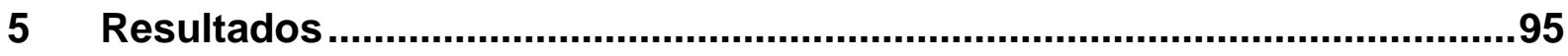

5.1 As Situações de Curtos-Circuitos Consideradas.....................................95

5.2 Apresentação dos Casos Analisados .................................................98

5.2.1 Linha em Condições Normais de Operação .................................98

5.2.2 Análise de Um Caso em Específico de Alta Impedância..................99 
5.2.3 Condições Normais com Variação de Carga..............................103

5.3 Análise Estatística ....................................................................... 106

5.3.1 Desempenho da Proteção Diferencial de Potência Local..............106

5.3.2 Desempenho da Proteção Diferencial de Potência ......................113

6 Conclusão..............................................................................................121



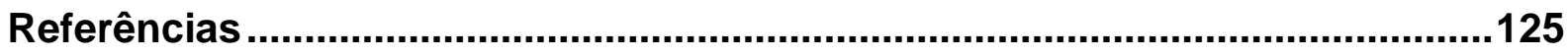




\section{Introdução}

O Sistema Interligado Nacional (SIN) representa um sistema formado por linhas de transmissão que cobrem grandes áreas, o qual pode ser ilustrado pela Figura 1.1. O SIN tem o papel de ligar regiões distantes, permitindo o melhor aproveitamento energético do país, garantindo que a sazonalidade do potencial energético de cada região seja respeitada, permitindo o intercâmbio entre as regiões. Como fato, tem-se que o SIN se encontra em constante expansão, e este crescimento vem tornando a operação e o controle do SIN cada vez mais complexo (ONS, 2012). Tais características do SIN se encaixam no conceito de grandes áreas, que será abordado neste trabalho, e, por este motivo, tal sistema será citado como exemplo de grandes áreas.

Devido à sua extensão, o componente do Sistema Elétrico de Potência (SEP) que se encontra mais suscetível às falhas são as Linhas de Transmissão (LT). Por este motivo, sua proteção deve ser capaz de diminuir o impacto de grandes perturbações sobre o sistema, as quais podem causar por exemplo, os blackouts ou "apagões". Neste cenário, as funções de proteção comumente utilizadas para resguardar um sistema de grandes áreas, apesar de constantes estudos, ainda apresentam algumas limitações que serão comentadas no decorrer desta dissertação e que ainda necessitam serem melhores abordadas.

Como fato, tem-se que a segurança e estabilidade de um SEP estão diretamente ligadas ao desempenho da atuação do sistema de proteção associado (HE et al., 2010). Neste contexto, têm surgido muitas aplicações utilizando Sistemas 
de Medição Fasorial Sincronizada (SMFS), o qual é capaz de fornecer fasores de tensão e corrente sincronizados em relação ao tempo de pontos físicos sobre os sistemas, como por exemplo, de subestações, geograficamente distantes. Isso é possível devido à estampa de tempo fornecida pelo GPS (Global Positioning System), que é um componente deste sistema de medição.

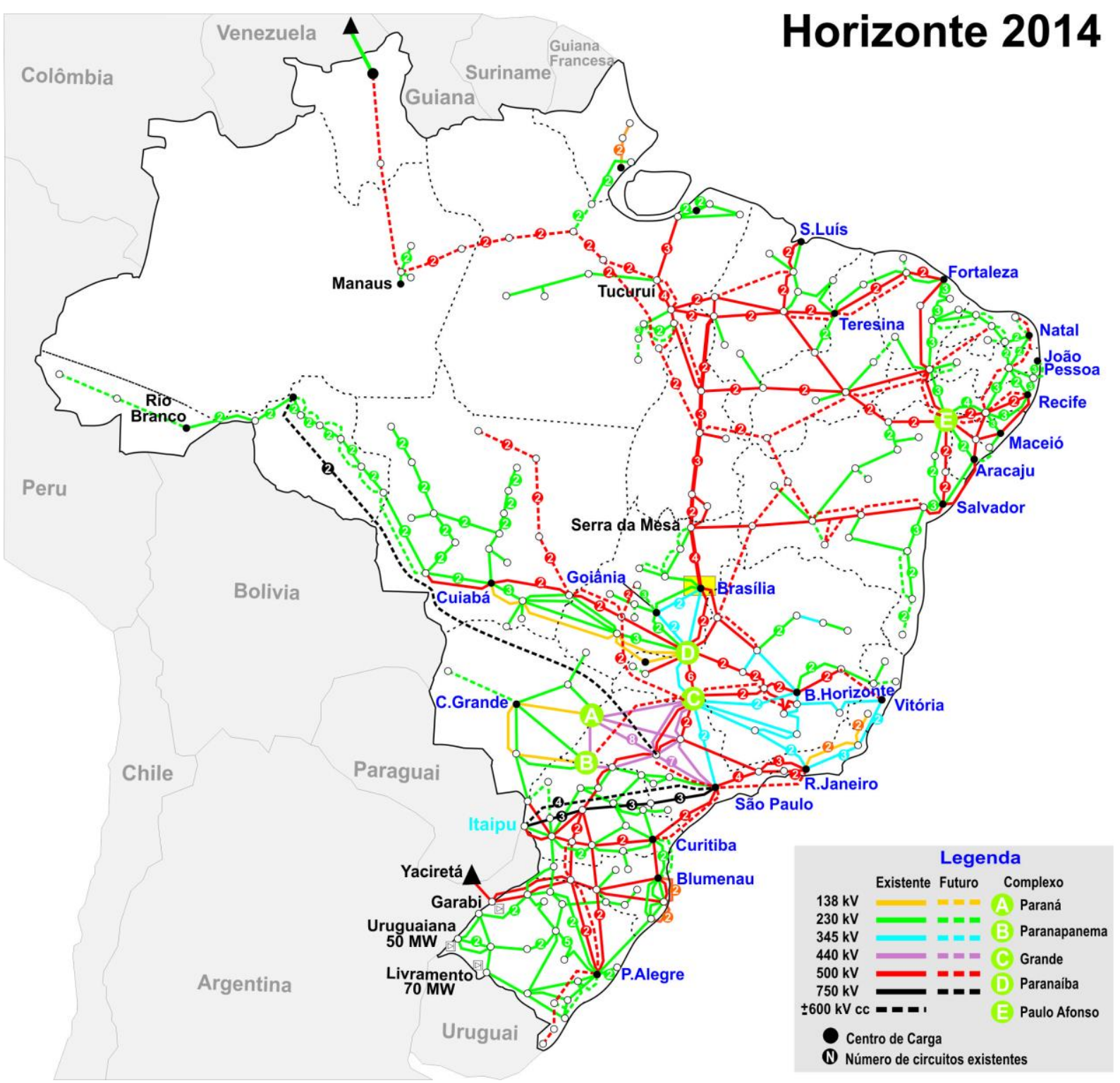

Figura 1.1 - Sistema Interligado Nacional.

Fonte: ONS, 2014. 
As PMU (Phasor Measurement Units), que também compõem o SMFS, são dispositivos avançados de monitoramento de sistemas de potência, que proveem medidas precisas de fasores de tensão e corrente, utilizando a referência de tempo do GPS. Devido à sincronização precisa das medidas, o centro de controle pode obter informações de alta resolução, fornecendo-lhe suporte para operação em tempo real, com uma visualização ampla e maior sensibilidade (KHAN; KHAN, 2012).

Segundo o Operador Nacional do Sistema (ONS) (ONS, 2007), espera-se que com o aumento da utilização das PMU, seja obtido um melhor desempenho das aplicações que serão relatadas posteriormente. Ainda de acordo com este relatório, o SMFS tem potencial aplicação em sistemas de proteção de grandes áreas como na proteção de retaguarda, ou outro esquema de proteção que seja de atuação gradativa, devido à latência do SMFS, como será abordado no próximo capítulo.

Vale ressaltar que este trabalho será baseado na concepção e aplicação de redes inteligentes (Smart Grids), que, atualmente, é um assunto de grande interesse da comunidade técnico-científica. Dentre os conceitos aplicáveis ao contexto de redes inteligentes, por esta pesquisa, busca-se um melhor aproveitamento da energia fornecida, protegendo o sistema elétrico de situações indesejáveis que possam vir a caracterizar colapsos propagados em grandes áreas. Além deste ponto, toda a parte conceitual e estrutural necessária e desejável para a completa execução da metodologia a ser apresentada, vem ao encontro dos conceitos inerentes às redes inteligentes. 


\subsection{Definição do Problema}

A linha de transmissão é o componente do SEP que mais está exposto aos danos causados por falhas (curtos-circuitos) (OLESKOVICZ, 2001). Tal fato gera constante preocupação, de modo que a proteção deste componente se torna um desafio para pesquisadores da área. Normalmente, de acordo com a literatura correlata, as filosofias mais utilizadas para a proteção de linhas de transmissão em SEP de grandes áreas são as proteções de distância e a diferencial de corrente (NAMDARI; JAMALI; CROSSLEY, 2008).

Basicamente, a função de proteção de distância deve perceber a falta a partir do cálculo da impedância da linha. Este é o parâmetro que sofre alteração brusca durante a condição de falta, que acarretará para esta situação em uma impedância de valor menor tomado a partir do ponto de medição até o de falta, e não mais a impedância total da $L T$, com o consequente aumento da corrente. Já a função de proteção diferencial de corrente, trabalha com a verificação das correntes que entram e saem do circuito protegido, utilizando como princípio a Lei de Kirchhoff das correntes. Em condições normais, a soma dessas correntes (corrente diferencial) é idealmente zero. Em condições de falta, essa corrente é diferente de zero, fazendo com que o sinal de desligamento da linha seja emitido, e os disjuntores associados sejam acionados.

Por outro lado, apesar de ainda serem consideradas funções de proteção adequadas para esta função, ambas possuem limitações, e, uma delas, é quanto à sensibilidade ao valor de impedância da falta. Este parâmetro varia muito de acordo com os elementos no caminho da falta, localização, entre outras condições, e estas duas filosofias de proteção muitas vezes não apresentam resposta satisfatória para 
faltas de alta impedância. Esta limitação pode causar uma não atuação do sistema de proteção, permitindo que a falta danifique o sistema.

Na presença de uma falta de alta impedância, a impedância da falta é vista pela função de proteção de distância como uma impedância em série com a impedância da linha. Este fato faz com que a função de proteção detecte a falta como se ela estivesse fora da sua zona de atuação. Já para a função de proteção diferencial de corrente, a falta de alta impedância, faz com que uma corrente muito pequena seja observada no ponto da falta, e, consequentemente, a proteção poderá não detectar a situação (XU et al., 2007).

A função básica de um sistema de proteção é detectar e eliminar faltas, o mais rápido possível. A proteção principal tem o papel de proteger o elemento e é esperado que seu tempo de atuação seja menor que dois ciclos (TAN et al., 2001). Já a proteção de retaguarda, tem um atraso no seu tempo de atuação para que seja priorizada a atuação da proteção principal, provendo ao sistema uma proteção adicional. A mesma será necessária quando houver falha de atuação por parte da proteção principal.

Com o foco na resolução deste problema, e visando garantir maior confiabilidade ao SEP como um todo, o desenvolvimento de uma metodologia de proteção de retaguarda utilizando dados provenientes de um SMFS, mostra-se uma alternativa atraente e viável. Porém, devido às limitações impostas pelo SMFS, devido ao atraso do sistema de comunicação, somado aos atrasos de processamento das PMU e do PDC (Phasor Data Concentrator), o mesmo não pode ser usado para esquemas de proteção em que sejam necessários pequenos tempos de resposta, pois suas limitações acarretarão no atraso da atuação desta proteção. 
Por este motivo, a metodologia de proteção aqui desenvolvida, será classificada como proteção de retaguarda.

Devido ao fato da crescente utilização mundial de PMU (SINGH et al., 2011) (KHAN; KHAN, 2012), optou-se nesta pesquisa por implementar a metodologia baseando-a num SMFS para a obtenção da variável de comparação, que neste caso, será a potência ativa trifásica.

Tomando como base as premissas anteriormente apresentadas, esta pesquisa se desenvolveu como apresentado no fluxograma da Figura 1.2.

Como apresentado na Figura 1.2, o início da pesquisa foi caracterizado por um levantamento bibliográfico na área de proteção de SEP. Neste levantamento, chegou-se ao trabalho desenvolvido por Menezes (2012), que passou a ser um dos trabalhos base para o desenvolvimento deste. Cabe esclarecer que a proposta do trabalho base também foi o desenvolvimento de uma proteção de retaguarda para linhas de transmissão aplicando a medição fasorial sincronizada. Contudo, o mesmo era fundamentado na filosofia de proteção diferencial, com a detecção da inversão do fluxo de potência para a determinação da linha de transmissão defeituosa. Através dos dados fornecidos pelo SMFS, o algoritmo desenvolvido por Menezes (2012) apontava a barra defeituosa através da análise da magnitude da tensão dos barramentos monitorados e do ângulo das correntes entre os barramentos interconectados ao barramento com maior afundamento de tensão. 


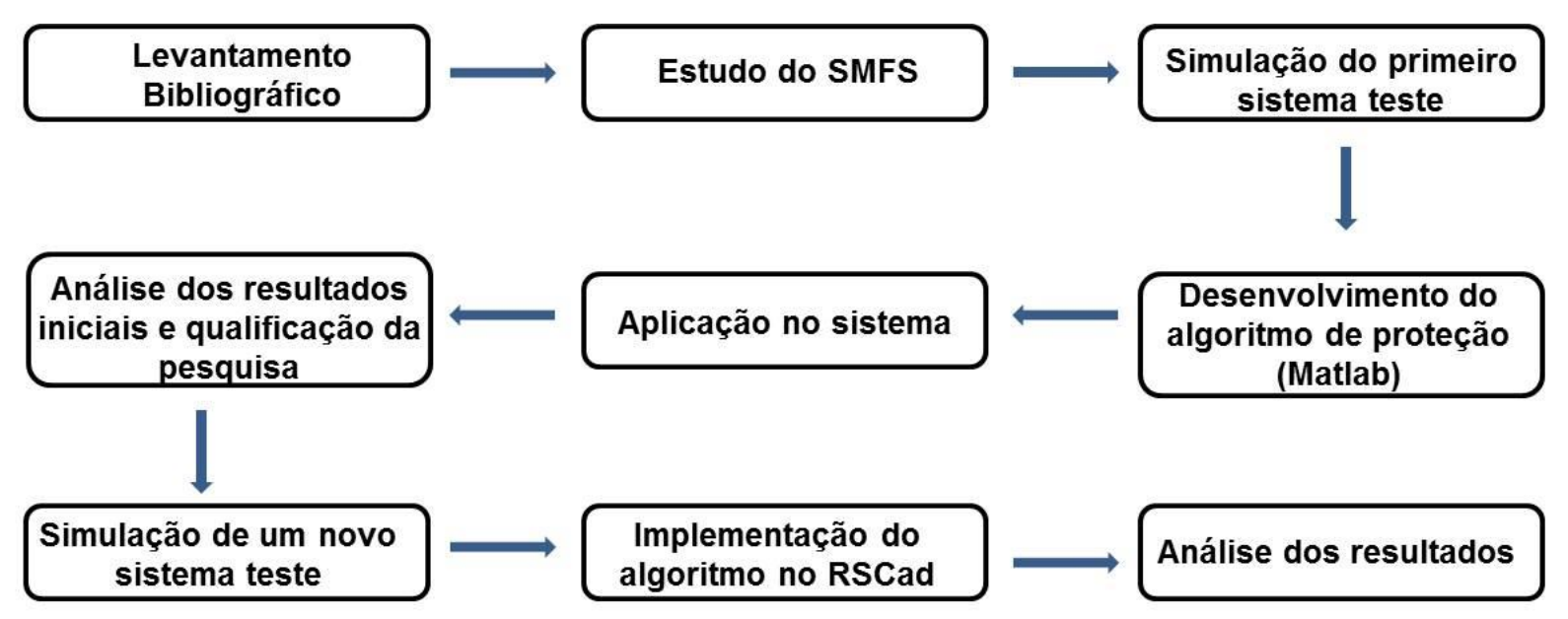

Figura 1.2 - Etapas de desenvolvimento da pesquisa.

A partir da revisão bibliográfica realizada, iniciou-se um estudo sobre o SMFS, para que a importância da metodologia fosse compreendida e melhor avaliada.

Em seguida, com a finalidade de reproduzir o trabalho de Menezes (2012), porém imprimindo uma validação do mesmo pelo emprego de outro software (no trabalho original o software ATP, Alternative Transients Program, foi utilizado), o sistema elétrico proposto foi simulado via o RTDS® (Real Time Digital Simulator), e um novo banco de dados refletindo as situações de faltas de interesse para este trabalho foi formulado, e será apresentado no capítulo de resultados.

Contudo, durante o desenvolvimento do algoritmo proposto, observou-se a necessidade de desenvolver uma metodologia que cobrisse todas as situações de faltas, e, principalmente, as faltas de alta impedância. Esta constatação ficou clara durante a simulação do trabalho base, onde a resposta da metodologia implementada por Menezes (2012) não era satisfatória para faltas de alta impedância. A partir de um estudo investigativo realizado, pôde-se concluir que tal situação foi e continua sendo alvo de muitos outros estudos, uma vez que as 
principais filosofias de proteção ainda são suscetíveis à falha frente a faltas desse porte.

Tomando por base os estudos técnico-científicos correlatos, a grandeza de comparação escolhida para esta pesquisa foi a potência ativa trifásica, pois alguns trabalhos com foco em faltas de alta impedância também utilizavam com sucesso esta mesma grandeza (NAMDARI; JAMALI; CROSSLEY, 2006). Através do banco de dados gerado via o RTDS®, o algoritmo inicialmente desenvolvido foi implementado e testado via o software Matlab. Por este, obteve-se sucesso na detecção das faltas consideradas, porém o sistema teste até então utilizado não permitia contemplar uma grande faixa de simulações de faltas para que a metodologia pudesse ser completamente validada, pois se observou a necessidade de um sistema maior, com distâncias maiores entre os barramentos, cargas e geradores, para que a sensibilidade da filosofia proposta ficasse mais evidente.

Sendo assim, o sistema teste apresentado por Menezes (2012) foi substituído pelo sistema de doze barras desenvolvido e apresentado pelo Institute of Electrical and Electronics Engineers (IEEE) (SANTOS et al., 2015). O banco de dados formado com o novo sistema permitiu então contemplar de forma satisfatória todos os tipos de falta, variações nos valores de impedância e de distância de falta, para validação da metodologia proposta. Vale ressaltar que toda a modelagem, desde o sistema até a lógica de proteção implementada, foi desenvolvida nos ambientes do RSCad (ambientes específicos para do RTDS®), conforme será posteriormente evidenciado. 


\subsection{Objetivos da Pesquisa}

Com foco em prover maior confiabilidade ao sistema de proteção, este trabalho tem o objetivo de desenvolver uma metodologia de proteção de retaguarda confiável para um sistema de proteção de grandes áreas, através da utilização de medidas provenientes de PMU alocadas geograficamente distantes. O objetivo principal é desenvolver uma metodologia que seja sensível à faltas de alta impedância, porém, a pretensão é que se alcance um resultado satisfatório para uma ampla faixa de valores de impedância de falta. Com esta pesquisa, pretende-se indicar a possibilidade do uso de SMFS em sistemas reais, sugerindo mais uma aplicação para o mesmo.

\subsection{Organização do Texto}

Este trabalho é composto por seis capítulos, passando basicamente pela Introdução, Revisão Bibliográfica, um sucinto referencial literário para o Sistema de Medição Fasorial, Metodologia, Resultados, Conclusões e Referências.

No primeiro capítulo foi apresentada uma abordagem inicial sobre o problema, definindo o foco do trabalho, e apontando os objetivos da pesquisa.

No segundo capítulo, trata-se da revisão bibliográfica, onde todos os conceitos necessários para o entendimento da metodologia serão apresentados. Neste capítulo serão citados trabalhos correlatos à pesquisa aqui descrita, que contribuíram para a formação e consolidação dos conceitos aplicados.

Na sequência, o terceiro capítulo apresentará uma breve revisão sobre todos os componentes do SMFS. Esta seção será de extrema importância para a 
orientação da pesquisa, visto que o SMFS tem algumas limitações e requisitos implícitos ao seu uso.

No quarto capítulo, o sistema elétrico teste usado para validação da metodologia será apresentado, bem como toda a metodologia desenvolvida, abordando todos os requisitos necessários para um bom entendimento do trabalho desenvolvido.

O quinto capítulo apresentará os resultados observados, ilustrando graficamente o desempenho da metodologia implementada.

No sexto e último capítulo, serão apresentadas as conclusões e observações finais acerca da metodologia implementada. Neste também serão apontadas algumas das diretrizes futuras para a continuação da pesquisa. 


\section{Revisão Bibliográfica}

\subsection{A Proteção de Grandes Áreas}

O Brasil é um país de grande extensão territorial que possui um grande potencial de geração de energia elétrica. Essas características fazem com que seu sistema seja singular a nível mundial. Seu sistema de transmissão é subdividido em 4 subsistemas: Norte, Sudeste/Centro-Oeste, Nordeste e Sul. Este sistema, conhecido como SIN, possui uma extensa malha de linhas de transmissão de alta e extra alta tensão que se ramifica em mais de 107 mil quilômetros dentro do território brasileiro, o que caracteriza uma grande área, interligando lugares distantes geograficamente. Segundo dados recentes do ONS, apenas $1,7 \%$ da energia demandada pelo país estão fora do SIN, em pequenos sistemas isolados (ONS, 2012).

Ao levar em conta as dimensões físicas do SIN, o elemento que se encontra em maior vulnerabilidade de ocorrências de falhas são as linhas de transmissão e, portanto, para que este sistema permaneça em operação a maior parte do tempo, e para que o mesmo seja protegido de eventos danosos, sente-se necessidade de desenvolver um sistema de proteção cada vez mais preciso (WEN-JING; QINGQUAN, 2008).

A proteção das linhas de transmissão, conforme afirmam Khorashadi e Li (2007), é a mais elaborada e desafiadora função de proteção. Ainda segundo os autores, cerca de dois terços das faltas em sistemas de potência ocorrem em linhas 
de transmissão, e por este motivo, as mesmas tem recebido constante atenção em estudos voltados à proteção.

De uma maneira em geral, conforme encontrado em Coury et al. (2007) e em IEEE (2002), as características essenciais de um relé, equipamento fundamental na composição de um sistema de proteção, podem ser sumarizadas como segue:

- Sensibilidade: diz respeito à capacidade do sistema de proteção e, em consequência, do relé, em responder às anormalidades nas condições de operação, e aos curtos-circuitos para as quais foi projetado;

- Seletividade: propriedade do sistema de proteção em reconhecer e selecionar entre aquelas condições para as quais uma imediata operação é requerida, e aquelas para as quais nenhuma operação ou retardo de atuação é exigido;

- Velocidade de atuação: esta é, com certeza, uma característica desejável e esperada para se remover o mais rápido possível uma situação de falta. Todavia, o relé deve tomar a sua decisão baseado nas formas de ondas das tensões e correntes, as quais são fortemente distorcidas devido aos fenômenos transitórios que seguem da ocorrência de uma falta. Diante de tal situação, o relé deve, então, capturar características essenciais das informações contidas nestas formas de ondas sobre as quais tomará uma segura decisão. A relação entre a resposta do relé e o grau de certeza decorrente é uma função inversa do tempo, sendo que esta função denota uma das principais características de todo o sistema de proteção; 
- Confiabilidade: define-se como a probabilidade de um componente, de um equipamento ou de um sistema, em satisfazer a função prevista sob dadas circunstâncias. A confiabilidade dos relés tem dois atributos: pode ser confiável e pode ser seguro. O relé será confiável se operar somente em condições para as quais foi projetado e, seguro, se o mesmo não operar para qualquer outra situação que por ventura venha a ocorrer sobre o sistema.

Neste sentido, haja vista a grande importância do sistema de proteção para o SEP como um todo, existe um grande e reconhecido esforço por parte dos pesquisadores no desenvolvimento de metodologias e esquemas (filosofias) de proteção. Tal esforço se justifica devido à expansão do SEP nos últimos anos, que acarretou em uma maior complexidade de operação, proteção e controle.

A concepção e a análise de um sistema de proteção de grandes áreas (WAPS - Wide Area Protection System) foi primeiramente proposta por Ingelsson et al. (1997) para evitar colapsos de tensão. No contexto atual, devido ao desenvolvimento da automação e da comunicação cada vez mais presentes na concepção das redes inteligentes, o WAPS é uma tecnologia que vem sendo utilizada para melhorar o desempenho da proteção e do monitoramento primando sempre pela estabilidade dos SEP. Pelas suas funcionalidades, em condições normais de operação, o WAPS deverá monitorar o SEP, e notificar quando da ocorrência de distúrbios. Neste sentido, durante os distúrbios, o mesmo deverá tomar decisões para eliminar a falta e proteger o sistema (SIRIWATWORASAKUL; HOONCHAREON, 2013).

Contudo, da prática, tem-se que a função de proteção de distância é uma alternativa atrativa e tecnicamente viável para a proteção de linhas de transmissão, 
devido a sua alta confiabilidade e sua baixa manutenção (WAIKAR; LIEW; ELANGOVAN, 1996) (KIM et al., 2000). Seu princípio é baseado no cálculo da impedância entre a localização do relé e o local da falta, e, através desse cálculo, é capaz de identificar se a falta é interna ou externa à sua zona de proteção. Porém, a função de proteção de distância, usualmente, não apresenta, por exemplo, uma operação satisfatória em linhas de transmissão com circuito duplo ou frente à faltas de alta impedância (KHORASHADI; LI, 2007). Como exemplo, a Figura 2.1 apresenta uma função de proteção de distância tipo mho, que irá operar apenas quando a impedância calculada estiver compreendida dentro do circulo delineado. Para este tipo de função de proteção, quanto maior a impedância de falta, mais se torna difícil para a mesma distinguir entre a falta de alta impedância e a carga, como pode ser observado na Figura 2.1 (IEEE, 2002).

Ainda com o foco na proteção de linhas de transmissão, é bem aceito o fato de que a função de proteção diferencial provê uma proteção sensível com as devidas demarcações das zonas de proteção (WEN; CHEN; YIN, 2014). Tal função é amplamente utilizada para a proteção de equipamentos de potência, como, por exemplo, transformadores e geradores, pois é um método confiável de proteção contra faltas internas (NAMDARI; JAMALI; CROSSLEY, 2008). Já para a proteção das linhas de transmissão via os relés diferenciais, a mesma está cada vez mais sendo aplicada em função do desenvolvimento das tecnologias de comunicação (XU et al., 2007). Ainda em complemento às aplicações em sistemas de transmissão, novos desenvolvimentos embasados na filosofia da proteção diferencial vêm apresentando soluções para a proteção de grandes áreas.

O princípio básico da função de proteção diferencial, como induzido por sua designação, consiste na comparação de grandezas de mesma natureza, mais 
comumente das correntes, que entram e saem do circuito, da porção, ou equipamento a ser protegido (PHADKE; THORP, 2009).



Figura 2.1 - Representação do relé de distância tipo mho. Adaptado: IEEE, 2002.

O principal objetivo da função de proteção diferencial de corrente aplicada às linhas de transmissão é detectar a existência de uma falta interna ao circuito protegido. Esta função de proteção opera comparando as correntes medidas em cada extremo da linha usando o princípio da Lei de Kirchhoff das correntes, que diz que a soma algébrica das correntes em um nó deve ser igual à zero. Caso ocorra uma falta interna a zona protegida, e a soma vetorial das correntes nos extremos da linha for diferente de zero, a proteção atuará. A função de proteção diferencial pode ser ilustrada pela Figura 2.2 e pelas equações que seguem:

$$
\begin{aligned}
& I_{d}=\left|I_{1}+I_{2}\right| \\
& I_{r}=\left|I_{1}-I_{2}\right|
\end{aligned}
$$

Onde: 
$I_{d}$ é a corrente diferencial;

$I_{r}$ é a corrente de restrição; e

$I_{1}$ e $I_{2}$ são as correntes de cada extremo da linha protegida.

Se:

$$
I_{d} \leq k I_{r},
$$

sendo $k$ o ajuste realizado para a sensibilidade da proteção, então significa que haverá o bloqueio da atuação. Porém, se:

$$
I_{d}>k I_{r},
$$

neste caso, haverá a operação da proteção, ocorrendo o desligamento da linha através dos disjuntores associados.

$\mathrm{Na}$ Figura 2.2, entende-se que a região protegida é delimitada pelos Transformadores de Correntes (TC). De forma ideal, para faltas externas ou em condições normais do sistema, as correntes $I_{1}$ e $I_{2}$ apresentam o mesmo módulo e sentidos opostos quando passam pelo relé, e, consequentemente, a corrente que excita o mesmo é nula. Já no caso de falta interna, existirá uma corrente resultante sobre o relé, e se a mesma ultrapassar um limiar pré-definido (ajuste), haverá atuação da proteção (MOLAS; SILVA, 2012).

Por outro lado, a função de proteção diferencial de corrente apresenta algumas limitações. Sua operação pode ser dificultada pela distorção e incompatibilidade de dados (NAMDARI; JAMALI; CROSSLEY, 2008), que acontece quando os dados são perdidos ou ocorre uma saturação no TC. Com dados corrompidos, a proteção associada não proporcionará um desempenho satisfatório. Outra possível causa de erros de operação desta função de proteção são as faltas de alta impedância. Quando da manifestação de uma falta de alta impedância interna ao circuito protegido, a corrente do extremo remoto da linha pode não mudar 
sua direção, o que resultará em uma falha na detecção da falta (DARWISH; TAALAB; AHMED, 2005).

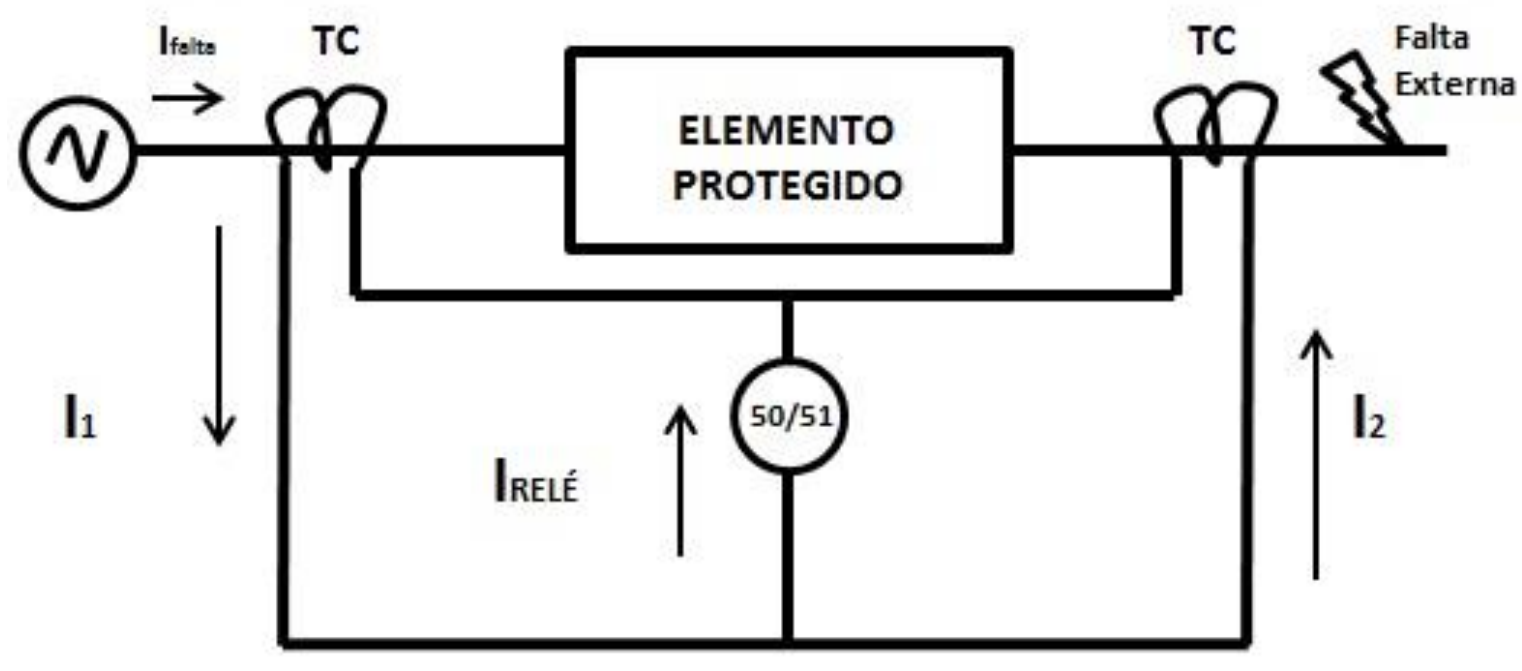

Figura 2.2 - Representação da proteção diferencial. Adaptado: MOLAS; SILVA, 2012.

Devido a essas limitações, e ao fato de que a estrutura e a operação do SEP estão se tornando cada vez mais complexos, o aprimoramento das metodologias de proteção é tratado como um desafio a ser melhor analisado e superado, pois a segurança e estabilidade do sistema estão diretamente ligados à atuação rápida e correta do sistema de proteção.

Tholomier e Apostolov (2009) analisaram as mudanças das condições do sistema que ocorrem durante um distúrbio e como isto impacta de várias formas nos sistemas de proteção. Segundo os autores, o comportamento dos relés de proteção associados às linhas de transmissão de grandes áreas pode ter um impacto significante no desenvolvimento dos distúrbios. Ainda segundo os mesmos autores, os relés de proteção aplicados às linhas de transmissão devem ser capazes de se adaptar às seguintes mudanças que podem ocorrer durante um distúrbio acometido sobre grandes áreas: 
- Mudanças na frequência do sistema;

- Mudanças nos parâmetros medidos localmente e causadas por uma oscilação de potência, tensões, correntes, impedâncias aparentes, etc.;

- Mudanças na configuração do sistema devido ao acionamento e desligamento de linhas de transmissão ou transformadores; e

- Mudanças no atraso na propagação dos sinais via o canal de comunicação da proteção associada.

Outro grande desafio da proteção aplicada às linhas de transmissão é em relação às faltas de alta impedância, as quais acontecem frequentemente em linhas de transmissão longas, e que tem sido um grande problema para as proteções convecionais (GAN et al., 2002). Tengdin, Westfal e Stephan (1996) definem a falta de alta impedância como uma falta que não produz corrente suficiente para ser detectada pelas proteções convencionais, e podem ser causadas, por exemplo, por um contato da linha com galhos de árvores, incêndios ou guindastes de construção (LEE et al., 1999).

Este tipo de falta resulta em um fenômeno que apresenta um comportamento não linear (IBRAHIM et al., 2008). Para ilustrar o interesse generalizado por parte dos pesquisadores e a dificuldade em se trabalhar com faltas de alta impedância, comenta-se que em um período de onze anos, pesquisadores da Texas A\&M University aplicaram duzentas faltas de alta impedância em cinco subestações diferentes e em dez alimentadores de distribuição. Das duzentas faltas, apenas trinta e cinco foram eliminadas pelas proteções convencionais (TENGDIN; WESTFALL; STEPHAN, 1996). 
Em Barros (2009) apresenta-se o desenvolvimento de uma metodologia para a detecção de faltas de alta impedância. No trabalho é salientada a diferença nos valores assumidos pela corrente de falta devido ao valor da resistência de falta. A autora considera ainda que o valor de 100 ohms para a resistência de falta pode ser considerado como falta de alta impedância.

Vale comentar que nas pesquisas de Yang e Morrison (1983), He et al. (2013) e Eissa (2006), o valor adotado como sendo de alta impedância para a validação das metodologias desenvolvidas foi de 300 ohms, enquanto que para a pesquisa de Xia, David e Li (1994) o valor foi de 500 ohms.

MAEZONO et al. (2009) fazem uma análise de uma falta de alta impedância, ocorrida em Julho de 2006 em uma linha de 525 kV que liga as Subestações de Assis e Londrina, PR, no Brasil. Através de um programa de cálculo de curto-circuito, os autores estimaram o valor da resistência de falta, a qual chegou a 528 ohms. Para este caso relatado, a proteção de distância não atuou. Os autores ainda salientam que estes valores de resistência de falta da ordem de centenas de ohms são passíveis de ocorrência, ainda que em Extra Alta Tensão (EHV - Extra High Voltage), e são mais comum do que se imagina, devido à associação direta de faltas à terra envolvendo a vegetação.

Para finalizar, cabe comentar que o advento das redes inteligentes trouxe muitas soluções e desafios no âmbito das aplicações e desenvolvimentos voltados à proteção e controle dos SEP. Os rápidos avanços das tecnologias de comunicação e medição aceleraram o desenvolvimento das proteções de grandes áreas baseadas em sistemas de medições de grandes áreas (WAMS - Wide Area Measurement Systems) (LUO; TAI; YANG, 2012). Vale também colocar que com a complexidade do sistema elétrico, a fragilidade do sistema interconectado tem aumentado cada vez 
mais, e, nesse sentido, os estudos em sistemas de proteção de retaguarda de grandes áreas (WABPS - Wide Area Backup Protection Systems) tem atraído muita atenção (SUN et al., 2012).

\subsection{A Proteção de Retaguarda de Grandes Áreas}

Para as linhas de transmissão, normalmente, emprega-se um esquema de proteção que compreende a proteção primária e a proteção de retaguarda. A proteção primária é a principal, para a qual se assume uma atuação instantânea. Espera-se que, na presença de uma situação de falta (curto-circuito), a proteção primária atue o mais rápido possível. Mas, se porventura essa proteção não atuar, a proteção de retaguarda, que é projetada com um atraso de tempo de atuação em relação ao tempo de atuação da proteção primária, deverá atuar, protegendo assim o elemento da falta. Este atraso se deve para que a prioridade seja dada à atuação da proteção primária, permitindo uma desejada coordenação entre as mesmas.

Para exemplificar a atuação de uma proteção de retaguarda, a Figura 2.3 apresenta uma situação de falta aplicada entre as barras $A$ e $B$. As proteções primárias correspondentes a esse trecho estão associadas aos relés $R 1$ e $R 5$, e devem ser os primeiros a atuar para este caso. Porém, se o relé $R 1$ não atuar, os relés $\mathrm{R} 2$ e $R 3$ irão atuar como relés de proteção de retaguarda local, tendo como ação inicial o acionamento do disjuntor $D 1$, e, posteriormente, os disjuntores $D 6, D 7$ e D8. Caso esses relés também não atuem, $R 9, R 10$ e $R 4$, constituirão uma proteção de retaguarda remota para a proteção primária $R 1$.

A função do sistema de proteção é a de proteger uma porção ou um equipamento de um SEP que esteja dentro de uma área delimitada, chamada de zona de proteção. Essa área delimitada, normalmente é marcada pelos TC e pelos 
disjuntores, que são os equipamentos responsáveis por fornecer dados de corrente ao relé, com um nível de corrente adequado para o mesmo. Para que seja garantida a completa proteção de todo o sistema a ser protegido, todos os elementos do mesmo devem estar dentro de pelo menos uma zona de proteção (COURY; OLESKOVICZ; GIOVANINI, 2007). Considerando a função de proteção de distância, por exemplo, a zona 1 é considerada a zona de atuação instantânea, e as demais zonas, quando houver, são zonas de proteção com retardado de tempo de atuação. Para Ma et al. (2011) e Tan et al. (2001), os elementos da zona 2 devem operar em um tempo de 0,5 segundos, e os de zona 3, em 1 segundo.

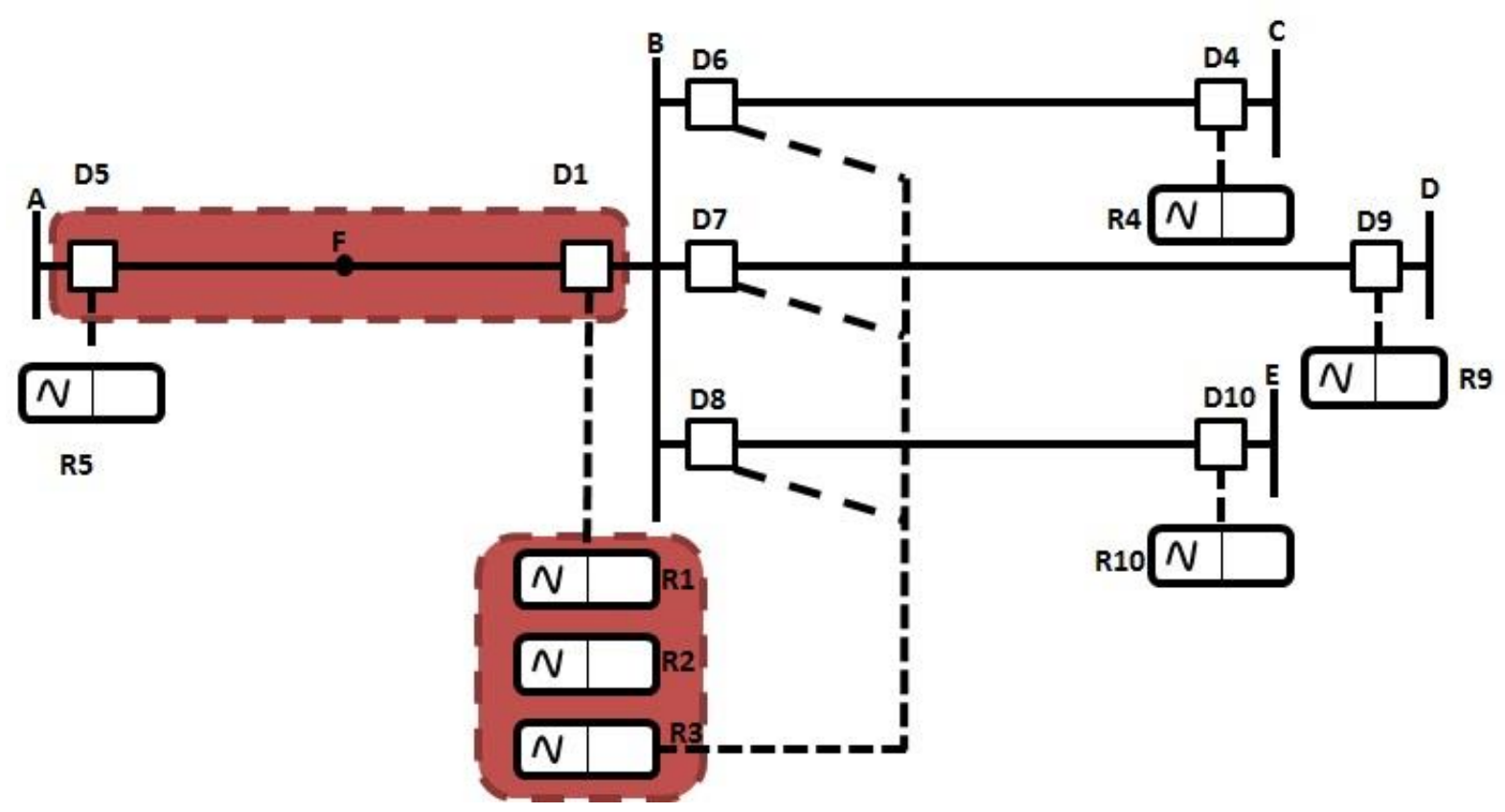

Figura 2.3 - Proteção de retaguarda.

Adaptado: (COURY; OLESKOVICZ; GIOVANINI, 2007).

Por décadas, a função de proteção de distância tem sido empregada como proteção convencional de retaguarda. Porém, com a complexidade em que se encontra o sistema nos dias atuais, a coordenação do seu tempo de atuação e alcance tem se tornado mais difícil. Essa complexidade também pode acarretar em 
um tempo maior para a atuação da proteção, ou, até mesmo, em uma porção maior desligada do sistema (SARIZAWA et al., 1998). Em Tan et al. (2001), os autores consideram que a principal limitação da proteção de retaguarda é devido ao fato de que sua atuação não considera o impacto no sistema como um todo, pois tem uma visão limitada da rede protegida com medições locais.

De fato, a proteção de retaguarda, bem como a proteção primária, são alvos constantes de estudos, e muitas alternativas apresentadas para resolver os problemas atrelados à proteção do SEP utilizam dados provenientes de um Sistema de Medição Fasorial Sincronizado (SMFS) para garantir e melhorar os quesitos de confiabilidade.

\subsection{O Sistema de Medição Fasorial Sincronizado}

O SMFS vem se tornando uma alternativa atrativa para aplicações em SEP. Suas funcionalidades vêm sendo cada vez mais exploradas com a finalidade de garantir mais confiabilidade. Este sistema é capaz de apresentar o estado instantâneo do sistema em análise de forma rápida, através do fornecimento dos sincrofasores, que são os fasores obtidos pela referência de tempo absoluta do GPS.

Fasores de tensão e corrente de sequência positiva são fornecidos pelo SMFS, e, em complemento, este também é capaz de medir a frequência local, e pode ser ajustado para medir componentes harmônicos e fornecer fasores de sequência negativa e zero, bem como fasores de tensão e corrente de fase (PHADKE; THORP, 2008).

Em Phadke (2002), é apresentado um breve resumo histórico das medidas fasoriais sincronizadas. O primeiro protótipo foi desenvolvido em 1988, pela Virginia 
Polytechnic Institute, nos Estados Unidos. O desenvolvimento das PMU se deu após a concepção do relé de distância de componentes simétricas (SCDR - Symmetrical Component Distance Relay) para proteção de linhas de transmissão de alta tensão. A principal novidade apresentada pelo SCDR foi o algoritmo baseado em medidas de tensão e corrente de sequência positiva, negativa e zero nos terminais da linha de transmissão, com a vantagem de processar apenas uma equação para determinar a localização para todos os tipos de faltas passíveis de ocorrência sobre o sistema.

Um resultado importante desse desenvolvimento foi o algoritmo recursivo para o cálculo das componentes simétricas de tensão e corrente, a transformada discreta de Fourier de componentes simétricas (SCDFT - Symmetrical Component Discrete Fourier Transform). Com isso, a medição precisa de tensão e corrente para outras inúmeras aplicações tornou-se evidente, porém, ainda com a necessidade de sincronizar os dados de todo o sistema. A sincronização precisa das amostras só foi possível com o advento do GPS. Atualmente, via os GPS, é possível alcançar uma sincronização com precisão de $1 \mu \mathrm{s}$, o que corresponde a $0,021^{\circ}$ para um sinal com frequência de $60 \mathrm{~Hz}$ (PHADKE, 2002).

Baseado no protótipo desenvolvido, a Macrodyne Co. começou a fabricar PMU para fins comerciais, com muitas inovações, incluindo um receptor de GPS interno, conversor analógico-digital de 16 bits para cada canal de entrada analógica e várias interfaces de modem para acesso remoto às PMU. Também foi desenvolvido o concentrador de dados, que coleta dados de várias PMU, organizando-os pelos correspondentes instantes de tempo, e fornecendo-os conforme solicitados. 
As primeiras aplicações em campo pela equipe da Virginia Tech foi em três subestações nos Estados Unidos: Bonneville Power Administration, American Eletric Power, e New York Power Authorithy. Após a Macrodyne iniciar a fabricação das PMU, suas unidades foram as próximas a serem instaladas em campo, chegando a centenas de unidades instaladas em todo o mundo.

É válido salientar que, apesar de haver várias aplicações de sincrofasores, inclusive no âmbito da proteção de SEP, a presente revisão bibliográfica terá seu foco voltado para a aplicação de PMU na proteção de retaguarda de grandes áreas e em proteção diferencial de potência.

\subsection{O Sistema de Medição Fasorial Sincronizado Aplicado na Proteção de Retaguarda de Linhas de Transmissão}

Para projetar um novo sistema de proteção de retaguarda, inicialmente é necessária uma análise de desempenho das proteções de retaguardas existentes. As pesquisas desenvolvidas por XU et al. (2006) apontam que, devido ao fato da proteção de retaguarda convencional utilizar medições locais como dados de entrada, sua ação não leva em conta o impacto no restante do sistema. Dessa forma, por exemplo, a transferência de carga depois de uma falha ser extinta, pode causar trips (aberturas) em cascata das proteções de retaguarda, levando a uma interrupção generalizada.

Da literatura consultada, observa-se que os problemas inerentes às proteções de retaguarda convencionais podem ser resolvidos utilizando-se das medições fasoriais provenientes de SMFS, e muitos trabalhos vêm apresentando soluções utilizando esta alternativa. 
Como por exemplo, um algoritmo de proteção de retaguarda para linhas de transmissão, desenvolvido para identificar a linha defeituosa é apresentado por Neyestanaki e Ranjabar (2015). Primeiramente, os autores desenvolvem um modelo para alocação ótima das PMU, minimizando o número de dispositivos requeridos para o esquema. Como passo principal, o algoritmo de proteção de retaguarda desenvolvido pelos autores determina a zona onde a falta ocorreu e a linha faltosa. Conforme apontado pelos autores, a metodologia é desenvolvida utilizando dados de medições de grandes áreas, e necessita de baixa capacidade computacional, fazendo com que o algoritmo encontre uma resposta rapidamente. Para este esquema, os autores garantem que o mesmo não será afetado por faltas de alta impedância, porém, as simulações para validação do método contemplam faltas somente até 100 ohms.

Já o trabalho desenvolvido por Nayak, Pradhan e Bajpai (2014), apresenta uma proteção de retaguarda para a localização do ramo onde ocorreu a falta. Inicialmente, o algoritmo encontra a barra mais próxima da falta comparando a magnitude das componentes de sequência positiva, negativa e zero da tensão de todas as barras da rede. Estas comparações se baseiam no princípio de que a tensão na barra mais próxima da falta sofrerá maior variação se comparada com as barras mais distantes. O segundo passo consiste na identificação da linha faltosa através do cosseno do ângulo entre as componentes de sequência da tensão e da corrente de cada barramento interconectado à barra apontada como a mais próxima da falta. O esquema apresentado foi muito bem detalhado pelos autores e testado em várias condições como o sistema com desbalanço de potência, situação de inversão de tensão/corrente causada pela influência de uma compensação série e testaram a influência da variação das cargas. O esquema demonstrou ser eficaz, 
porém os autores não consideraram simulações contemplando faltas de alta impedância.

Uma metodologia que utiliza a filosofia diferencial foi desenvolvida por Eissa, Masoud e Elanwar (2010) e, posteriormente aplicada em Menezes (2012), sendo este último, a base inicial para o desenvolvimento desta pesquisa. A metodologia em questão utiliza os dados provenientes de um SMFS e, através dos fasores de tensão e corrente de sequência positiva, observa onde houve a maior queda de tensão entre os barramentos monitorados apontando um possível barramento com defeito. E, para confirmar a ocorrência, verifica se houve inversão do fluxo de potência através do ângulo da corrente de sequência positiva entre as linhas conectadas a tal barramento, tornando possível a distinção entre faltas internas e externas à área delimitada entre os barramentos. O sistema teste para validação da metodologia foi simulado via o software Matlab Simulink, por Eissa, Masoud e Elanwar (2010), e via o software ATP (simulação do sistema teste) e Matlab (algoritmo implementado), por Menezes (2012). Conforme colocado pelos autores, o algoritmo obteve sucesso em todos os casos analisados, porém, não foram reportadas análises contemplando alta impedância de falta. No trabalho de Menezes (2012), a análise foi feita apenas para a faixa de 0 a 100 ohms.

\subsection{A Proteção Diferencial de Potência como Proteção de Retaguarda de Linhas de Transmissão}

Com a preocupação de desenvolver uma metodologia que cubra algumas limitações da proteção principal, a metodologia a ser apresentada neste trabalho utiliza como grandeza de comparação a potência ativa trifásica. Outros trabalhos 
também utilizam tal grandeza para comparação, com metodologias semelhantes a que será apresentada.

Dentre os trabalhos encontrados, Darwish, Taalab e Ahmed (2005), Darwish et al. (2006), Darwish et al. (2009), Taalab, Darwish e Ahmed (2007) e Kawady, Taalab e Ahmed (2010) investigaram, avaliaram e validaram a utilização da comparação do fluxo das potências ativas e reativas em linhas para distinguir entre faltas internas e externas às mesmas. Neste caso, a proteção é chamada de Proteção Diferencial de Potência (PDP), pois se utiliza dos conceitos aplicáveis à filosofia diferencial, tendo como variável analisada as potências ativa e reativa. Esta metodologia é sugerida pelos autores para a proteção de linhas para que as mesmas sejam resguardadas na presença de faltas de alta impedância.

O esquemático apresentado na Figura 2.4 ilustra o processo realizado pela PDP. Os sinais de tensão e corrente são medidos, amostrados, e é realizada a extração fasorial através da DFT (Discrete Fourier Transform). Obtidos os fasores, a potência ativa e reativa é calculada localmente a partir do produto complexo da tensão e da corrente de cada barramento. Através do intercâmbio de dados, calculase então a diferença entre as potências ativa e reativa ( $\Delta \mathrm{P}$ e $\Delta \mathrm{Q}$, respectivamente) dos dois barramentos, bem como a potência ativa e reativa média $\left(P_{a v}\right.$ e $Q_{a v}$, respectivamente) através das equações de 2.5 a 2.8 :

$$
\begin{gathered}
\Delta P=P_{s}-P_{R} \\
\Delta Q=Q_{s}-Q_{R} \\
P_{a v}=\frac{\left(P_{s}+P_{R}\right)}{2} \\
Q_{a v}=\frac{\left(Q_{s}+Q_{R}\right)}{2}
\end{gathered}
$$


Vale frisar que $P_{\mathrm{av}}$ e $\mathrm{Q}_{\mathrm{av}}$ são utilizados para o cálculo do valor do parâmetro de comparação a ser configurado para denotar a sensibilização da proteção. Se o valor de $\Delta \mathrm{P}$ ou de $\Delta \mathrm{Q}$ for maior que o valor de ajuste calculado, a proteção deverá atuar.

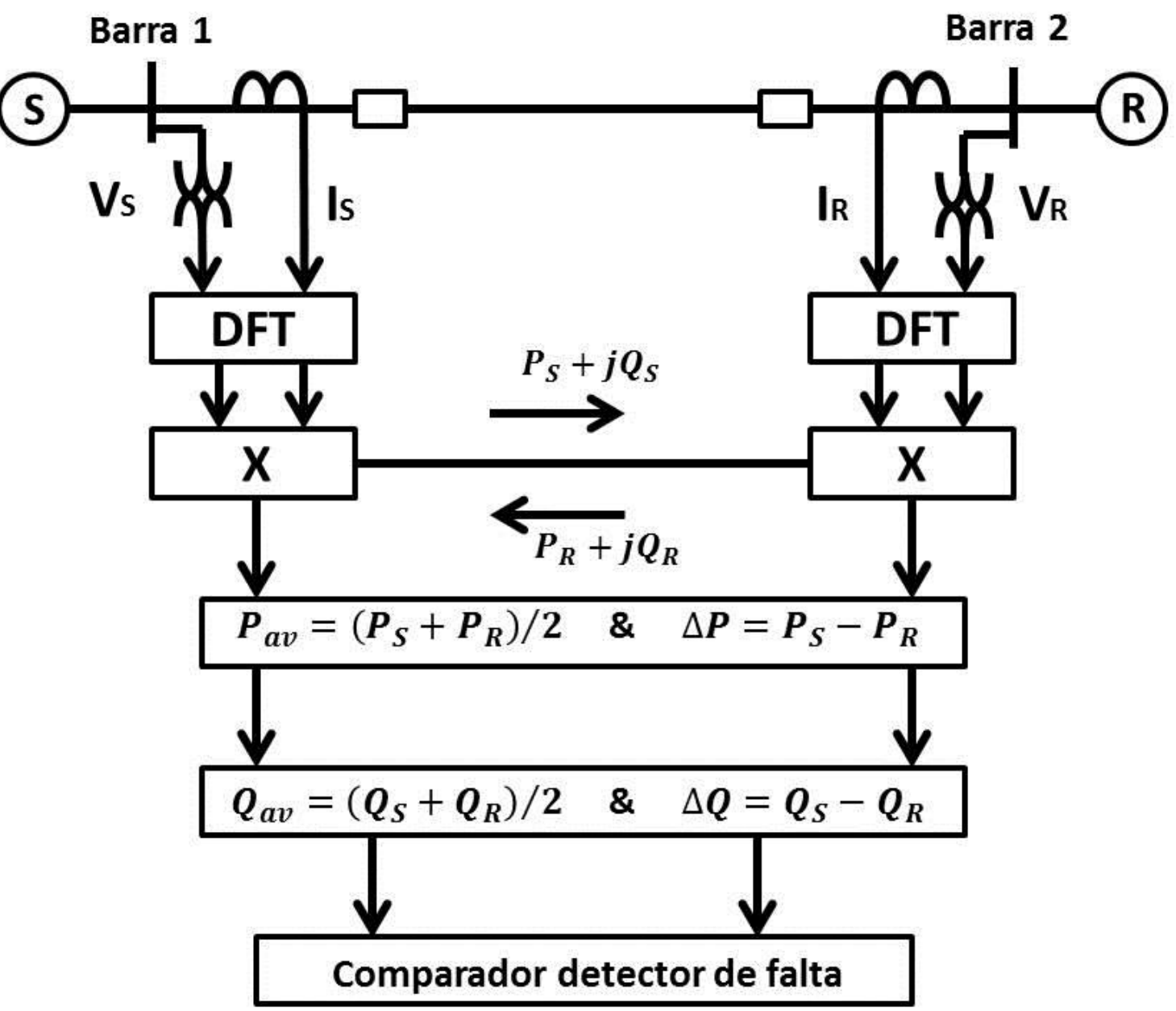

Figura 2.4 - Representação da proteção diferencial de potência. Fonte: DARWISH et al. (2009).

A proposta dos autores foi validada frente várias situações como energização da linha, desvios de frequência e variação de carga. As simulações foram realizadas com todos os tipos de falta e com variação da resistência de falta com valores até 1000 ohms. O algoritmo se mostrou eficaz na detecção de faltas de alta impedância e distinguiu corretamente as faltas internas das externas. O estudo demonstrou-se bem consolidado, e conferiu uma importância ao estudo da variação 
da potência como grandeza a ser analisada em sistemas de proteção reais. Os autores não consideraram a utilização de medidas sincronizadas para o estudo.

No trabalho de Namdari, Jamali e Crossley (2008), onde a proteção diferencial é baseada apenas na comparação entre o fluxo das potências ativas na linha protegida, é destacado o desempenho da proteção diferencial de potência para a proteção de grandes áreas quando comparada com a proteção de corrente diferencial. Os autores destacam três vantagens para a abordagem:

- Redução da quantidade de dados transferidos entre os barramentos;

- Redução do tempo de processamento; e

- A viabilidade de aplicação da proposta para linhas longas.

Como apresentado em Yabe (1997) alguns anos antes, esta mesma metodologia foi utilizada na proteção de transformadores trifásicos e, anos depois, aperfeiçoada e apresentada em Bahmani, Jahromi e Ranjbar (2006). A metodologia se mostrou útil nesse caso, pois, para a proteção de transformadores, a proteção diferencial de corrente apresenta dificuldades de distinguir entre faltas internas e o transitório de magnetização, enquanto que a proteção diferencial de potência tem seu método baseado na verificação da energia consumida pelo arco formado durante a falha no isolamento.

Para finalizar, de acordo com o explicitado acima, observa-se a necessidade de aprimoramento das metodologias convencionais para garantir que a maior parte das faltas passíveis de ocorrência nos SEP seja observada e restringida pelo sistema de proteção associado. Baseados nos trabalhos desenvolvidos utilizando a proteção diferencial de potência, o presente trabalho apresentará uma proteção que observa a variação de potência, tendo o SMFS como principal fonte de medição. 


\section{Sistema de Medição Fasorial Sincronizado}

\subsection{Introdução}

O surgimento das PMU conferiu uma significante melhora na confiabilidade das aplicações para as quais são utilizadas, oferecendo sincronização no tempo e uma alta resolução da informação, sem precedentes, sobre grandes áreas, em tempo real (GOLSHANI et al., 2013).

WAMS compreende quatro partes importantes em seu desenvolvimento: PMU, redes de comunicação, PDC, e a aplicação (GOLSHANI et al., 2013). Portanto, para a sua compreensão, faz-se necessária uma explicação mais detalhada de seus principais componentes e dos conceitos básicos relacionados aos fasores.

Vale comentar que a introdução a este assunto será fundamentada em sua potencial aplicação em esquemas de proteção. Nesta pesquisa, este assunto será aplicado à proteção de retaguarda de linhas de transmissão, a partir do desenvolvimento e implementação de uma metodologia que terá como foco principal a eliminação de faltas de alta impedância, que ocorrem principalmente em linhas longas e são um grande problema para os esquemas convencionais de proteção, como a de distância, anteriormente apresentada (GAN et al., 2002). 


\subsection{Análise Fasorial}

Fasores são usados em muitas funções de proteção e aquisição de dados. Referenciando-os em uma base de tempo comum, estes se tornam informações confiáveis para comparação em um sistema de grandes áreas. O conceito de sincrofasores vem trazer essa possibilidade de um método melhorado para a monitoração de grandes áreas, devido a essa base de tempo comum entre as medidas.

Considerando uma função senoidal pura, representada, por exemplo, pela Figura 3.1 e equação 3.1, tem-se:

$$
x(t)=X_{m} \cos (\omega t+\Theta)
$$

Onde:

$\omega$ é a frequência do sinal $(\mathrm{rad} / \mathrm{s})$;

$\Theta$ é o ângulo de fase do sinal (rad); e

$X_{m}$ é a amplitude do sinal.

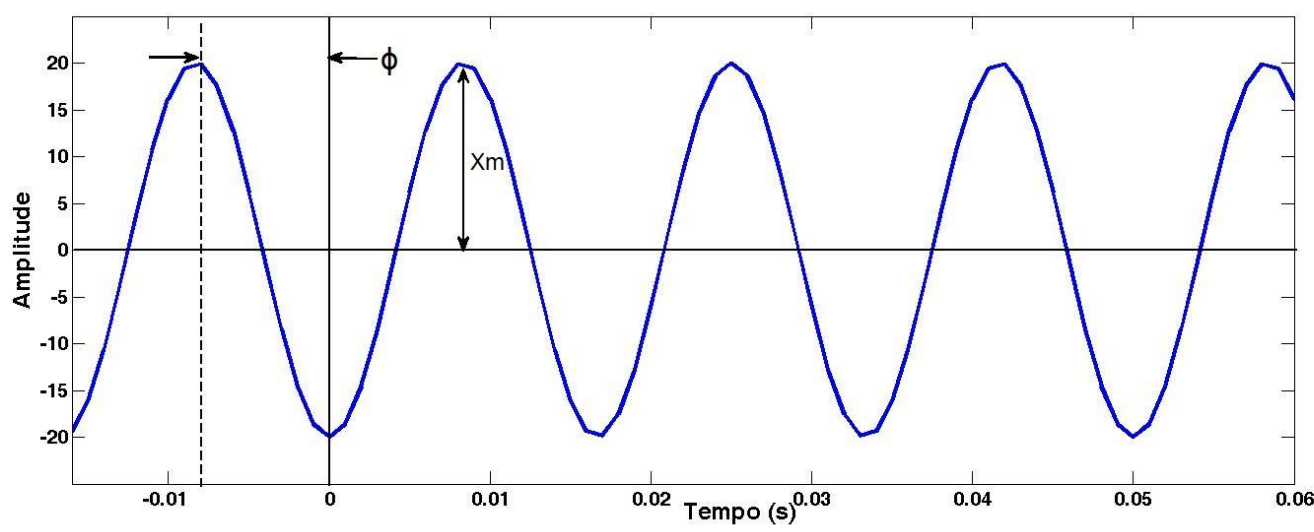

Figura 3.1 - Representação de um sinal senoidal puro.

Este sinal pode ser representado por um fasor, como representado na Figura 3.2, com a amplitude e fase dadas por: 


$$
X=\frac{X m}{\sqrt{2}} \angle \Theta=\left(\frac{X_{m}}{\sqrt{2}}\right)(\cos \Theta+j \operatorname{sen} \Theta)=X_{R}+j X_{i}
$$

Onde:

$X_{R}$ é a componente real de $X ; \mathrm{e}$

$X_{i}$ é a componente imaginária de $X$.

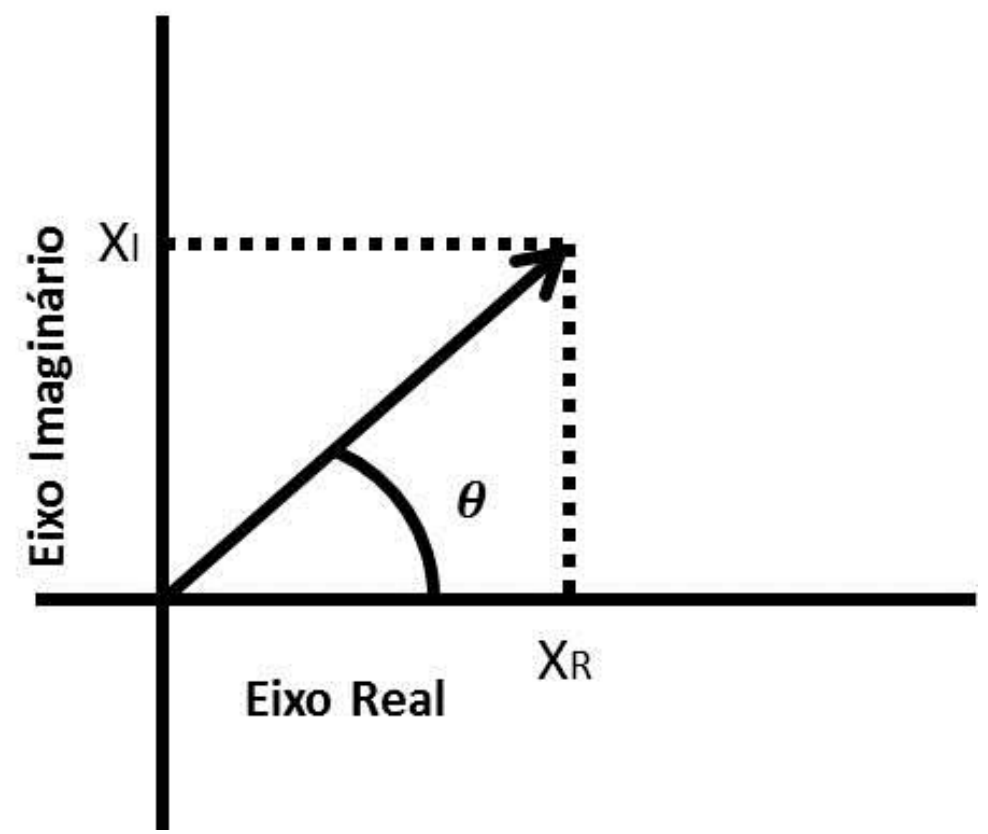

Figura 3.2 - Figura 3.3-Representação fasorial de $X$. Adaptado: PHADKE; THORP (2008).

\subsection{Componentes do Sistema de Medição Fasorial Sincronizada}

WAMS baseados em medidas fornecidas por PMU medem fasores de tensão e corrente com alta precisão. Os fasores são sincronizados pela estampa de tempo fornecida pelo GPS. Posteriormente, os fasores são coletados por PMU alocadas em subestações geograficamente distantes e enviados para o Concentrador de Dados Fasoriais (PDC - Phasor Data Concentrator), que recebe esses dados e os organiza de acordo coma a estampa de tempo fornecida pelo GPS, e os disponibiliza de acordo com a solicitação das aplicações. Esta estrutura 
pode ser ilustrada pela Figura 3.3, sendo que cada componente será brevemente apresentado nos tópicos seguintes.

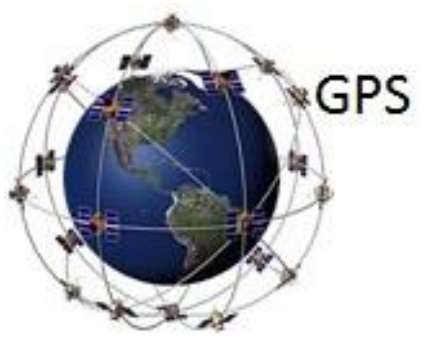

Link de comunicação

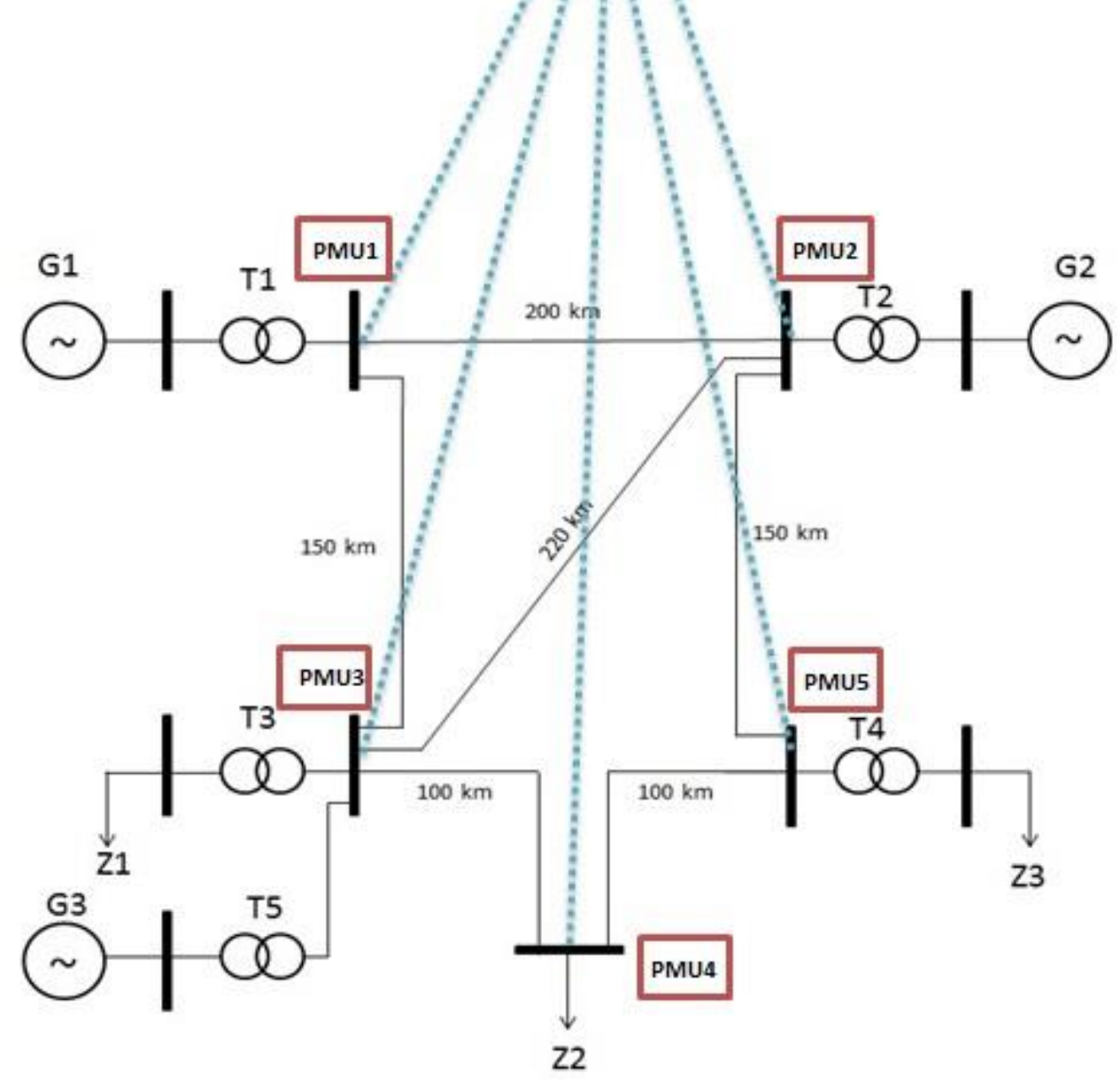

Figura 3.4 - Representação de um SMFS.

Adaptado: MENEZES (2012) .

\subsubsection{Global Positioning System}

O GPS é um sistema de posicionamento, navegação e coordenação de tempo, disponibilizado pelos Estados Unidos. A Força Aérea americana é responsável por desenvolver, manter e operar o sistema. Ele é constituído por uma 
constelação de 27 satélites (27 em operação, e 4 extras para o caso de um dos satélites sair de operação), orbitando a $20.350 \mathrm{~km}$ da superfície da Terra (NATIONAL COORDINATION OFFICE, 2014). Os mesmos são responsáveis por fornecer informações precisas de tempo e de coordenadas espaciais de latitude, longitude e altitude de receptores localizados na superfície terrestre. Cada GPS contém múltiplos relógios atômicos que contribuem para a precisão dos dados de tempo dos sinais. Os receptores dos GPS decodificam esses sinais, sincronizando cada receptor com os relógios atômicos.

Atualmente, o GPS é um elemento essencial para a infraestrutura global da informação. O fato de ser um sistema gratuito, aberto e seguro, conduziu ao desenvolvimento de centenas de aplicações, inclusive para sistemas de potência. Depois de repetidas ocorrências de blecautes nos SEP, as empresas e concessionárias de energia passaram a adotar dispositivos de sincronização de tempo com base no GPS em usinas e subestações. Isso tem possibilitado uma melhor análise dos eventuais distúrbios, observando, por exemplo, como os mesmos se propagam na rede (NATIONAL COORDINATION OFFICE , 2014).

O uso mais comum do GPS é para determinar as coordenadas do receptor, mas para as PMU, o dado mais importante fornecido pelo GPS é o sinal de um Pulso Por Segundo (PPS). Este sinal consiste de um trem de pulsos retangulares ocorrendo a uma frequência de $1 \mathrm{~Hz}$. A borda de subida do PPS é utilizada como referência para o cálculo do ângulo de fase. O UTC (Universal Time Coordinated), que é a base de tempo do GPS, é o fuso horário de referência a partir do qual se calculam todas as outras zonas horárias mundiais. Usando o GPS, as PMU permitem às concessionárias de energia determinar os fasores de tensão e corrente 
do sistema com relação a uma referência fixa no tempo (COURY; OLESKOVICZ; GIOVANINI, 2007). A medida de tempo tem a precisão de $1 \mu \mathrm{s}$, o que, em sistemas com frequência em $60 \mathrm{~Hz}$, significa uma precisão de 0,0022 (MURTHY et al., 2014).

Segundo a norma IEEE C37.118.1 (IEEE POWER ENGINEERING SOCIETY, 2011) a etiqueta de tempo é constituída por três componentes:

- A contagem do Segundo do Século (SOC - Second of Century), que corresponde ao número de segundos transcorridos desde a meianoite do dia $1^{\circ}$ de janeiro de 1970 até o presente segundo;

- O contador da fração do segundo (FRACSEC - Fraction of Second); e

- O flag de status do tempo, que indica a qualidade do tempo medido.

Então, a partir destes componentes o tempo pode ser calculado, como expressa a equação 3.3 .

$$
T e m p o=S O C+\frac{F R A C S E C}{T I M E_{-} B A S E}
$$

Onde TIME_BASE corresponde ao número inteiro de subdivisões do segundo.

\subsubsection{Unidades de Medição Fasorial}

A PMU é um equipamento que é capaz de medir os fasores de tensão e corrente de forma sincronizada, os quais são obtidos através da amostragem das formas de onda de tensão e corrente ao mesmo tempo, utilizando um sinal de sincronismo provido pelo GPS. O processo de funcionamento da PMU é semelhante à de um relé, com início na aquisição e filtragem dos dados, passando pela 
sincronização e digitalização do sinal e extração do fasor, conforme apresentado na Figura 3.4.

A PMU possui um receptor de GPS interno ao seu hardware. O sinal recebido é demodulado e dele é gerado outro sinal, que pode ser entendido como um código pulsado contendo informações de data e tempo, transmitido através de uma portadora e atualizado a cada segundo. Além disso, o receptor de GPS fornece também o sinal de 1 PPS.

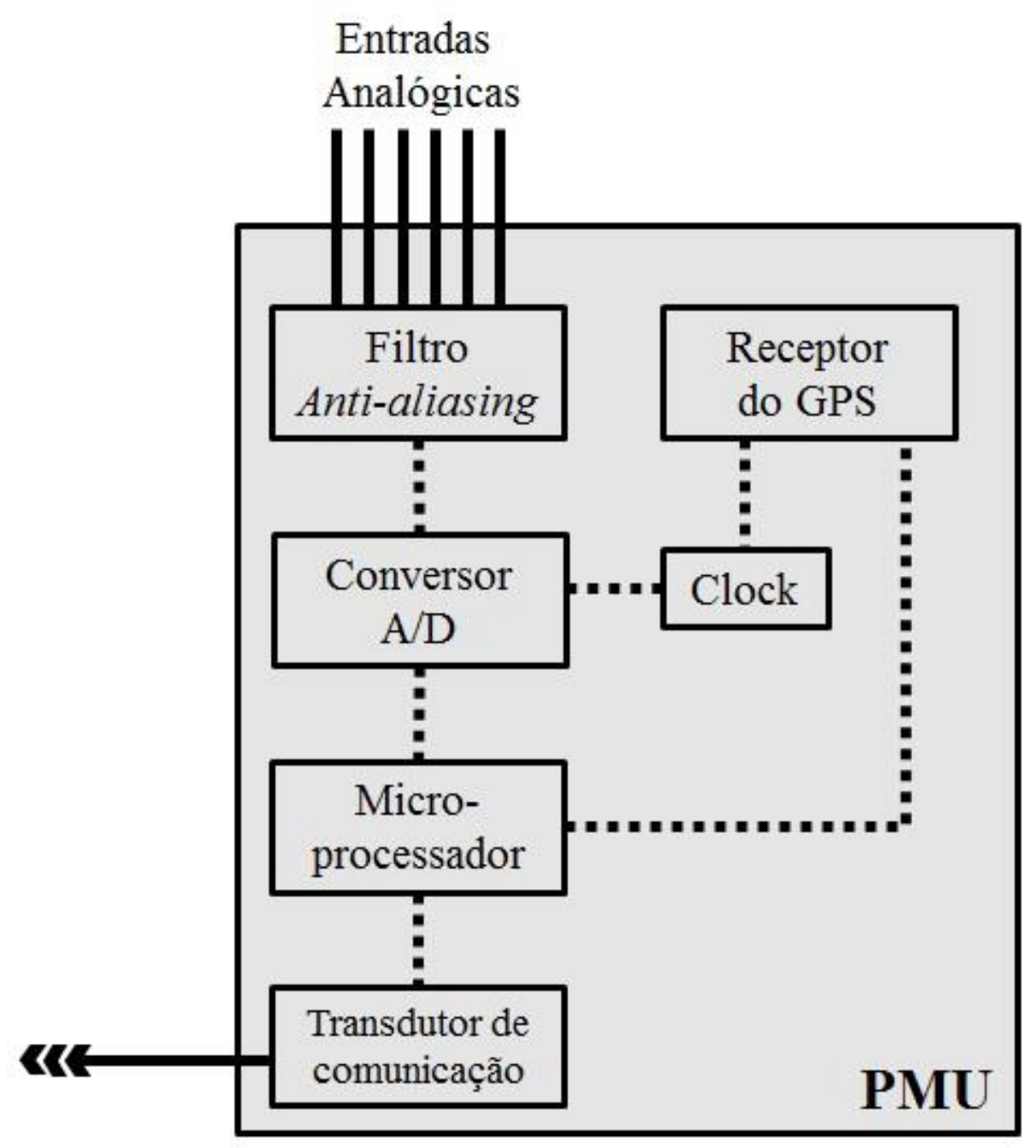

Figura 3.5 - Hardware básico de uma PMU.

Adaptado: PHADKE; THORP (2008). 
Os sinais de tensão e corrente da entrada analógica têm os ruídos filtrados pelo filtro anti-aliasing. O processo de filtragem é aplicado com a finalidade de remover os componentes cuja frequência seja igual ou maior que duas vezes o mais alto componente de frequência deste sinal (Teorema de Nyquist) (COURY; OLESKOVICZ; GIOVANINI, 2007). Este processo é importante, pois evita o efeito aliasing (sobreposição), que consiste na interpretação de componentes de frequência superiores como componentes de frequências menores, como também elimina sinais indesejados (SILVA, 2010).

Após o processo de filtragem, os sinais são discretizados através do conversor Analógico-Digital (A/D), sendo que a taxa escolhida para este conversor ditará a resposta em frequência do filtro anti-aliasing. Com a evolução dos microprocessadores e conversores, as novas PMU podem operar com uma taxa de até 256 amostras por ciclo (REASON TECNOLOGIA S.A., 2011). Esse pode ser considerado um grande avanço, visto que as primeiras PMU possuíam uma taxa de amostragem de 12 amostras por ciclo do sinal na frequência nominal (PHADKE; THORP, 2008).

O microprocessador é o responsável pela execução do cálculo dos fasores de tensão e corrente a partir da Transformada Discreta de Fourier (TDF), que será detalhada na próxima seção. Após todo o processo descrito, os fasores são enviados ao PDC, e, posteriormente, utilizados para as aplicações aos quais são solicitados.

Vale relembrar que o monitoramento adequado de um SEP é de extrema importância, pois os operadores que controlam a operação do sistema necessitam de informações confiáveis para a tomada de decisões. Atualmente, o sistema SCADA (Supervisory Control and Data Acquisition) é o responsável por esse 
monitoramento. Porém, este sistema possui uma alta latência, fazendo com que os operadores sejam forçados a fazer algumas suposições em suas análises e cálculos (QUANTA TECHNOLOGY, 2014). Contudo, com o advento dos WAMS baseados na tecnologia das medições fasoriais sincronizadas associadas com a transmissão de dados por links de comunicação com rápidas taxas de transmissão, esse cenário está mudando.

Desta forma, percebe-se como a PMU e os demais componentes do SMFS tem se tornado de grande utilidade para o SEP como um todo.

\subsubsection{A Transformada Discreta de Fourier}

Das aplicações práticas, tem-se que a depender das funções do sistema de proteção, este recebe os sinais de tensão e corrente, os interpreta, os utiliza para a função o qual foi projetado e emite um sinal de saída. Estes sinais de tensão e corrente são de tempo contínuo, assumindo um valor para cada instante de tempo. Desta maneira, para interpretá-los, o sistema de proteção precisa que estes sinais sejam discretizados, ou seja, amostrados. A amostragem consiste em capturar os valores do sinal de tempo contínuo em intervalos de tempo uniformemente distribuídos.

A Transformada Discreta de Fourier (TDF) ou, do inglês, Discrete Fourier Transform (DFT), é uma das ferramentas matemáticas mais utilizadas em várias áreas da engenharia onde o objetivo seja o de analisar sinais periódicos de tempo discreto, e pode ser representada pela equação 3.4 .

$$
X=\frac{2}{N} \sum_{k=0}^{N-1} x_{k} e^{-j \frac{2 \pi}{N} k}
$$

Onde: 
$\mathrm{N}$ representa o número de amostras por ciclo (taxa de amostragem);

$X_{k}$ é a amostra; e

K é o número da amostra.

No caso da PMU, a TDF é utilizada para a extração fasorial. De acordo com Phadke e Kasztenny (2009), os algoritmos mais utilizados nas PMU disponíveis comercialmente são baseados nesta transformada. Esta transformada considera que a forma de onda medida consiste de um componente fundamental, acrescida de outros componentes harmônicos. Pela transformada um par ortogonal de funções base senoidais é correlacionado com os dados amostrais para extrair os componentes da função base da forma de onda de entrada.

Conforme apresentado em Phadke e Thorp (2008), há uma ligação direta entre a velocidade de processamento dos dados e a precisão do fasor encontrado via a TDF. Tal precisão está diretamente ligada com a janela de dados, pois quanto maior a janela de dados, maior o número de dados disponíveis para o cálculo da extração fasorial. Por outro lado, quanto maior for a janela de dados, mais tempo levará para a realização do cálculo. Segundo Miranda (2005, apud Menezes, 2012, p.48), a TDF de ciclo completo é normalmente utilizada para o cálculo dos fasores, devido ao bom compromisso entre o atraso do processamento e o resultado do cálculo fasorial.

\subsubsection{O Concentrador de Dados Fasoriais}

O PDC tem como função receber os sincrofasores coletados pelas PMU e organizar esses dados a partir de etiquetas de tempo, armazenando-os e disponibilizando-os de acordo com as solicitações das aplicações. Em sua origem, o PDC tinha apenas o papel de organizar as medidas, como foi descrito, e, também 
monitorava todas as medidas do sistema, uma vez que era o único elemento em comum que se comunicava com os demais elementos do sistema. Porém, como os sistemas de medição, e como o desenvolvimento das aplicações vem crescendo, as funções do PDC se expandiram para incluir a manipulação, o processamento e o armazenamento de dados (IEEE POWER AND ENERGY SOCIETY, 2013).

Bem como as PMU, o PDC também necessita da sincronização, com o objetivo de evitar erros causados pela distância física entre o mesmo e as PMU. Uma signficante vantagem do PDC, é a possibilidade de detecção de situações críticas, como, por exemplo, a oscilação de potência e a instabilidade de tensão (BUTTAYAK et al., 2012). Contudo, conforme apontado por Phadke e Thorp (2008),

o PDC impõe uma maior latência ao uso dos dados em tempo real, mas esta não é controlável.

Dependendo da arquitetura e do tamanho da rede, alguns PDC podem atuar como super PDC, com a função de coletar dados provenientes de outros PDC, conectado a uma base dados para análises (MARTINEZ et al., 2005).

\subsubsection{Sistema de Comunicação e Transferência de Dados}

Alcançar um caminho de comunicação confiável entre as PMU e o PDC é um grande desafio para o desenvolvimento das redes de comunicação para aplicações das redes inteligentes. Quanto à transferência de dados, vale ressaltar a importância de dois aspectos: a capacidade de transmissão e a latência. O primeiro aspecto se refere à taxa de transferência de dados que um canal de comunicação pode suportar. O segundo aspecto diz respeito ao atraso de tempo entre o instante que o dado é criado e quando este está disponível para sua aplicação desejada. 
Com o objetivo de prover definição e especificação para a comunicação de PMU, foi criada a norma IEEE C37.118 - 2011 (IEEE POWER AND ENERGY SOCIETY, 2011). De acordo com a norma, cada pacote de dados enviados pela PMU tem um formato composto por quatro tipos de mensagens (EISSA et al., 2012), (YUEHAI et al., 2011), (KANSAL; BOSE, 2011):

- Head Frame: é usado para dar a descrição do dispositivo, e é enviado apenas uma vez;

- Command Frame: controla a operação dos dispositivos de medição fasorial, enviado do PDC para a PMU, se requisitado;

- Configuration Frame: corresponde à configuração completa das PMU e PDC, contendo a informação necessária para decodificar as mensagens, enviado apenas quando há mudanças no sistema; e

- Data Frame: Utilizado para o fluxo de dados em tempo real, contendo as medidas, enviado das PMU para o PDC, durante a operação do sistema.

A mensagem inicia com uma palavra de 2 bytes, SYNC, seguida de uma palavra de 2 bytes, FRAMESIZE, outra de 2 bytes, IDCODE, e a estampa de tempo, SOC (4 bytes) e FRACSEC (4 bytes). A palavra formada por SYNC fornece sincronização. IDCODE identifica a unidade que está enviando ou recebendo as mensagens, e FRAMESIZE é o tamanho, em bytes, de todo o frame de dados. Por fim, todas as mensagens terminam com uma palavra de checagem $(\mathrm{CHK})$. $\mathrm{O}$ formato da mensagem enviada pelas PMU é apresentado na Figura 3.5. Em condições normais de operação, apenas o Data Frame é comunicado. 


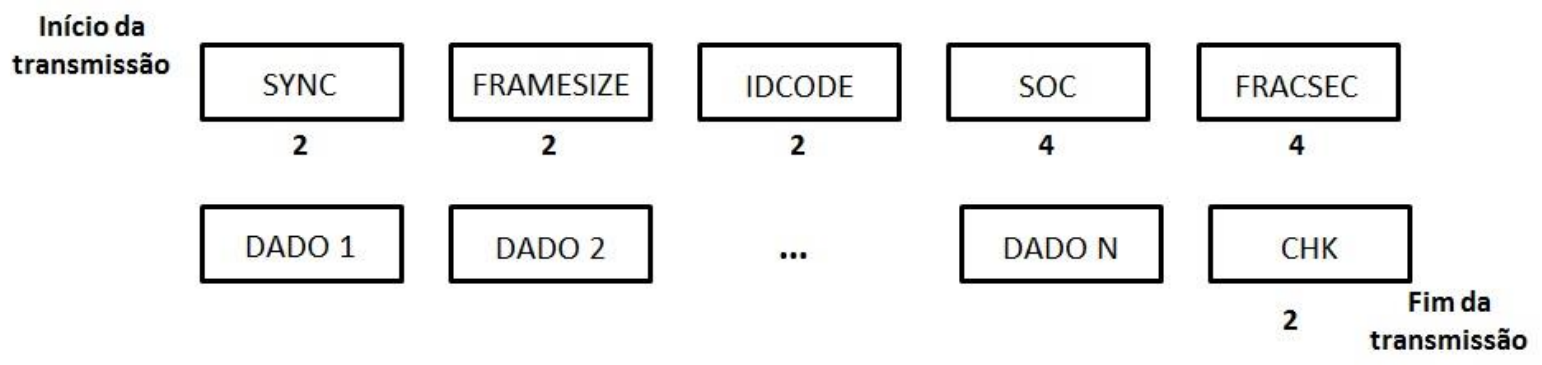

Figura 3.6 - Formato das mensagens da PMU. Fonte: IEEE POWER AND ENERGY SOCIETY (2011).

Os dados correspondem aos valores de frequência, taxa de mudança de frequência, dados analógicos e digitais, bem como dos fasores medidos. O tamanho da mensagem varia com o número de fasores e dos dados analógicos e digitais a serem transmitidos. Para a transmissão de um único fasor em formato de número inteiro, o tamanho da mensagem será de 30 bytes, e 38 bytes para transmissão do fasor no formato de número real (PHADKE; THORP, 2010).

A largura de banda é a medida da capacidade de transmissão de um determinado canal de comunicação. Para o sistema de comunicação das PMU, a largura de banda é determinada pelo tamanho das mensagens, pela taxa de transmissão e pelos gastos de comunicação. Para a frequência de $60 \mathrm{~Hz}$, a taxa de reportagem de dados pode variar de 10 a 60 fasores por segundo (IEEE POWER AND ENERGY SOCIETY, 2011). Com o advento do conceito dos WAMS, a infraestrutura dos SEP tem sido equipada com canais de comunicação com alta largura de banda, devido ao crescimento em número das medições e monitoramento do sistema utilizando PMU (LIN et al., 2012).

No que concerne à latência, as suas principais causas podem ser devidas aos aspectos listados na Tabela 3.1. Nota-se que a menor latência é da ordem de 20 milissegundos (ms), e a máxima de 10 segundos. 
Tabela 3.1 - Causas da alta latência do SMFS.

Fonte: IEEE POWER AND ENERGY SOCIETY (2011).

\begin{tabular}{cc}
\hline \hline Causas da Latência & Variação típica do valor da latência \\
Janela de amostragem & $17 \mathrm{~ms}$ a $100 \mathrm{~ms}$ \\
Filtragem das medidas & $8 \mathrm{~ms}$ a $100 \mathrm{~ms}$ \\
Processamento da PMU & $0,005 \mathrm{~ms}$ a $30 \mathrm{~ms}$ \\
Processamento e alinhamento do PDC & $2 \mathrm{~ms}$ a $2 \mathrm{~s}$ \\
Saída Serial & \\
Sistema de comunicação (entrada e saída) & $0,05 \mathrm{~ms}$ a $20 \mathrm{~ms}$ \\
Distância & $0,05 \mathrm{~ms}$ a $30 \mathrm{~ms}$ \\
Atrasos computacionais na aplicação & $3,4 \mu \mathrm{s} / \mathrm{km}$ a $6 \mu \mathrm{s} / \mathrm{km}$ \\
comunicação & $0,05 \mathrm{~ms}$ a $8 \mathrm{~s}$ \\
\hline \hline
\end{tabular}

${ }^{1}$ Corresponde a conexão serial RS-232. A comunicação serial envia e recebe bytes de informação, enviando e recebendo um bit por vez.

A escolha do meio de comunicação deve levar em conta os aspectos de comunicação até aqui descritos. Para aplicações que requerem uma quantidade significante de dados, com baixa latência, o meio a ser aplicado é a fibra óptica. Para as aplicações que não requerem grandes volumes de dados e um tempo de resposta mais lento, pode-se utilizar outros tipos de canais de comunicação como circuitos de telefone, canais de micro-ondas ou PLC (Power Line Carrier) (PHADKE; THORP, 2010). O meio de comunicação mais interessante para este caso são os 
cabos de fibra óptica. Os cabos possuem uma alta capacidade de canal, alta taxa de transferência e imunidade a interferência eletromagnética (PHADKE; THORP, 2008).

Vale também comentar que, de forma simplista, o protocolo de comunicação pode ser definido como um conjunto de regras que controla a comunicação e especifica o formato dos dados. Segundo a norma C37.118 - 2011 (IEEE POWER AND ENERGY SOCIETY, 2011), o SMFS comumente utiliza o Internet Protocol (IP) para a rede de comunicação, que pode ser o TCP (Transmission Control Protocol) ou UDP (User Datagram Protocol), de acordo com a preferência e necessidades do usuário.

Devido ao atraso do sistema de comunicação, somado aos atrasos de processamento das PMU e do PDC, o SMFS não pode ser usado para esquemas de proteção em que sejam necessários pequenos tempos de resposta. Segundo Kansal e Bose (2011), as aplicações baseadas em PMU podem ter uma latência que varia entre $100 \mathrm{~ms}$ a 1 segundo. No trabalho realizado em Lira et al. (2011), os autores consideram que para a maioria das aplicações em proteção e controle que utilizam medidas provenientes de SMFS, as mesmas podem ter uma resposta satisfatória com tempos de até 200 ms.

\subsubsection{Aplicações de PMU}

Como já mencionado, a tecnologia de medidas fasoriais sincronizadas foi introduzida como resultado de pesquisas realizadas na década de 80 , e, desde então, essa tecnologia apresenta-se como uma alternativa para várias áreas e aplicações relacionadas ao SEP, devido a uma maior precisão e ao sincronismo no tempo, contribuindo para a melhoria do monitoramento, controle e proteção do SEP como um todo. Pela literatura correlata consultada, observam-se muitas aplicações e 
a perspectiva é positiva quanto à utilização de novas metodologias que utilizem PMU. Já existem muitos WAMS baseados em PMU por todo o mundo (SINGH et al., 2011).

Contudo, cada aplicação exige um requisito diferente em relação à taxa de amostragem, latência máxima e confiabilidade da comunicação de dados. Neste contexto, em ONS (2007), Volskis et al. (2008) e Andrade (2008), apontam-se possíveis aplicações de PMU no SIN e seus impactos. Estes trabalhos tem como foco a identificação de um conjunto de aplicações potenciais de PMU que possam ser implantadas, de forma que contribuam com a operação do sistema, por parte do ONS, na tomada de decisões em tempo real.

As aplicações potenciais descritas nas referências citadas são:

- Monitoramento do ângulo de fase de tensão;

- Monitoração de oscilações do sistema;

- Monitoração do limite de carregamento da linha;

- Monitoração de harmônicos para grandes áreas;

- Avaliação avançada de estabilidade da tensão;

- Análise de contingência on-line;

- Proteções de sistemas para grandes áreas - WAPS; e

- Controle de sistema para grandes áreas.

Também são descritas funções específicas para o emprego de PMU, como:

- Estimação de estado otimizado por sincrofasores;

- Medição do estado e cálculo do estado; e

- Melhoria e validação dos modelos dos sistemas. 
As diversas aplicações de PMU mencionadas podem fornecer melhorias e benefícios para apoiar os operadores de sistema do ONS na tomada de decisão em tempo real.

Ainda de acordo com o ONS (2007), para um esquema de WAPS, o qual é o foco deste trabalho, a utilização de medições fasoriais sincronizadas será apropriada para esquemas de proteção que não operem em velocidade ultrarrápida. Portanto, funções de proteção de retaguarda, relés de sincronismo, relés de perda de campo, relés de desligamento de carga por sub-frequência e por sub-tensão, e esquemas de ação corretiva, são todos potenciais candidatos para ter o desempenho melhorado através do uso de medição fasorial.

Em Moraes e Volskis (2008), e Moraes e Hu (2010), são descritos os desafios da aplicação de PMU no SIN. Os autores se preocuparam em explicar a função do ONS, que é o órgão responsável por operar o SIN brasileiro, e descrevem os desafios enfrentados por esse órgão devido à complexidade de tal sistema. Conforme bem relatam os autores, devido ao seu tamanho, o SIN enfrenta problemas para coordenação da geração, que influencia diretamente no custo da energia, bem como problemas com desbalanço de carga e distúrbios devido à geração, causando variação de frequência, situações de colapso de tensão, e até mesmo condições de ilhamentos e perda de importantes centros de carga. E, para agregar mais confiabilidade a esses sistemas, os autores apontam as aplicações de PMU como uma nova forma de monitoramento, proteção e controle.

Contudo, é discutido que para garantir os benefícios da implantação de PMU, os projetos de WAMS devem considerar não apenas aplicações funcionais com diferentes, e, às vezes, contraditórios requerimentos, mas também uma especificação de uma estrutura padronizada com a pretensão de obter uma 
consonância de operação de vários PMU. Essa consonância diz respeito à compatibilização de questões além de protocolos de comunicação padrão para um comportamento coerente, ou interoperabilidade, de todas as unidades de medição em situações de regime permanente e condições dinâmicas. Alcançar este comportamento coerente é o verdadeiro desafio a ser vencido. Portanto, o sistema deve ser implantado visando uma expansão futura do mesmo, que suporte aplicações diversas, além da qual tal sistema foi implantado.

Silva Filho et al. (2010) descrevem os testes realizados pela empresa Eletrobrás Furnas utilizando o pacote de software PDC adquirido em 2009. A empresa vem testando a medição fasorial sincronizada desde 2006 através de equipamentos de proteção e Registradores Digitais de Perturbações (RDP) instalados pelo sistema elétrico da empresa. O projeto do SMFS de Furnas possuía até a época, 14 PMU ligadas a este PDC, com a previsão de adição de novas unidades. Os testes realizados testaram três aplicações:

- Previsão de perda de estabilidade e proteção sistêmica;

- Aprimoramento de esquemas de controle de emergência de troncos de transmissão; e

- Medição de parâmetros de sequência positiva de linhas de transmissão.

Segundo o que foi reportado, este PDC está em operação desde o início de 2010 e tem demonstrado grande estabilidade, facilidade de operação e manutenção, confiabilidade e utilidade no apoio às interpretações de condições operacionais do sistema.

Em Jiang et al. (2000) e Jiang et al, (2012), é apresentada uma alternativa de localização de falta utilizando dados provenientes de PMU. Segundo os autores, 
o método se mostra interessante e preciso, tornando-se um grande potencial de aplicação.

Outros trabalhos como Ashton, Taylor e Carter (2012), Mantuano Filho, Sollero e Moraes (2005), Santos (2013), tratam sobre as possíveis aplicações de PMU em SEP, o que deixa claro que as funções das PMU devem ser testadas a exaustão para que sua aplicabilidade seja garantida e atinja a confiabilidade esperada. 


\section{Metodologia}

Este capítulo tem por objetivo apresentar as metodologias que foram desenvolvidas com foco na proteção de retaguarda de grandes áreas utilizando dados de um SMFS.

Embasada no levantamento bibliográfico apresentado até o momento, as metodologias desenvolvidas tiveram seu foco principal no desempenho do sistema de proteção de retaguarda frente às faltas de alta impedância, que podem ser as faltas mais incomuns, porém factíveis.

As metodologias foram desenvolvidas com o auxílio do RTDS®. Através do software RSCAD, o sistema elétrico de interesse para a pesquisa foi modelado, bem como realizada a validação das metodologias propostas, que serão detalhadas mais a frente.

\subsection{O RTDS $®$}

A modelagem do SEP via o RTDS®, bem como todas as considerações pertinentes, serão apresentadas na próxima seção. Vale colocar que via o RTDS® é possível simular o SEP em operação contínua, em tempo real e em malha fechada, permitindo a instalação e interação, por exemplo, de equipamentos de proteção e controle. Neste sentido, o RTDS® é uma ótima ferramenta para projetar e realizar exaustivos estudos e testes de esquemas de proteção e controle. Com uma grande quantidade de recursos de entradas e saídas analógicas e digitais, o mesmo permite que elementos físicos, como relés de proteção e componentes de controle, sejam 
conectados ao simulador, possibilitando a interação desses elementos com o sistema simulado durante o teste em malha fechada. Isso permite um teste do comportamento dinâmico do sistema, garantindo que várias situações reais do sistema sejam testadas, e, consequentemente, provendo melhores ajustes aos componentes.

As aplicações decorrentes do uso do RTDS® podem beneficiar várias áreas, como (CEPEL, 2011):

- Esquemas de relés de proteção e sistemas de proteção e controle integrados;

- Sistemas de controle para HVDC (High Voltage Direct Current), SVC (Static VAr Compensator), componentes FACTS (Flexible Alternative Current Transmission System), e máquinas síncronas, incluindo AVR (Automatic Voltage Regulator) e PSS (Power System Stabilizer);

- Operações gerais e estudos relacionados ao comportamento de sistemas CA (Corrente Alternada) e CC (Corrente Contínua);

- Interações de sistemas CA e CC; e

- Interações entre vários circuitos elétricos.

Apenas para efeito ilustrativo, a interface inicial do RSCAD é apresentada na Figura 4.1. Na Figura 4.2 apresenta-se para efeito também ilustrativo, uma das configurações do equipamento. Vale ressaltar que este equipamento em uso neste trabalho, encontra-se alocado junto às dependências do Laboratório de Sistemas de Energia Elétrica (LSEE), do Departamento de Engenharia Elétrica e de Computação (SEL/EESC/USP), em São Carlos - SP. 


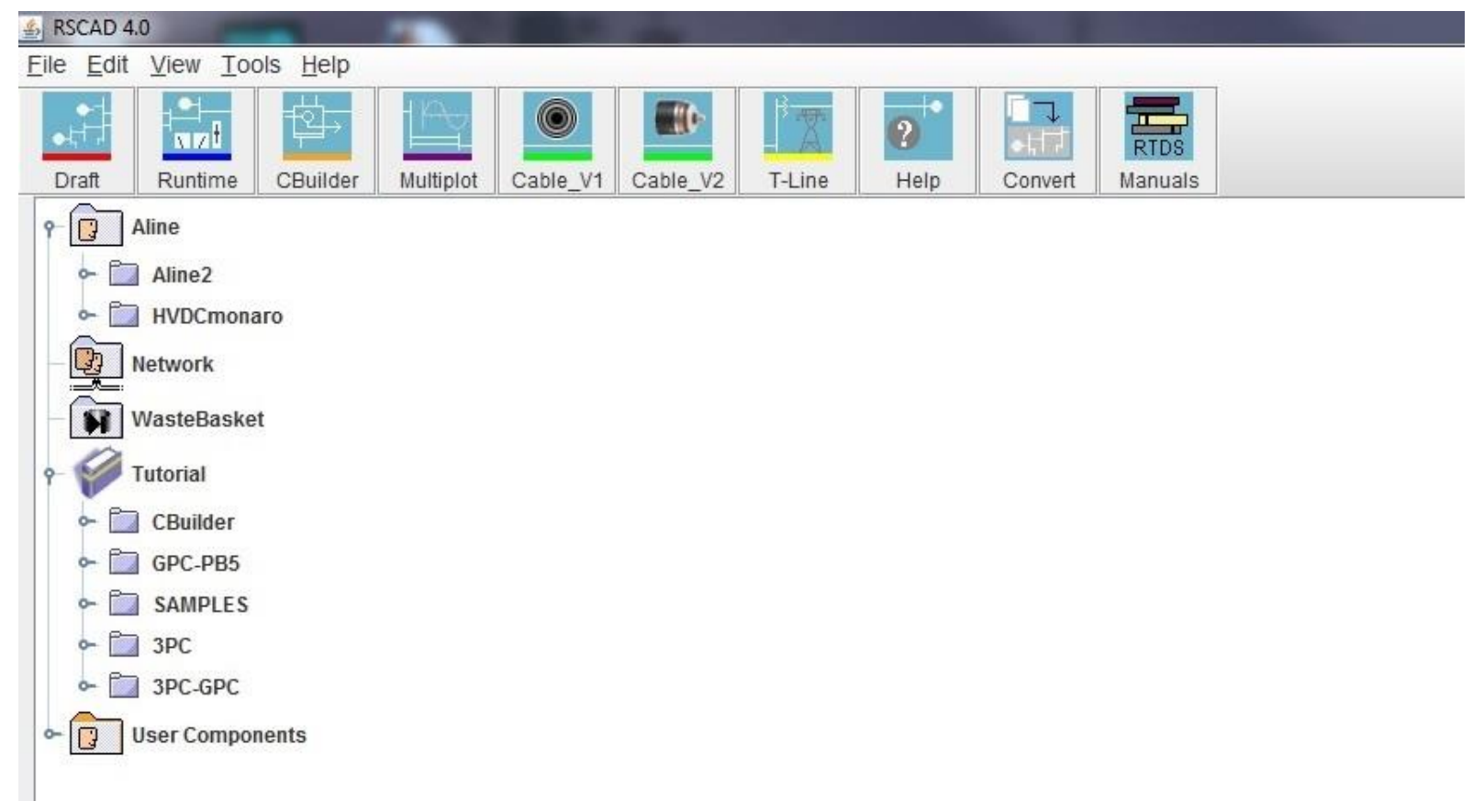

Figura 4.1 - Uma das janelas propiciadas pela interface do RTDS®.

A partir das simulações realizadas no sistema teste modelado no RTDS®, é possível obter os dados de tensão, corrente e tempo que serão utilizados para alimentar o algoritmo proposto. Vale ressaltar que até o momento não foram realizados testes em malha fechada. Porém, para uma fase futura de teste/validação mais aprimorada da metodologia proposta, pode-se dispor desta potencialidade conectando relés comerciais para comparar a metodologia desenvolvida com metodologias comumente utilizadas para proteção de retaguarda de linhas de transmissão de grandes áreas. Neste sentido, vale frisar que para o estado atual da pesquisa, a metodologia como apresentada poderia ser desenvolvida dispondo de softwares mais simples, sem a necessidade de simulações em tempo real, como seria, por exemplo, pelo uso do software ATP. 


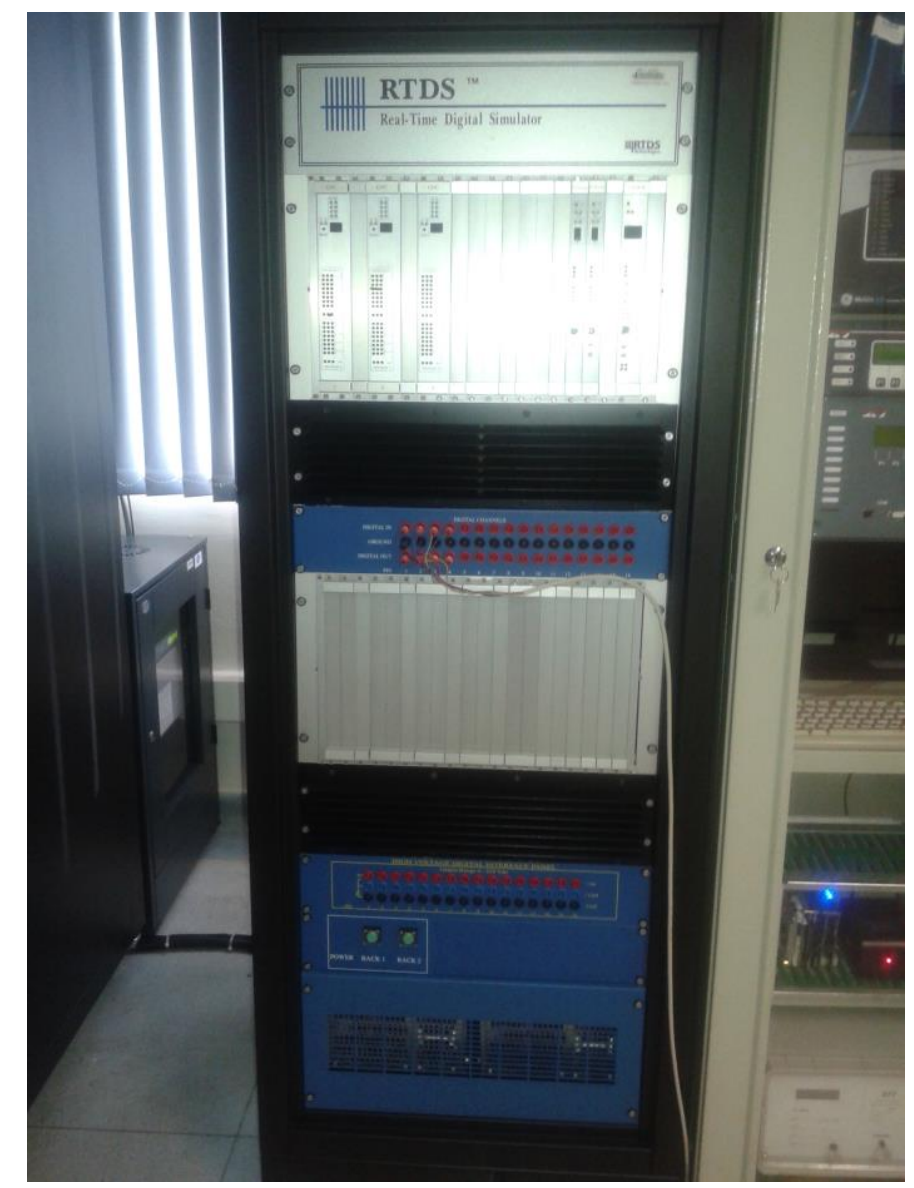

Figura 4.2 - O rack contendo a configuração do RTDS® em uso no LSEE.

O RSCAD permite a simulação de PMU através de um componente que emula o comportamento deste dispositivo. Este componente possui 8 PMU operando independentemente, provendo até 12 fasores por PMU, medidas de frequência e a taxa de mudança da frequência. Este componente é capaz de prover informações de tensão e corrente de fase, tensões e correntes de sequência positiva, negativa e zero, bem como gráficos dos sinais em valores reais e imaginários ou em magnitude e ângulo.

Cada PMU deve ser alimentada com 6 sinais de entrada: 3 sinais de tensão e 3 sinais de corrente. Os sinais de entrada passam por um filtro passa-baixa com uma frequência de corte de $1 / 3$ da taxa de amostragem do RTDS®, que é de 20 $\mathrm{kHz}$, e, portanto, essa frequência de corte é de aproximadamente $6 \mathrm{kHz}$. O dado 
amostrado alimenta uma DFT de 8 amostras por ciclo. A taxa de reportagem dos fasores para as simulações a serem apresentadas, foram de 60 fasores por segundo. O tempo de resposta da PMU é simulado pelo RTDS®, e este tempo é de aproximadamente $16 \mathrm{~ms}$.

Vale relembrar que a possibilidade de simulação em malha fechada não foi explorada até essa etapa da pesquisa. A simulação também não contemplou a simulação do sistema de comunicação, e os atrasos foram considerados fixos e conhecidos, com base na bibliografia correlata consultada.

\subsection{Descrição do Sistema Elétrico Simulado}

Para a validação da metodologia, realizou-se, via o RTDS®, a simulação de um SEP teste. O SEP simulado é o sistema de transmissão de 12 barras do IEEE, apresentado na Figura 4.3, encontrado no trabalho de Jiang, Annakage e Gole (2006), para estudos de FACTS e ligeiramente modificado por SANTOS et al. (2015). No modelo modificado, o dispositivo FACTS foi retirado, pois o foco do estudo não contemplava a análise do desempenho da proteção na presença de tal dispositivo.

O sistema de transmissão simulado é constituído por sete linhas de transmissão que tem seus comprimentos entre 100 e 600 km. Possui quatro geradores, e doze barramentos, sendo dois de $345 \mathrm{kV}$, seis de $230 \mathrm{kV}$ e quatro de 22 kV. Este sistema demonstrou ser adequado para os propósitos desta pesquisa, pois possui linhas que interligam longas distâncias, corroborando com o objetivo do trabalho, que visa proteger uma grande área via um SMFS.

No trabalho realizado por Monaro (2013), os dados deste sistema simulado foram bem detalhados e serão brevemente apresentados nas próximas seções. 


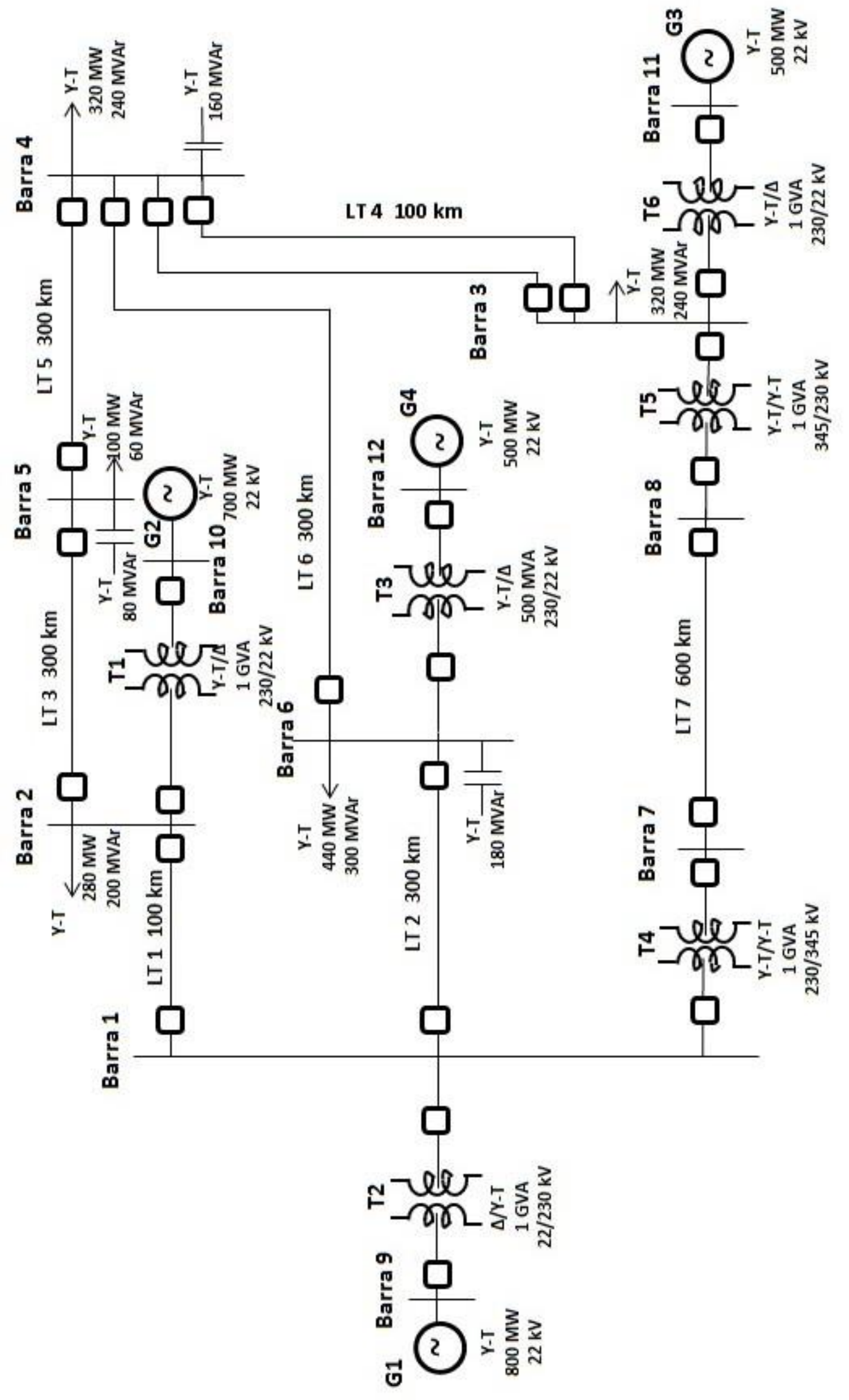

Figura 4.3 - Sistema teste simulado.

Fonte: SANTBS et al. (2015) 


\subsubsection{Linhas de Transmissão}

O sistema simulado é formado por sete linhas de transmissão, cujos dados referentes à classe de tensão, ao comprimento e à conexão entre as barras de cada linha de transmissão são evidenciados na Tabela 4.1, na Tabela 4.2 e na Figura 4.4.

Tabela 4.1 - Dados das linhas de transmissão.

\begin{tabular}{cccccccc}
\hline \hline Linha & LT 1 & LT 2 & LT 3 & LT 4 & LT 5 & LT 6 & LT 7 \\
\hline Tensão (kV) & 230 & 230 & 230 & 230 & 230 & 230 & 345 \\
$\begin{array}{c}\text { Comprimento } \\
(\text { km) }\end{array}$ & 100 & 300 & 300 & 100 & 300 & 300 & 600 \\
$\begin{array}{c}\text { Conexão } \\
\text { (barras) }\end{array}$ & $1-2$ & $1-6$ & $2-5$ & $4-3$ & $4-5$ & $4-6$ & $7-8$ \\
\hline \hline
\end{tabular}

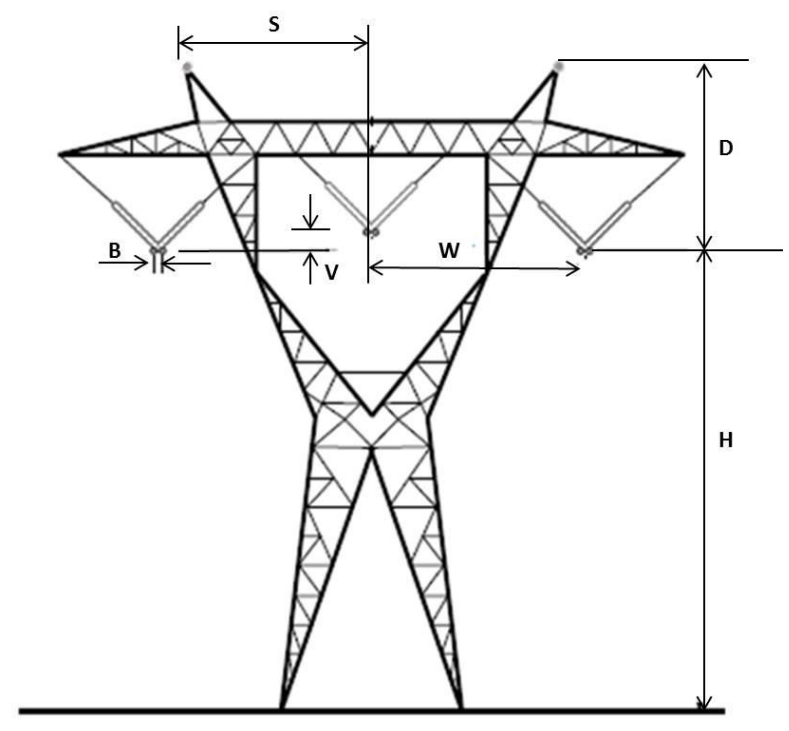

Figura 4.4 - Desenho da torre de transmissão do modelo simulado no RTDS® Fonte: MONARO (2013) 
Tabela 4.2 - Dados construtivos das linhas de transmissão simuladas no RTDS®

\begin{tabular}{|c|c|c|}
\hline Tensão (kV) & 230 & 345 \\
\hline$H(m)$ & 14,4 & 17,53 \\
\hline$V(m)$ & 1,22 & 3,50 \\
\hline$W(m)$ & 5,49 & 7,25 \\
\hline$S(m)$ & 3,05 & 4,65 \\
\hline$D(m)$ & 3,81 & 5,0 \\
\hline Cond. Por fase & 1 & 2 \\
\hline$B(m)$ & - & 0,46 \\
\hline Tipo de cabo & 954ACSR 54/7 & $795 A C S R$ 26/19 \\
\hline Números de cabos terra & 2 & 2 \\
\hline Flecha $(m)$ & 5.94 & 7,92 \\
\hline Flecha cabo terra $(m)$ & 4,45 & 7,25 \\
\hline Resistência do solo $(\Omega / \mathrm{km})$ & 100 & 100 \\
\hline
\end{tabular}

Para o desenvolvimento da pesquisa, estas linhas se demonstraram coerentes por se tratar de linhas longas que interligam longas distâncias, o que caracteriza uma grande área. As linhas a serem monitoradas por PMU são as linhas representadas na Figura 4.3 como LT3, LT5 e LT6. 


\subsubsection{Cargas}

Para que fossem representados os centros consumidores de energia, em algumas barras do sistema foram conectadas cargas do tipo $R$-L. Além disso, em algumas barras foram alocados bancos de capacitores para que houvesse a correção do fator de potência, assim como a melhora no perfil da tensão do sistema. A Tabela 4.3 mostra todos os dados dessas cargas que foram conectadas ao sistema simulado.

Tabela 4.3-Dados das cargas simuladas.

\begin{tabular}{cccccc}
\hline \hline Barra & $\mathbf{2}$ & $\mathbf{3}$ & $\mathbf{4}$ & $\mathbf{5}$ & $\mathbf{6}$ \\
\hline Tensão (kV) & 230 & 230 & 230 & 230 & 230 \\
$\begin{array}{c}\text { Carga ativa } \\
\text { (MW) }\end{array}$ & 280 & 320 & 320 & 100 & 440 \\
$\begin{array}{c}\text { Carga reativa } \\
\text { (Mvar) }\end{array}$ & 200 & 240 & 240 & 60 & 300 \\
$\begin{array}{c}\text { Compensação } \\
\text { capacitiva } \\
\text { (Mvar) }\end{array}$ & - & - & 160 & 80 & 360 \\
\hline \hline
\end{tabular}

\subsubsection{Geradores}

Os geradores síncronos utilizados no sistema simulado são todos constituídos de dois polos. Os dados dos mesmos são apresentados na Tabela 4.4. 
Tabela 4.4 - Dados dos geradores.

\begin{tabular}{ccc}
\hline \hline Geradores & Potência nominal & Tensão nominal \\
G1 & $800 \mathrm{MVA}$ & $22 \mathrm{kV}$ \\
G2 & $700 \mathrm{MVA}$ & $22 \mathrm{kV}$ \\
G3 & $500 \mathrm{MVA}$ & $22 \mathrm{kV}$ \\
G4 & $500 \mathrm{MVA}$ & $22 \mathrm{kV}$ \\
\hline \hline
\end{tabular}

\subsection{Algoritmo Desenvolvido}

Os algoritmos propostos neste trabalho tem como finalidade 0 desenvolvimento de uma proteção de retaguarda de linhas de transmissão para um SEP de grande área utilizando dados provenientes de um SMFS. Conforme já mencionado, este trabalho utilizará a variação da potência ativa como informação para a entrada do algoritmo de proteção.

Vale esclarecer que a primeira metodologia proposta e a ser apresentada é uma adaptação do esquema de proteção apresentado em Song et al. (2012). Esta última refere-se a um novo sistema de proteção de linhas de transmissão em corrente contínua. Tal metodologia permite que as faltas internas e faltas externas possam ser identificadas de forma eficaz utilizando somente a variação da magnitude da corrente em ambos os extremos da linha. Sendo assim, este esquema de proteção necessita apenas da comunicação do estado de um lado para o outro. Por isso, a velocidade da comunicação não precisa ser demasiadamente elevada. 
Apenas para diferenciar as metodologias apresentadas, esta será mencionada como Proteção Diferencial de Potência Local (PDPL).

A segunda metodologia a ser apresentada nesta dissertação utiliza um princípio similar às metodologias apresentadas na revisão bibliográfica. Ela fará o cálculo da diferença de potência entre os dois extremos da linha. Esta será mencionada apenas como Proteção Diferencial de Potência (PDP). O diferencial da forma como esta será apresentada, é que a mesma usará cálculos com dados provenientes de um sistema de medição fasorial sincronizado.

Vale esclarecer que, as duas metodologias serão direcionadas para a proteção de todas as linhas de transmissão que constituem o SEP ilustrado na Figura 4.3. Vale frisar que associadas às respectivas linhas de transmissão, encontram-se instaladas as PMUs desejadas para todo o processo.

\subsubsection{Proteção Diferencial de Potência Local - PDPL}

Como é de conhecimento, em um SEP em condições normais, um extremo da linha estará fornecendo potência ativa e o outro estará consumindo. Mesmo na presença de variação de carga, essa condição continua verdadeira.

Para incorporar tais condições na metodologia proposta, foi necessário adotar um sentido considerado positivo para a medição e cálculo das potências, como apresentado na Figura 4.5. Para realizar o cálculo das potências ativas trifásicas de cada extremo de uma linha utilizaram-se das seguintes equações:

$$
\begin{aligned}
& P_{12}=V_{A} I_{12 A} \cos \left(\theta_{V A}-\theta_{I 12 A}\right)+V_{B} I_{12 B} \cos \left(\theta_{V B}-\theta_{I 12 B}\right)+V_{C} I_{12 C} \cos \left(\theta_{V C}-\theta_{I 12 C}\right) \\
& P_{21}=V_{A} I_{21 A} \cos \left(\theta_{V A}-\theta_{I 21 A}\right)+V_{B} I_{21 B} \cos \left(\theta_{V B}-\theta_{I 21 B}\right)+V_{C} I_{21 C} \cos \left(\theta_{V C}-\theta_{I 21 C}\right)
\end{aligned}
$$

Onde:

$P$ é a potência calculada; 
$V$ é a amplitude do fasor de tensão de fase;

lé a amplitude do fasor de corrente de fase;

$\Theta$ é o ângulo dos fasores.

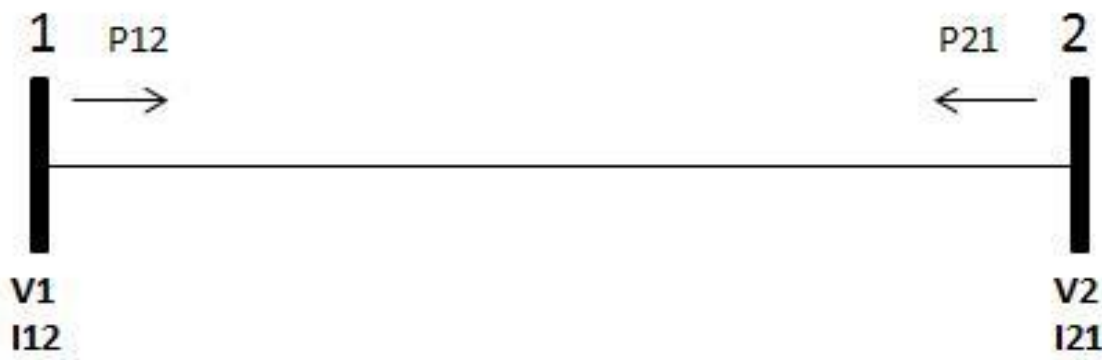

Figura 4.5 - Sentido adotado para a medição e cálculo das potências.

O cálculo consiste da comparação entre dois estados da potência em um extremo: a potência ativa instantânea e a potência medida em instantes passados. No caso da simulação realizada, as potências a serem comparadas tem uma diferença de 1 segundo. Essa variação, que é calculada conforme as equações 4.3 e 4.4, é a base de comparação para o desenvolvimento desta metodologia.

$$
\begin{aligned}
& \Delta P_{12}=P_{12 \text { atual }}-P_{21 \text { anterior }} \\
& \Delta P_{21}=P_{21 \text { atual }}-P_{21 \text { anterior }}
\end{aligned}
$$

A filosofia básica do algoritmo consiste no fato de que a variação da potência ativa somente será positiva nos dois extremos de uma linha (adotando a convenção de que a potência é positiva ao sair de um barramento) caso haja uma falta entre esta linha. Antes da falta ocorrer, pode ser considerado que a barra 1 fornece potência ativa para a barra 2 . Em tal condição, $P_{12}$ é positivo e $P_{21}$, portanto, negativo. Caso o valor de $\mathrm{P}_{12}$ aumente, $\mathrm{P}_{21}$, majoritariamente deve diminuir, ou seja, se um lado aumenta o intercâmbio de potência ativa, o outro necessariamente deve 
receber mais potência, subtraindo as perdas na transmissão. Tal afirmação só não será verdadeira, exclusivamente, no caso em que haja uma falta entre os barramentos 1 e 2 .

Na situação de falta externa a essa linha, a variação será positiva para uma barra, e negativa para a outra, dependendo da configuração do sistema. Essa lógica da variação das potências é apresentada de forma genérica na Tabela 4.4.

Tabela 4.4 - Variação de potência nas barras genéricas 1 e 2.

\begin{tabular}{c|cc}
\hline \hline \multirow{2}{*}{ Falta } & \multicolumn{2}{|c}{ Variação } \\
\cline { 2 - 3 } & $\Delta P_{12}$ & $\Delta P_{21}$ \\
\hline Interna & + & + \\
Externa & $+/-$ & $-/+$ \\
Inexistente (com variação de carga) & & $-/+$ \\
\hline \hline
\end{tabular}

De acordo com a convenção apresentada (Tabela 4.4), o algoritmo analisará as situações enfrentadas, e de acordo com a variação observada enviará o sinal de trip, ou continuará no processo de observação do sistema em análise (situação de inexistência de falta).

A comunicação entre os dois extremos deverá ser simples, ou seja, cada extremo deverá enviar um bit de estado, 0 ou 1, para informar variação negativa e positiva, respectivamente.

A metodologia, conforme apresentada, pode ser explicada pelo fluxograma da Figura 4.6. Já a implementação da metodologia via o RTDS® é representada pela Figura 4.7. 


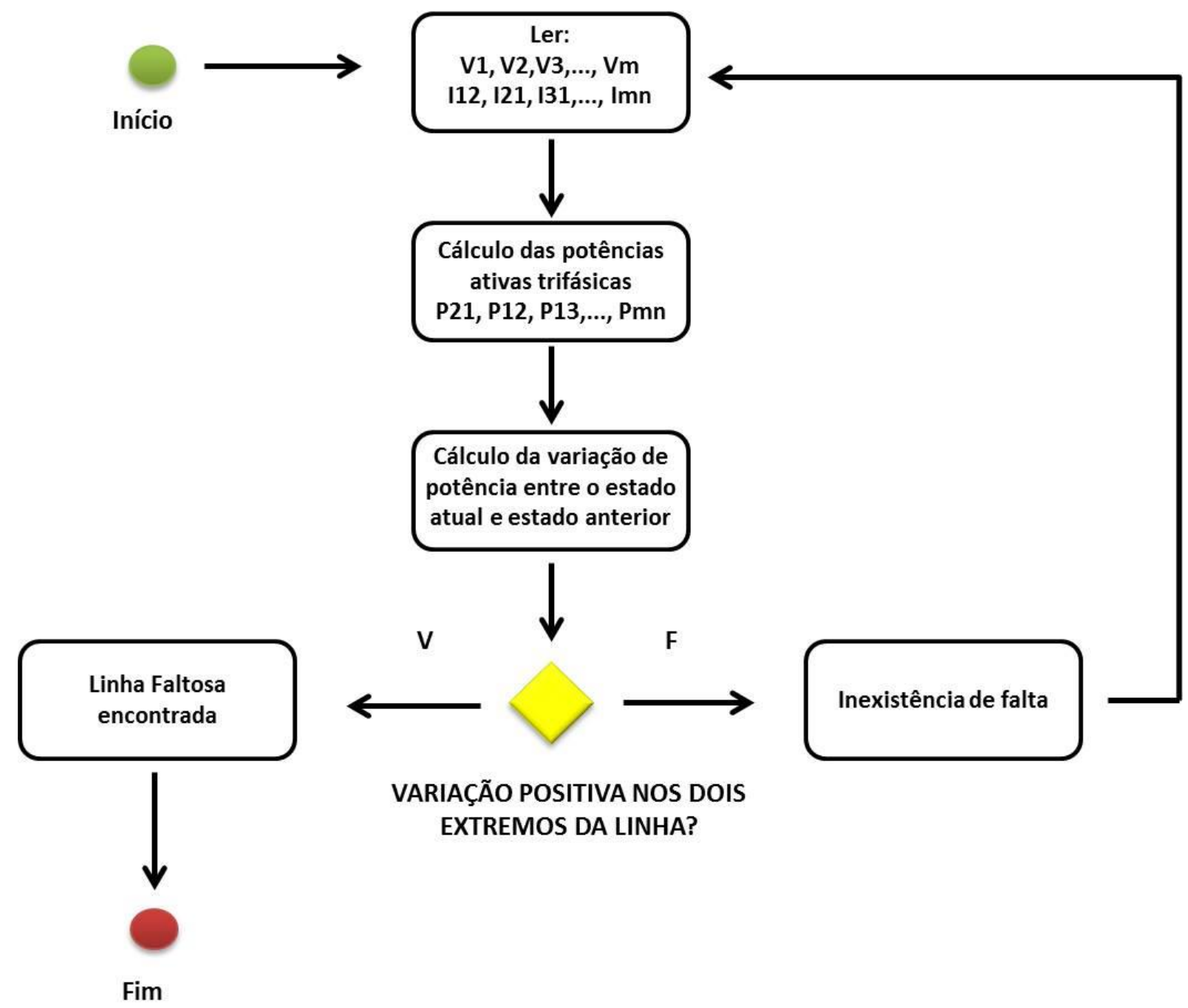

Figura 4.6 - Fluxograma da metodologia desenvolvida para a PDPL.

A implementação do algoritmo no RSCad é feita através do CBuilder, que é um ambiente no qual é possível a implementação de novos componentes a partir do desenvolvimento de um algoritmo na linguagem de programação $C$. $O$ algoritmo tem início no cálculo das potências ativas trifásicas a partir dos fasores de tensão e corrente de fase. $P_{\text {atual }}$ é a medida calculada instantaneamente e $P_{\text {anterior }}$ é a medida calculada 1 segundo antes. As medidas são atualizadas a cada novo fasor recebido. Após este passo, o algoritmo calcula a diferença entre os estados atual e anterior. Se as duas variações forem positivas, haverá o envio de um bit 1 . 


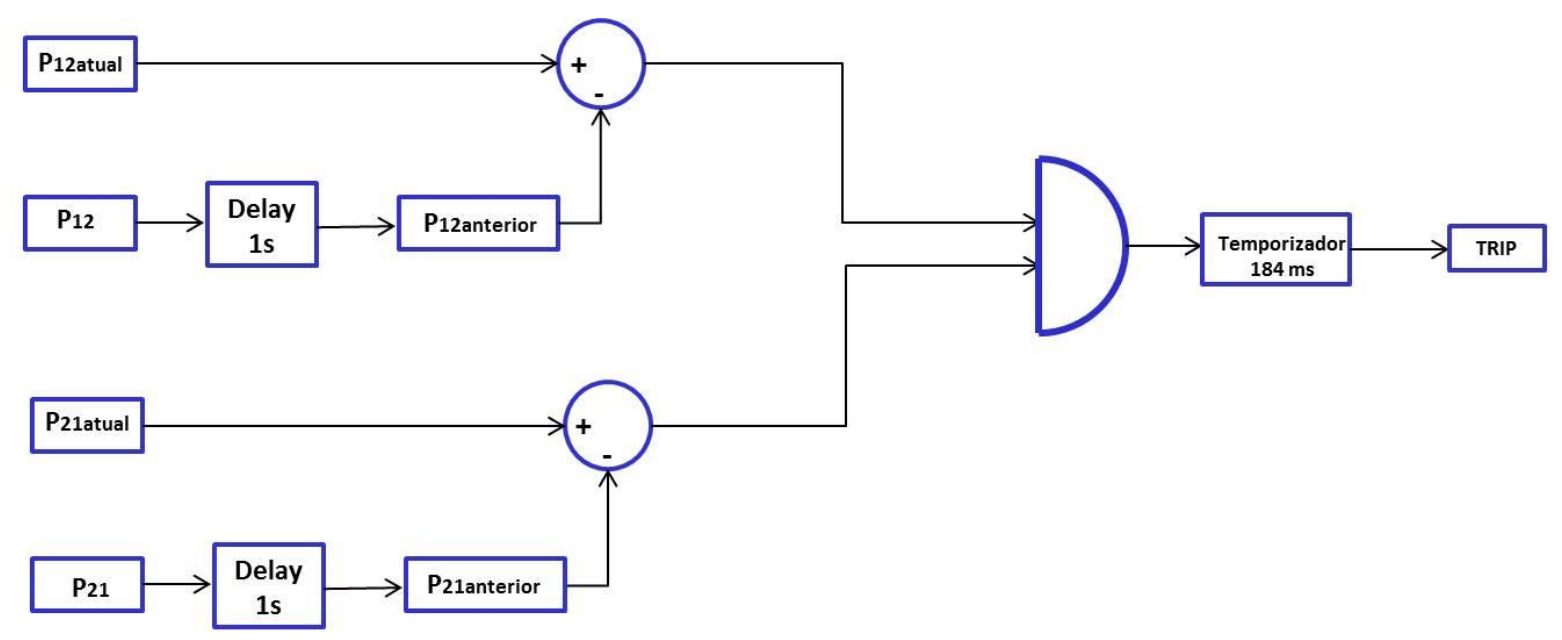

Figura 4.7 - Diagrama de blocos da implementação do algoritmo PDPL.

O tempo estipulado para a atuação da metodologia não foi simulado, mas sim tomado como baseado pelo que é reportado na literatura associada, que indica que o tempo para resposta de um sistema de proteção de retaguarda que utiliza dados provenientes de SMFS é de até 200 ms. Com base neste tempo, o algoritmo conta 3.680 amostras que irão resultar na resposta de um bit igual a 1 . Isto se justifica pelo fato de que o passo de integração do RTDS® é de $50 \mu$ s, e para chegar a 184 ms, são necessárias as 3.680 amostras. Os 184 ms se justificam pelo fato do RTDS® simular a latência da PMU, que pode ser de até 16 ms.

\subsubsection{Proteção Diferencial de Potência}

Esta metodologia é baseada na lei da conservação da energia. Em condições normais, desprezando-se as perdas, a potência fornecida por um lado é recebida pelo outro como mostrado na Figura 4.8 (a). Em condições de falta interna na linha protegida, parte da potência enviada por um extremo da linha não será recebida pelo outro, já que esta potência será desviada para o ponto de falta, como é ilustrado pela Figura 4.8 (b). 


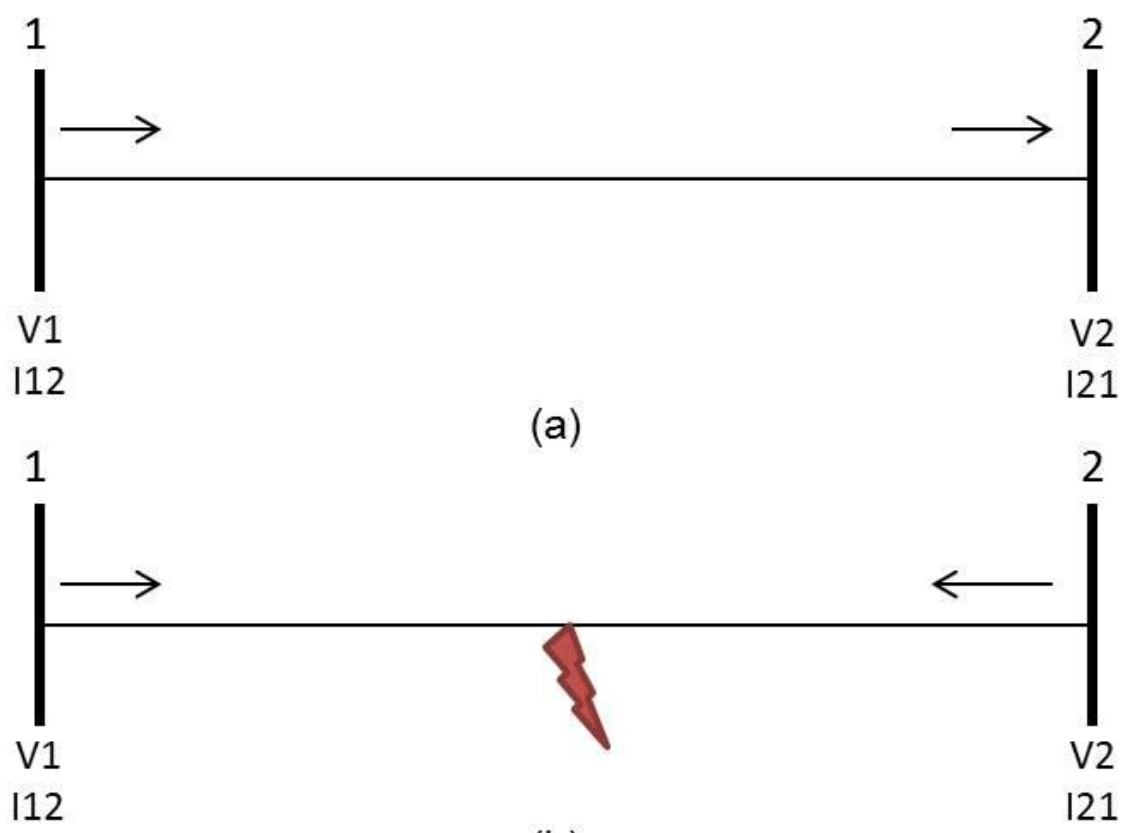

(b)

Figura 4.8 - Representação do comportamento da potência em condições normais (a) e em condições de falta interna (b).

A metodologia consiste no cálculo da potência ativa trifásica nos dois extremos da linha, como já apresentado nas equações 4.1 e 4.2. Após esse cálculo é feita a comparação das potências como mostrado na equação a seguir:

$$
P_{\text {diferencial }}=P_{12}+P_{21}
$$

Considerando que existem perdas de potência na linha, é determinado um limiar de ajuste que será determinado mais a frente. No caso de $P_{\text {diferencial }}$ ser maior que o ajuste (limiar) estabelecido, a proteção atuará. Vale ressaltar, que o sentido considerado como positivo, é o mesmo adotado na metodologia da PDPL. Ao contrário da metodologia apresentada anteriormente, esta exige uma comunicação mais rápida e mais confiável, pois a comunicação entre os dois extremos consiste em valores de potência. A metodologia PDP pode ser representada pela Figura 4.9 e sua implementação ilustrada pela Figura 4.10. 


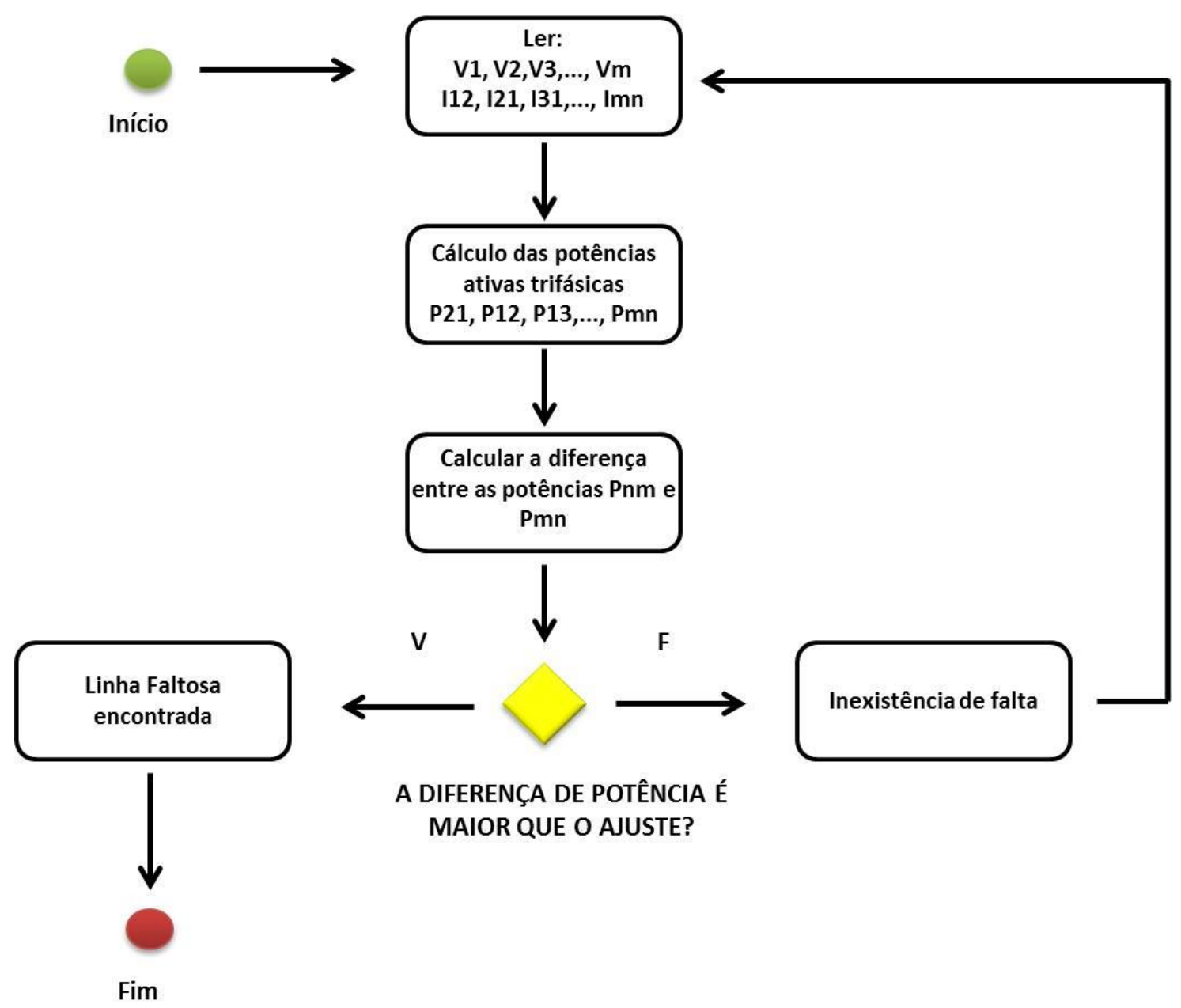

Figura 4.9 - Fluxograma da metodologia desenvolvida para a PDP.



Figura 4.10 - Diagrama de blocos da implementação do algoritmo PDP.

A implementação desta metodologia, bem como a anterior, também é desenvolvida no CBuilder. O algoritmo tem início no cálculo das potências ativas 
trifásicas a partir dos fasores de tensão e corrente fornecidos pelas PMU. O passo seguinte é calcular a $P_{\text {diferencial. }}$ Em seguida, a $P_{\text {diferencial }}$ é comparada com o ajuste: se $P_{\text {diferencial }}$ for maior, o algoritmo conta uma amostra positiva, e então, ele espera por mais 3.679 amostras para emitir o sinal de trip.

\subsection{Exemplificação das Metodologias}

A seguir serão abordadas três situações operacionais "didáticas" sobre uma linha de transmissão, supondo alguns valores de potência nas três situações. Os casos apresentados serão os da Figura 4.11. O caso apresentado pela Figura 4.11 (a) ilustra o sistema em condições normais, sem variação de carga. No caso da Figura 4.11 (b), ilustra-se o momento em que ocorre uma falta. E finalmente, na Figura 4.11 (c), é apresentado o sistema em condições normais novamente, porém, quando da ocorrência de uma variação de carga.

\subsubsection{Proteção Diferencial de Potência Local}

$\mathrm{Na}$ primeira condição de operação apresentada, não ocorre variação de carga e a potência permanece inalterada. Utilizando as equações 4.3 e 4.4, que representam tal metodologia, percebe-se que não haverá as variações necessárias para a atuação da proteção. Os valores apresentados para $P_{12}$ e $P_{21}$ na Figura 4.11

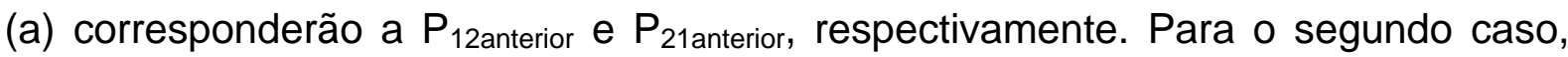
considerando as potências apresentadas neste caso como as potências $P_{12 \text { atual }} \mathrm{e}$

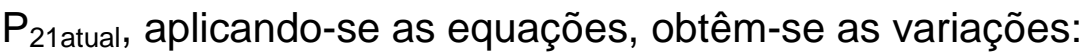

$$
\begin{gathered}
\Delta P_{12}=P_{12 \text { atual }}-P_{12 \text { anterior }}=271,357-230,671=40,686 \mathrm{MW} \\
\Delta P_{21}=P_{21 \text { atual }}-P_{21 \text { anterior }}=-189,595-(-224,469)=34,874 \mathrm{MW}
\end{gathered}
$$


Com esse resultado, a metodologia aponta que houve uma falta interna, visto que a variação da potência nos dois extremos foi positiva.

No terceiro e último caso, apresentado pela Figura 4.8 (c), aplicando novamente as equações 4.3 e 4.4, obtêm-se:

$$
\begin{gathered}
\Delta P_{12}=P_{12 \text { atual }}-P_{12 \text { anterior }}=240,6-230,671=10,071 \mathrm{MW} \\
\Delta P_{21}=P_{21 \text { atual }}-P_{21 \text { anterior }}=-234,4-(-224,469)=-9,931 \mathrm{MW}
\end{gathered}
$$

\subsubsection{Proteção Diferencial de Potência}

Para esses casos adotados, considera-se que a diferença de potência encontrado no caso da Figura 4.8 (a) é o valor de ajuste para estes casos, pois o mesmo representa o valor das perdas na linha, que corresponde a:

$$
P_{\text {diferencial }}=230,671+(-224,469)=6,202 M W
$$

Portanto, a proteção só irá atuar quando a diferença de potência for maior que este valor. No segundo caso, por exemplo, a proteção atua, pois a diferença de potência entre os dois extremos será muito maior que o ajuste estabelecido, como calculado abaixo:

$$
P_{\text {diferencial }}=271,357+(-189,595)=81,762 \mathrm{MW}
$$

Já no terceiro caso, a proteção não atuará, pois a variação de carga ocorre de forma uniforme: se $P_{12}$ aumenta, $P_{21}$ receberá esse aumento na mesma proporção, como comprova o equacionamento que segue:

$$
P_{\text {diferencial }}=240,6+(-234,4)=6,2 \mathrm{MW}
$$




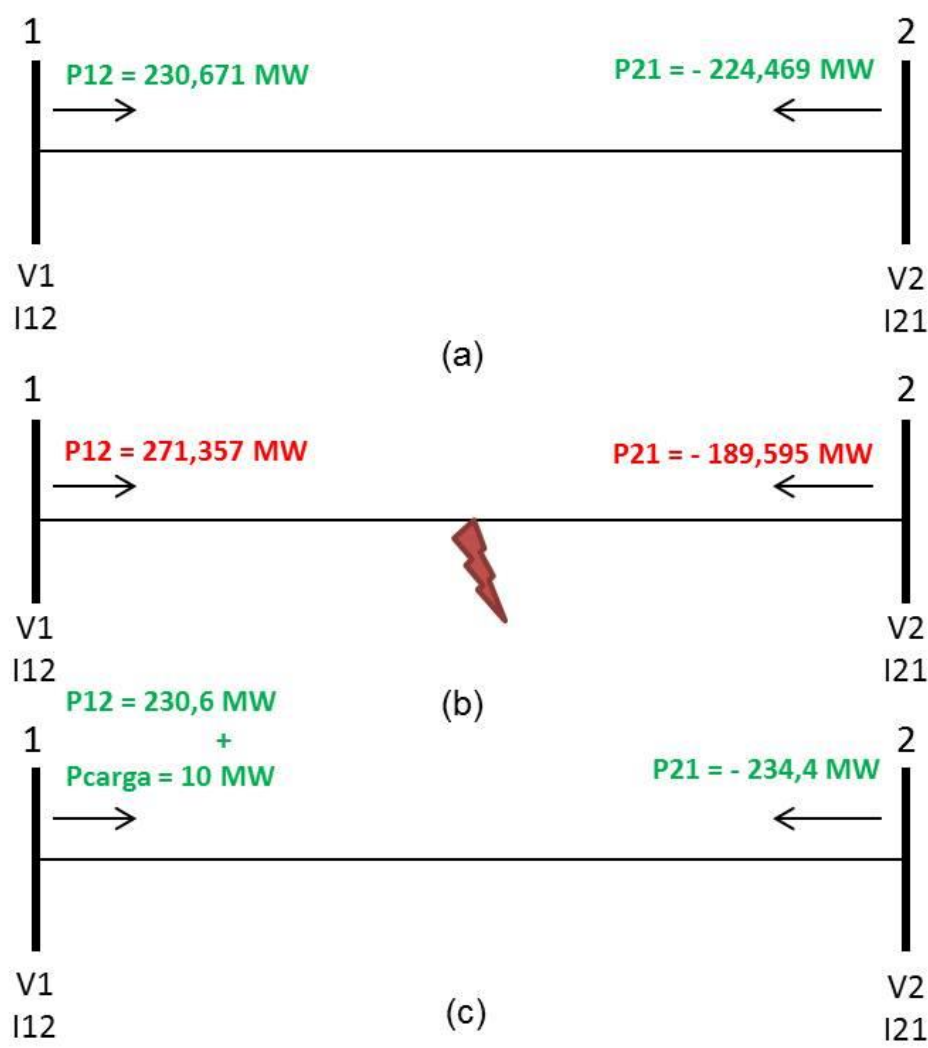

Figura 4.11 - Exemplificação do sistema em três condições: Condições normais de operação sem variação de carga (a); Condições de falta (b); Condições normais de operação sem variação de carga(c).

\subsection{Limiares de Atuação para as Proteções}

Para as simulações, os ajustes de atuação das proteções foram estabelecidos para que as proteções detectassem a falta acima de um valor estipulado. Para a PDPL, foi estabelecido que a mesma deverá atuar apenas se a diferença entre $\mathrm{P}_{\text {atual }}$ e $\mathrm{P}_{\text {anterior }}$ for superior a $5 \mathrm{MW}$. Para a PDP, a metodologia apenas indicará a presença de uma falta se a diferença entre as potências dos

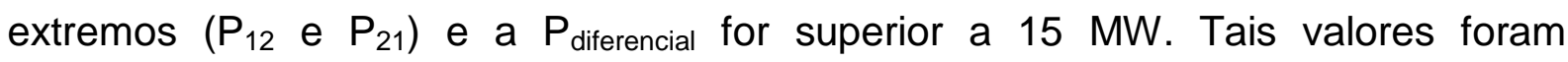
estipulados a partir da observação dos valores assumidos pelas potências em todas as linhas do sistema, através de simulações, para que a metodologia não atuasse de forma indevida. Para tal, foram realizadas várias simulações de faltas trifásicas e 
monofásicas, com o menor e o maior valor de resistência de falta utilizados nas simulações, de $0,001 \Omega$ e $400 \Omega$, respectivamente. Estas faltas foram simuladas em dois locais: no barramento e no meio da linha. Estes parâmetros foram utilizados, pois se considera que as combinações deles podem gerar as situações de menor e de maior severidade a serem detectadas pela metodologia. Para a utilização destas metodologias em outros sistemas, será necessário realizar novas simulações para estabelecer estes limiares.

Quanto ao tempo de atuação, o mesmo foi ajustado para alcançar valores esperados e encontrados em metodologias correlatas (LIRA et al., 2011). Espera-se que o SMFS tenha uma resposta, para sistemas de proteção, de até 200 ms. Como o RSCad simula a demora da resposta da PMU (aproximadamente $16 \mathrm{~ms}$ ), no processo dos algoritmos, como já comentado, foi implementada uma contagem de amostras com característica de falta para que se atingisse os $200 \mathrm{~ms}$. 


\section{Resultados}

\subsection{As Situações de Curtos-Circuitos Consideradas}

Como verdade, tem-se que a situação de curto-circuito causa uma brusca variação nos valores de tensão e corrente. Estas ocorrências podem mudar significativamente as condições de operação do sistema, e, na maioria dos casos, levando-o ao desequilíbrio. Como fato, tem-se que as linhas de transmissão são os componentes do SEP que mais estão susceptíveis à ocorrência de curtos-circuitos, podendo gerar muitos danos ao sistema. Neste cenário, sabe-se que uma atuação rápida do sistema de proteção pode evitar além de blecautes e danos físicos à rede, o gasto com reparos por parte da concessionária, tanto no sistema, quanto aos consumidores.

Para a validação das metodologias nesta pesquisa, as simulações contemplaram todos os tipos possíveis de curtos-circuitos: fase-terra, bifásico-terra, bifásico e trifásico. Conforme ilustra a Tabela 5.1, as faltas foram simuladas em três linhas do SEP teste apresentado na Figura 4.8. As situações foram simuladas em oito pontos ao longo das linhas, sendo a localização da porcentagem considerada definida em relação ao tamanho da linha. A referência para a distância considerada é a distância em relação à barra numerada com o menor valor, como, por exemplo, 25\% da linha 2-5, correspondente a $75 \mathrm{~km}$ de distância da barra 2 .

A ocorrência de resistências de falta muito altas é considerada não muito comum no SEP. Porém, as mesmas podem ocorrer, e alguns sistemas de proteção 
podem não estar preparados para atuar frente às mesmas. Como o foco principal do trabalho é validar as metodologias frentes a estas condições, julgou-se necessária uma grande variação de valores de resistência de falta. Para tanto, foram considerados dez valores de resistência de falta $(0,001 ; 5 ; 25 ; 50 ; 75 ; 100 ; 150 ; 200$; 300 e $400 \Omega$ ), considerando-se tanto valores representativos de baixa, como de alta impedância.

Outro parâmetro alterado nas simulações foi o ângulo de incidência da falta. A falta, na prática, pode ter início em qualquer ponto (posição) da forma de onda da tensão. Porém, se houver a intenção de considerar tanto o pior como o caso mais brando, deve-se considerar a falta acontecendo quando a tensão está em seu valor máximo e no seu de mínimo, respectivamente. Dessa forma, foram considerados e incorporados às simulações os ângulos de $0^{\circ}$ e $90^{\circ}$.

Pela composição das variáveis envolvidas (10 tipos de faltas, 8 localizações, 10 valores de resistência, e 2 ângulos de incidência da falta), o conjunto total de casos simulados totalizou 4.800 casos, ou seja, 1.600 casos sobre cada uma das três linhas de transmissão consideradas, conforme apresentado na Tabela 5.1.

Devido ao grande número de casos simulados, utilizou-se um recurso disponível no $R T D S \Theta$, onde se permite o uso de um script, que corresponde a um algoritmo, que realiza as simulações de forma automática. As faltas foram realizadas nas linhas 3, 5 e 6, que estão localizadas entre os barramentos 2-5, 5-4 e 4-6, respectivamente. Todas elas possuem o mesmo comprimento, $300 \mathrm{~km}$, e a mesma tensão, 230 kV. A diferença entre elas são as características de carga, e a distância do centro de geração, fazendo com que cada simulação caracterize uma situação distinta observada sobre o SEP em análise. 
Tabela 5.1 - Banco de dados formado via as simulações dispondo do RTDS.

\begin{tabular}{|c|c|c|c|c|}
\hline $\begin{array}{l}\text { Tipo de } \\
\text { falta }\end{array}$ & Localização (\%) & $\operatorname{Rf}(\Omega)$ & $\begin{array}{c}\text { Ângulo de } \\
\text { incidência } \\
(\Theta)\end{array}$ & Total \\
\hline$A-T$ & $\begin{array}{l}0 ; 5 ; 10 ; 25 ; 50 \\
\quad 75 ; 90 \text { e } 95\end{array}$ & $\begin{array}{c}0,001 ; 5 ; 25 ; 50 ; 75 ; 100 \\
150 ; 200 ; 300 \text { e } 400\end{array}$ & $0^{\circ}$ e $90^{\circ}$ & 480 \\
\hline$B-T$ & $\begin{array}{l}0 ; 5 ; 10 ; 25 ; 50 \\
75 ; 90 \text { e } 95\end{array}$ & $\begin{array}{l}0,001 ; 5 ; 25 ; 50 ; 75 ; 100 \\
\quad 150 ; 200 ; 300 \text { e } 400\end{array}$ & $0^{\circ}$ e $90^{\circ}$ & 480 \\
\hline$C-T$ & $\begin{array}{l}0 ; 5 ; 10 ; 25 ; 50 \\
75 ; 90 \text { e } 95\end{array}$ & $\begin{array}{l}0,001 ; 5 ; 25 ; 50 ; 75 ; 100 \\
\quad 150 ; 200 ; 300 \text { e } 400\end{array}$ & $0^{\circ}$ e $90^{\circ}$ & 480 \\
\hline$A B-T$ & $\begin{array}{l}0 ; 5 ; 10 ; 25 ; 50 \\
\quad 75 ; 90 \text { e } 95\end{array}$ & $\begin{array}{c}0,001 ; 5 ; 25 ; 50 ; 75 ; 100 \\
150 ; 200 ; 300 ; 400\end{array}$ & $0^{\circ}$ e $90^{\circ} \circ$ & 480 \\
\hline$B C-T$ & $\begin{array}{l}0 ; 5 ; 10 ; 25 ; 50 \\
\quad 75 ; 90 \text { e } 95\end{array}$ & $\begin{array}{l}0,001 ; 5 ; 25 ; 50 ; 75 ; 100 \\
\quad 150 ; 200 ; 300 \text { e } 400\end{array}$ & $0^{\circ}$ e $90^{\circ}$ & 480 \\
\hline$A C-T$ & $\begin{array}{l}0 ; 5 ; 10 ; 25 ; 50 \\
75 ; 90 \text { e } 95\end{array}$ & $\begin{array}{l}0,001 ; 5 ; 25 ; 50 ; 75 ; 100 \\
\quad 150 ; 200 ; 300 \text { e } 400\end{array}$ & $0^{\circ}$ e $90^{\circ}$ & 480 \\
\hline$A B$ & $\begin{array}{l}0 ; 5 ; 10 ; 25 ; 50 \\
75 ; 90 \text { e } 95\end{array}$ & $\begin{array}{l}0,001 ; 5 ; 25 ; 50 ; 75 ; 100 \\
150 ; 200 ; 300 \text { e } 400\end{array}$ & $0^{\circ}$ e $90^{\circ}$ & 480 \\
\hline$B C$ & $\begin{array}{l}0 ; 5 ; 10 ; 25 ; 50 \\
\quad 75 ; 90 \text { e } 95\end{array}$ & $\begin{array}{l}0,001 ; 5 ; 25 ; 50 ; 75 ; 100 \\
\quad 150 ; 200 ; 300 \text { e } 400\end{array}$ & $0^{\circ}$ e $90^{\circ}$ & 480 \\
\hline$C A$ & $\begin{array}{l}0 ; 5 ; 10 ; 25 ; 50 \\
75 ; 90 \text { e } 95\end{array}$ & $\begin{array}{l}0,001 ; 5 ; 25 ; 50 ; 75 ; 100 \\
150 ; 200 ; 300 \text { e } 400\end{array}$ & $0^{\circ}$ e $90^{\circ}$ & 480 \\
\hline$A B C$ & $\begin{array}{l}0 ; 5 ; 10 ; 25 ; 50 \\
\quad 75 ; 90 \text { e } 95\end{array}$ & $\begin{array}{c}0,001 ; 5 ; 25 ; 50 ; 75 ; 100 \\
150 ; 200 ; 300 \text { e } 400\end{array}$ & $0^{\circ}$ e $90^{\circ}$ & 480 \\
\hline \multicolumn{4}{|c|}{ Total de faltas simuladas nas três linhas } & 4800 \\
\hline
\end{tabular}




\subsection{Apresentação dos Casos Analisados}

Como mostra a Tabela 5.1, o volume de simulações realizadas foi satisfatoriamente grande. Por este motivo, serão apresentados, primeiramente, alguns casos em específico e, posteriormente, um levantamento estatístico da atuação da proteção sobre o banco total de dados formulado.

\subsubsection{Linha em Condições Normais de Operação}

O primeiro caso a ser demonstrado, ilustra o comportamento das linhas monitoradas do sistema, na intenção de observar o valor da potência em condições normais de operação. Tais situações serão utilizadas para observar a mudança de estado tanto na PDPL, como para os ajustes da PDP. Como exemplo, a linha 3 será utilizada para ilustrar as respostas frente às duas metodologias.

Para este caso, $\mathrm{O}$ valor da potência ativa trifásica antes da falta foi de $\mathrm{P}_{25}=$ 230,5 MW, com $P_{52}=-224,5 \mathrm{MW}$, como mostram as Figuras 5.1 e 5.2. Dessa forma, esses dois valores serão os valores que irão corresponder à variável $P_{\text {anterior }}$ das Equações 4.3 e 4.4, da PDPL.

No caso do algoritmo, da PDP, faz-se necessário o cálculo da diferença entre as potências, conforme a Equação 4.5. Neste cálculo é encontrado que $P_{\text {diferencial }}$ é igual a 6,1 MW para a LT3, que é um valor menor que o ajuste estabelecido anteriormente. 


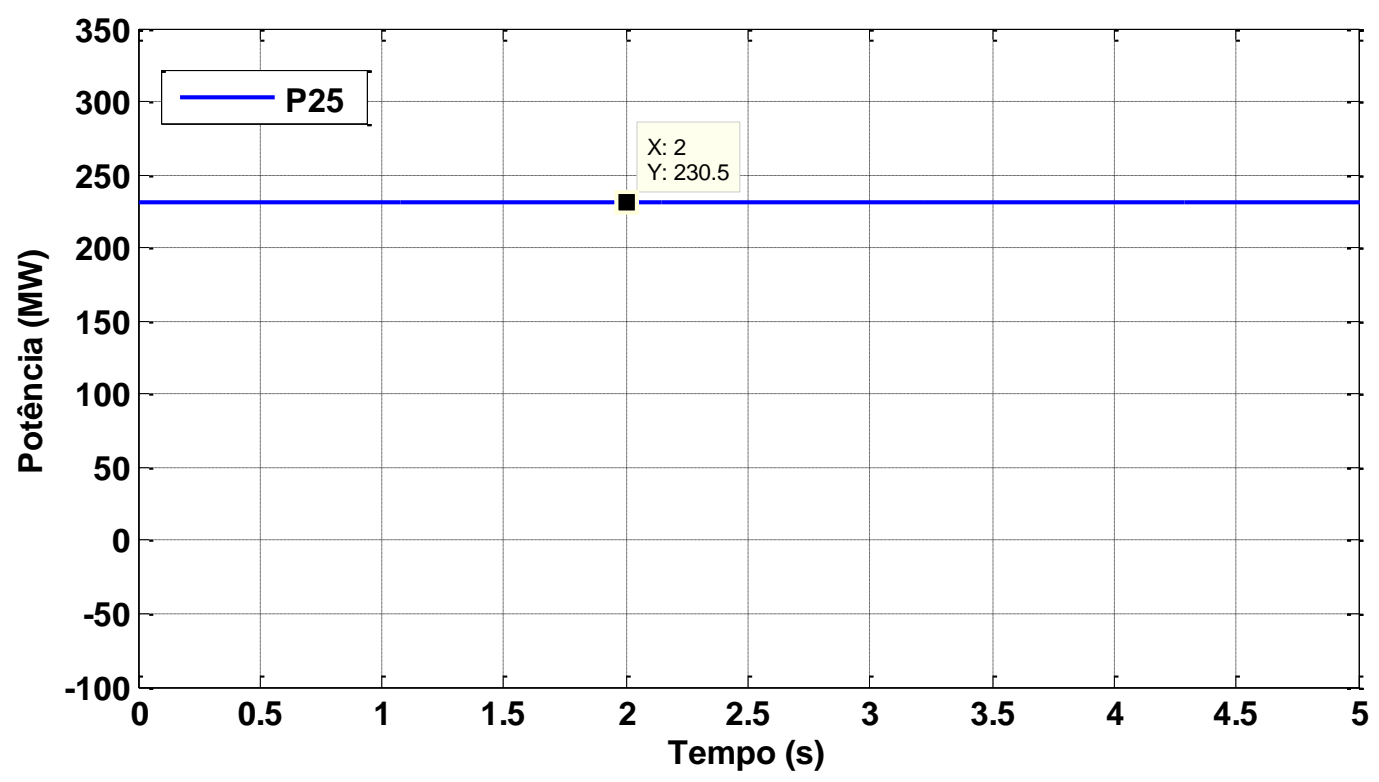

Figura 5.1 - Potência ativa trifásica $P_{25}$ para o sistema em condições normais (LT3).

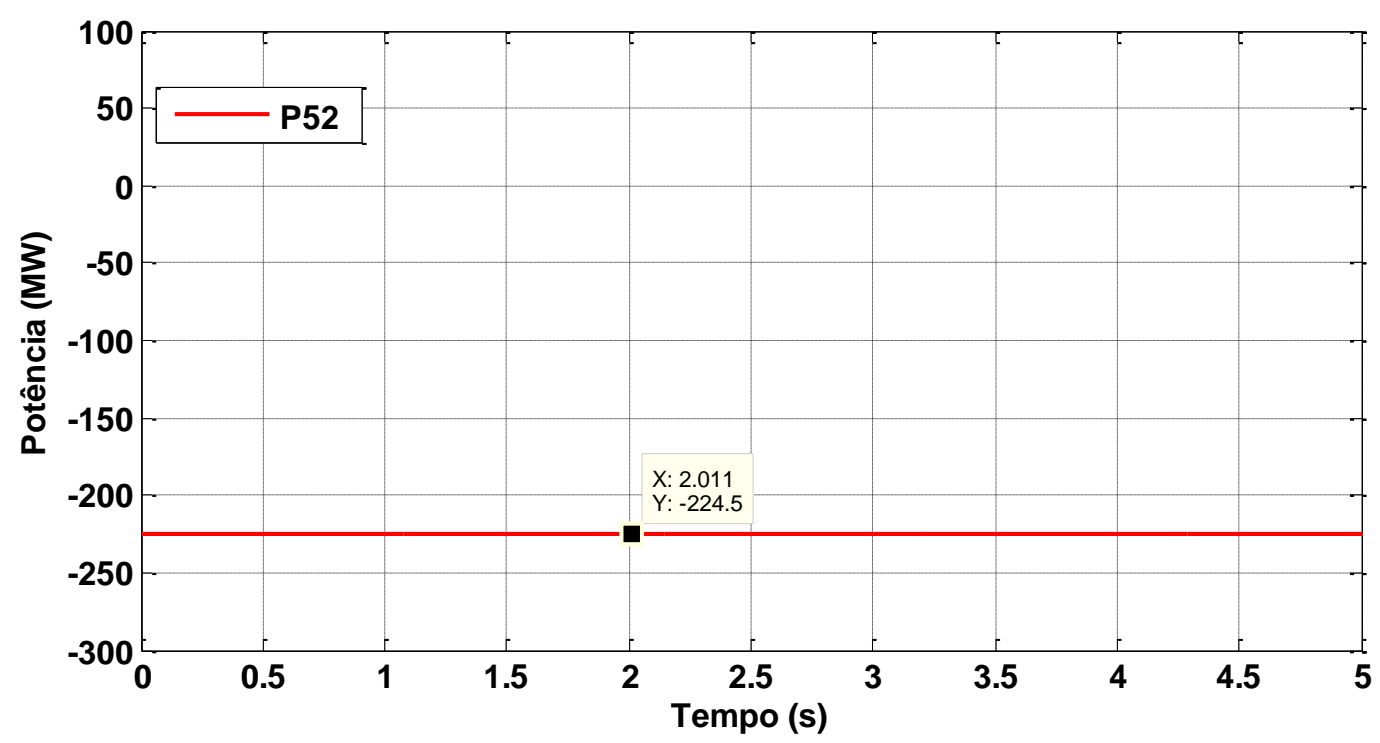

Figura 5.2 - Potência ativa trifásica $P_{52}$ para o sistema em condições normais (LT3).

\subsubsection{Análise de Um Caso em Específico de Alta Impedância}

De acordo com a metodologia apresentada para a PDPL, espera-se que na presença de uma falta haja uma variação positiva para as duas barras. Para a 
metodologia da PDP, foi estabelecido que em presença de falta, a proteção detectaria uma diferença de potência entre os dois extremos.

Para verificar estas condições, foi simulada uma falta monofásica $A-T$ na LT3, a $225 \mathrm{~km}$ da barra 2, com resistência de falta $\left(\mathrm{R}_{\mathrm{f}}\right)$ igual a 400 ohms e ângulo de incidência de $0^{\circ}$.

Através dos dados fornecidos pelo $R T D S \AA$, o algoritmo foi alimentado com os dados de tensão e corrente provenientes das medições nas barras 2 e 5, bem como das demais barras monitoradas, onde estariam alocadas as PMU. A Figura 5.3, representa a potência $P_{25}$, que é a potência da barra 2 para a barra 5 para esta situação. Já a Figura 5.4, representa a potência $P_{52}$, que é a potência da barra 5 para a barra 2 .

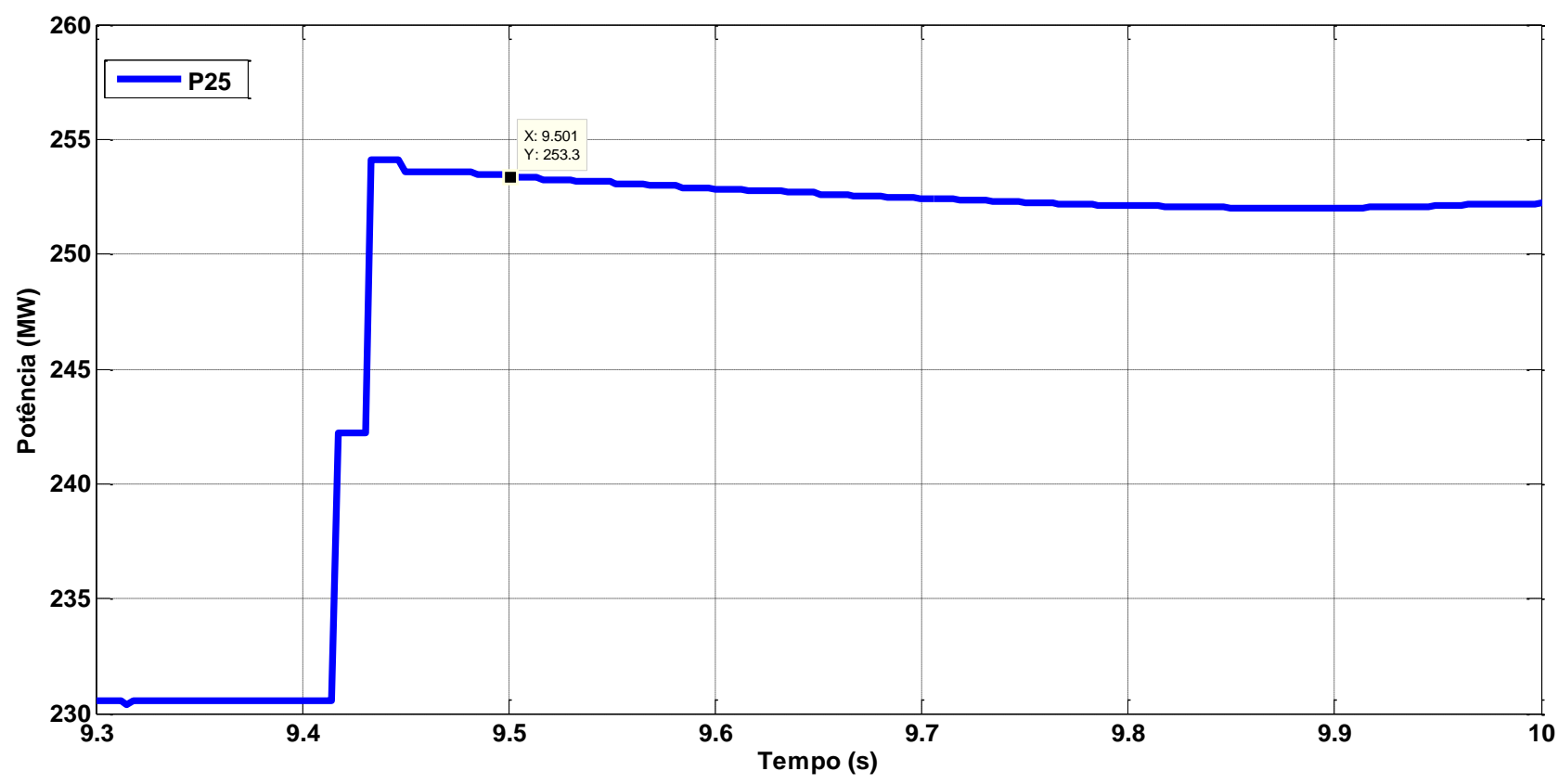

Figura 5.3 - Potência ativa trifásica $P_{25}$ para uma falta na $L T 3$.

Quando a falta ocorre, são observados $P_{25}=253,3 \mathrm{MW}$ e $P_{52}=-206 \mathrm{MW}$, com uma variação de $\Delta \mathrm{P}_{25}=22,7 \mathrm{MW}$ e $\Delta \mathrm{P}_{52}=18,4 \mathrm{MW}$. Desta forma, a metodologia da PDPL aponta a situação de falta, pois, como esperado, a variação 
da potência ativa trifásica apresentou variação positiva nos dois extremos da linha para a falta interna caracterizada.

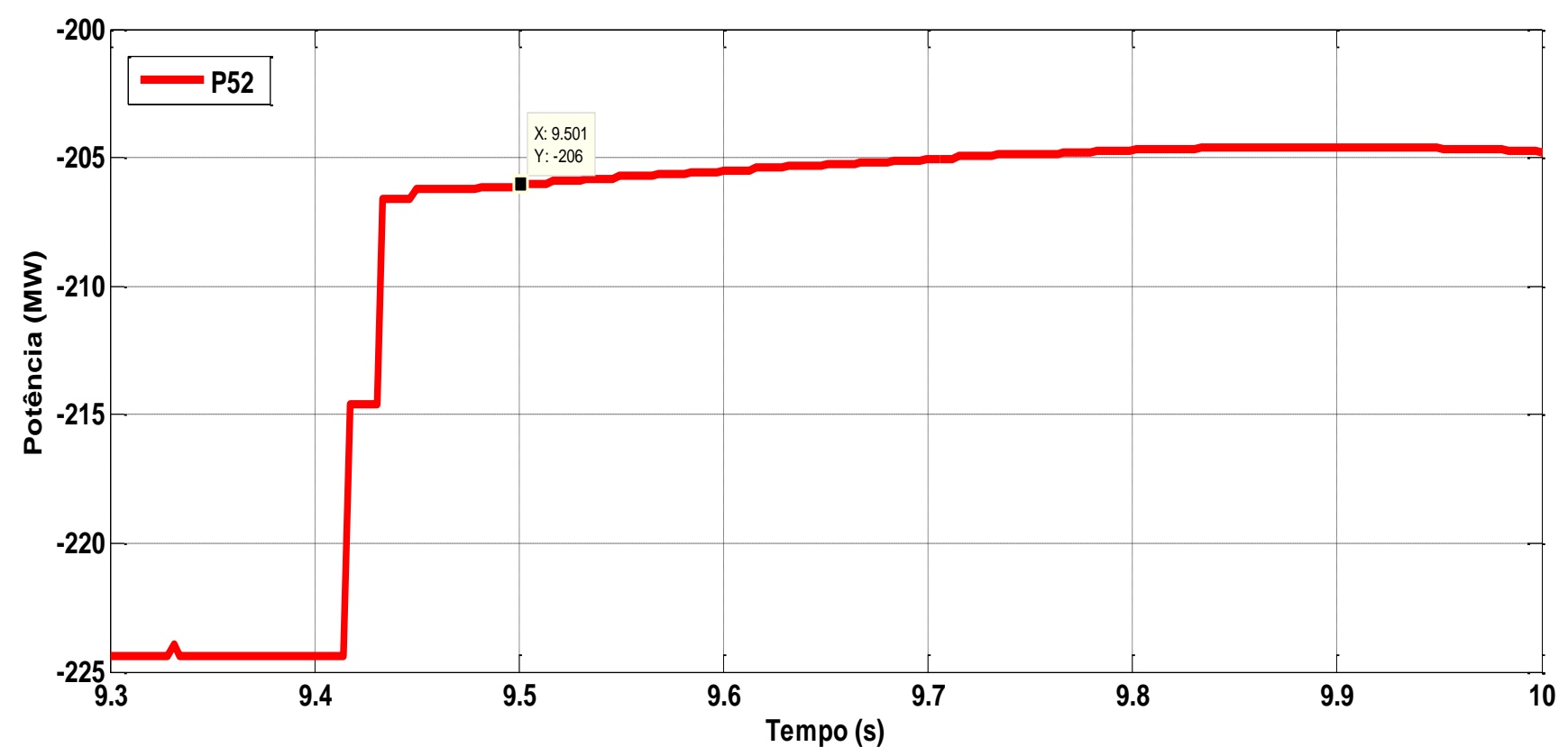

Figura 5.4 - Potência ativa trifásica $P_{52}$ para uma falta na $L T 3$.

Para a metodologia da PDP, a falta também é encontrada com sucesso, pois a diferença de potência entre os dois extremos ( $\left.P_{\text {diferencial }}\right)$ será de 47,3 MW. Valor este bem superior ao ajuste estabelecido.

Utilizando este mesmo caso de falta, porém observando a potência ativa trifásica da LT6, é possível fazer uma análise para o caso de falta externa. As Figuras 5.5 e 5.6 representam o comportamento da potência que vai do barramento 4 para o 6 e do 6 para o 4, respectivamente. A potência $P_{46}$ em condições normais possui o valor de 19,47 MW, enquanto que a $\mathrm{P}_{64}$ tem o valor de -19,2 MW. Quando a falta ocorre na LT3, a $\mathrm{P}_{46}$ assume o valor de 15,52 MW e a $\mathrm{P}_{64}$ o valor de $-15,28$ MW. 


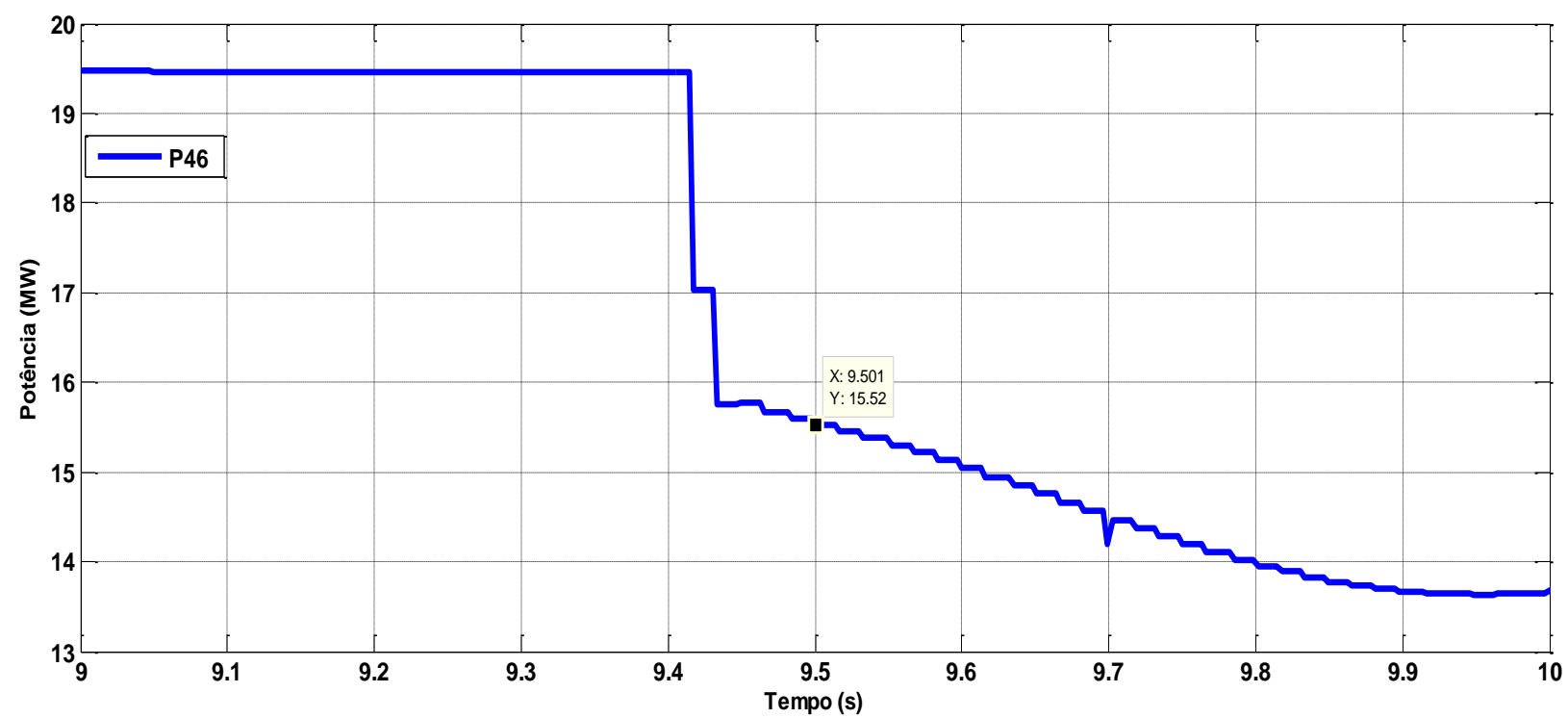

Figura 5.5 - Potência ativa trifásica $P_{46}$ para uma falta na $L T 3$.



Figura 5.6 - Potência ativa trifásica $P_{64}$ para uma falta na $L T 3$.

Fazendo a análise para a PDPL, a $\Delta \mathrm{P}_{46}$ é igual $-3,95 \mathrm{MW}$ e a $\Delta \mathrm{P}_{64}$ é igual a 3,92 MW. Como houve variação positiva para um extremo da linha, e negativa para o outro extremo, o algoritmo não atuará incorretamente, e apontará que a falta não foi na linha em análise. 
Para a PDP, a proteção também não atuará de forma incorreta, pois a $P_{\text {diferencial }}$ terá o valor de 0,24 MW.

\subsubsection{Condições Normais com Variação de Carga}

Para a simulação de um sistema em condições normais de operação com variação de carga, foi chaveada uma carga com potência ativa igual a $100 \mathrm{MW}$ no barramento 4, para que se pudesse observar como 0 algoritmo das duas metodologias responderia a esta situação.

As Figuras 5.7 e 5.8 apresentam os valores de potência para a linha em condições normais, sem variação de carga. $O$ valor da potência da barra 5 para a barra 4 é de 192,2 MW, e da barra 4 para a barra 5 é de -188,1 MW.

Quando a carga de $100 \mathrm{MW}$ é chaveada, o valor da potência da barra 5 para a 4 aumenta para $222,5 \mathrm{MW}$, e da barra 4 para a barra 5 diminui para $-216,9 \mathrm{MW}$, conforme mostram as Figuras 5.9 e 5.10.

Mediante a este caso, o algoritmo da PDPL verifica que houve uma variação positiva para $P_{54}$, e negativa para $P_{45}$, facilmente denotada pelos gráficos da Figura 5.9 e da Figura 5.10, respectivamente, indicando que a linha opera sem falta.

Afirma-se que o mesmo procedimento de análise foi aplicado para todas as demais linhas do sistema, observando-se sempre o mesmo tipo de resposta. Ou seja, para esta mesma característica de variação de potência ativa trifásica, o algoritmo aponta a inexistência de falta para o sistema.

Para o algoritmo da metodologia da PDP, calculando-se a diferença de potência antes da carga ser chaveada e depois, o valor da diferença será aproximadamente o mesmo, sendo este de 4,1 MW em condições normais, e 5,6 MW para a condição normal com variação de carga. 


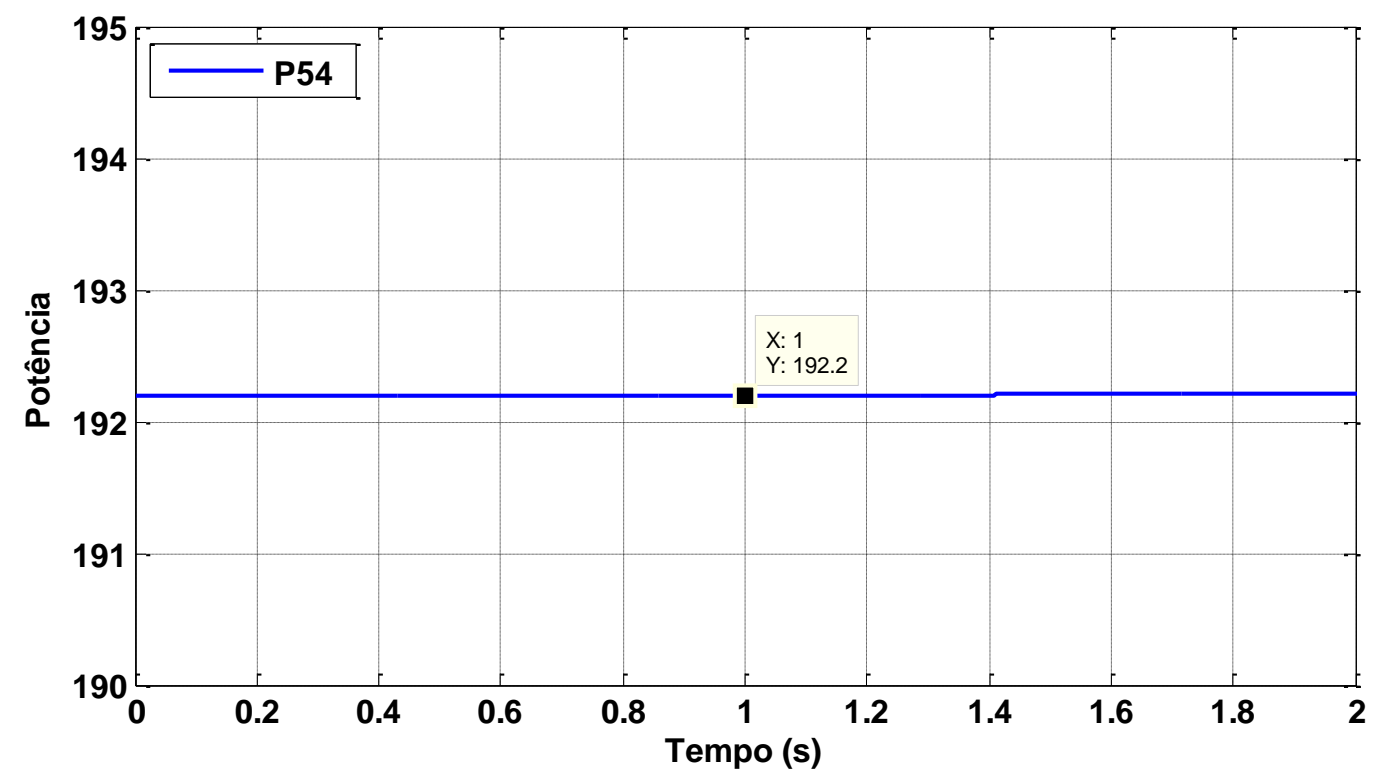

Figura 5.7 - Potência ativa trifásica $P_{54}$ para o sistema em condições normais (LT5).

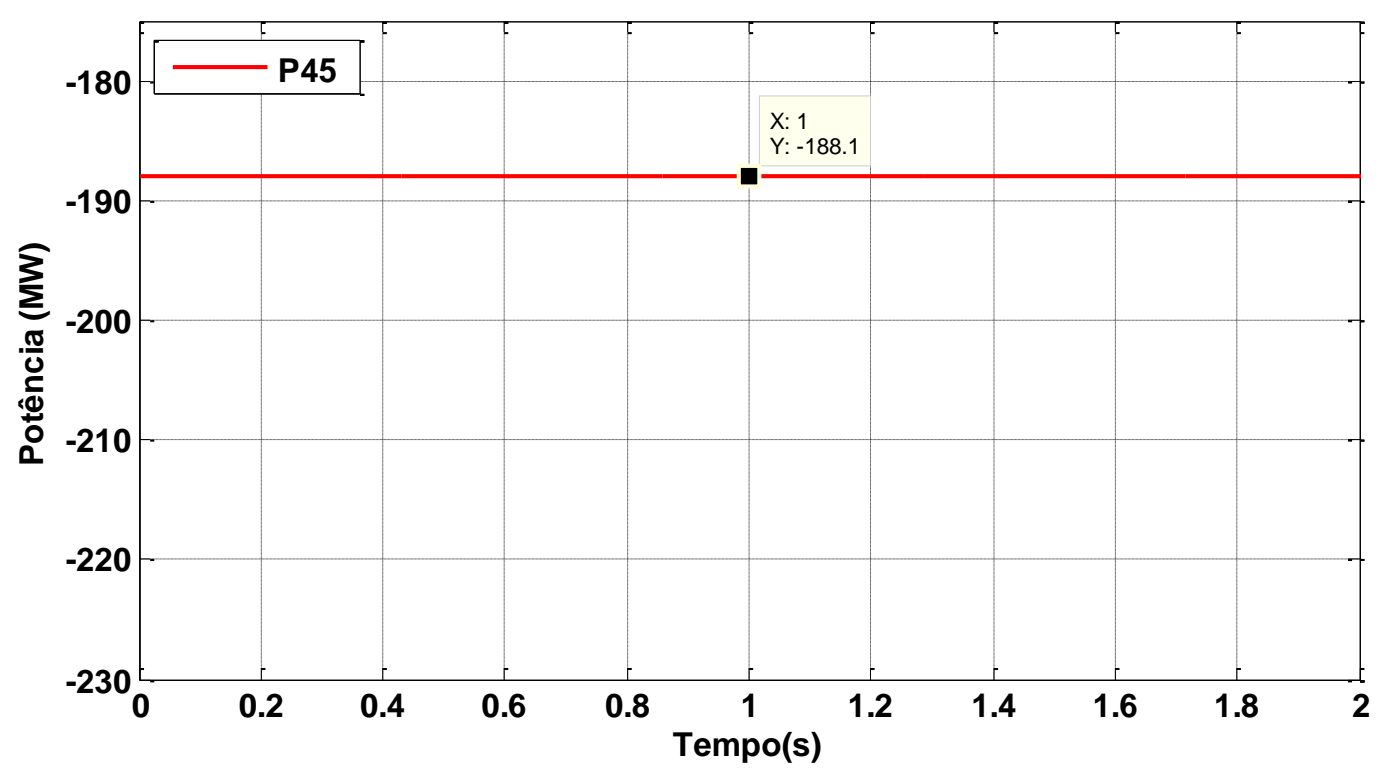

Figura 5.8 - Potência ativa trifásica $P_{45}$ para o sistema em condições normais (LT5). 




Figura .5.9 - Potência ativa trifásica $P_{54}$ para o sistema em condições normais com variação de carga (LT5).

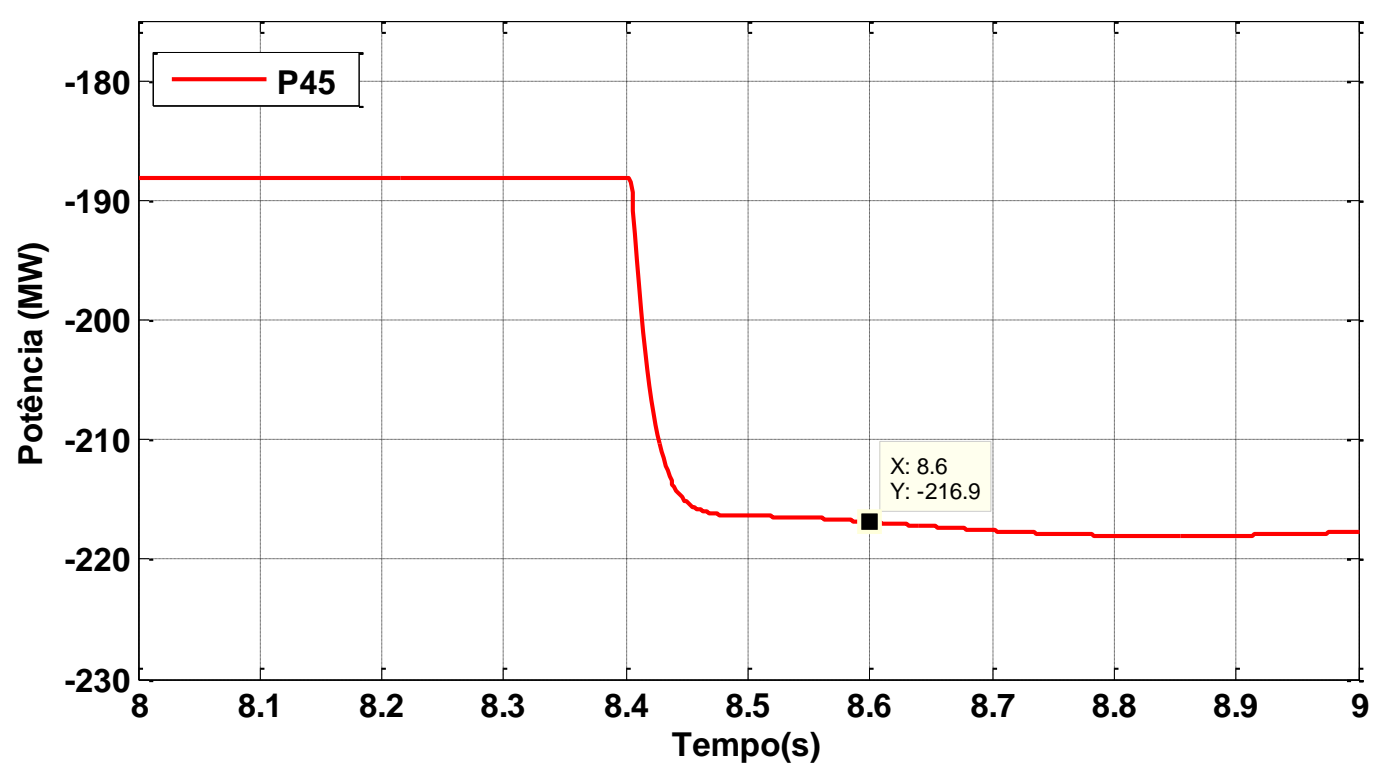

Figura 5.10 - Potência ativa trifásica $P_{45}$ para o sistema em condições normais com variação de carga (LT5).

Por este resultado, verifica-se que as filosofias apresentadas não irão atuar de forma incorreta para uma variação de carga, uma vez que as lógicas desenvolvidas permitem que sejam distinguidas faltas internas das externas, e que 
as mesmas verificam e consideram as condições normais de operação do sistema, aumentando a confiabilidade da metodologia aplicada.

Porém, como será mostrado na próxima seção, o algoritmo ainda não pode ser considerado $100 \%$ correto, necessitando de alguns ajustes.

\subsection{Análise Estatística}

Para realizar uma análise mais detalhada do desempenho das duas metodologias, faz-se necessária uma breve análise estatística, já que existe um grande volume de simulações realizadas. Para um sistema de proteção, além de a proteção atuar de forma confiável, outro parâmetro de extrema importância é a velocidade de atuação. Para tanto, serão analisados os desempenhos da proteção para o tipo de falta, para a localização, para o ângulo de inserção da falta e para a resistência de falta frente à velocidade de atuação das duas metodologias abordadas.

\subsubsection{Desempenho da Proteção Diferencial de Potência Local}

Uma possível análise a ser feita é apresentada pelos gráficos das Figuras 5.11 e 5.12. Os gráficos representam o desempenho da metodologia da PDPL, frente às faltas $A C$, com ângulo de inserção da falta de $0^{\circ}$, na linha 3.

Percebe-se que para resistências muito baixas $(0,001$ ohms - representada em azul, e 5 ohms - representada em verde) a proteção não atuou (Figura 5.11). Já para as simulações considerando a faixa de 100 ohms a 400 ohms (Figura 5.12), a proteção atuou corretamente para todos os pontos da linha. Através das figuras também é possível observar que a proteção de retaguarda atuou dentro do tempo esperado de 200 ms para a maior parte dos casos. 
Para ilustrar o desempenho como um todo em relação à resistência de falta, a Tabela 5.2 mostra o tempo médio de atuação e o percentual de acerto para a PDPL, utilizando um total de 480 faltas para cada resistência de falta. A tabela ressalta o desempenho apresentado pelas Figuras 5.11 e 5.12, mostrando que a metodologia apresenta certa sensibilidade quanto às baixas resistências de faltas, porém ela não atua em $100 \%$ dos casos. Por outro lado, por esta mesma tabela, verifica-se que a metodologia apresentou resultado satisfatório para altas resistências de falta, com tempos médios aceitáveis para a detecção da falta, que é alvo deste estudo.



Figura 5.11 - Desempenho da metodologia da PDPL frente a baixos valores de resistência de falta.

A sensibilidade do algoritmo quanto às faltas de baixa impedância se justifica pelo fato de que, no momento da falta, a corrente é muito alta, porém a tensão chega próxima de zero. Com isso, a potência vai à zero, o que dificulta a detecção da falta. 


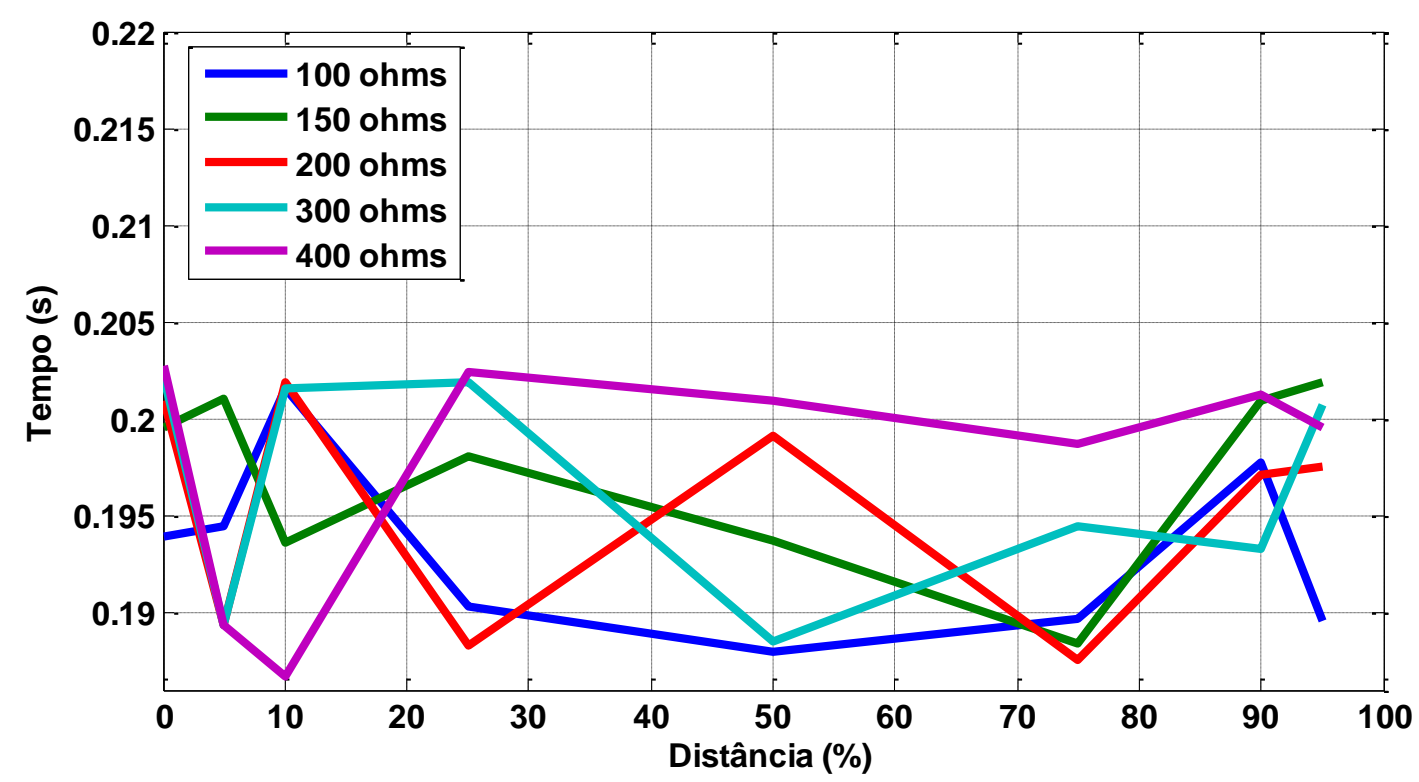

Figura 5.12 - Desempenho da metodologia da PDPL frente a valores altos de resistência de falta.

Tabela 5.2 - Desempenho da PDPL em relação à resistência de falta.

\begin{tabular}{ccc}
\hline \hline Resistência de falta $(\Omega)$ & Tempo médio (s) & \% de acerto \\
\hline 0,001 & 0,286 & 28,9 \\
5 & 0,21 & 48,5 \\
25 & 0,20 & 100 \\
50 & 0,196 & 100 \\
75 & 0,196 & 100 \\
100 & 0,197 & 100 \\
150 & 0,197 & 100 \\
200 & 0,197 & 100 \\
300 & 0,198 & 100 \\
400 & 0,199 & 100 \\
\hline \hline
\end{tabular}

Quanto à análise da sensibilidade da PDPL em relação ao tipo de falta, apresenta-se o gráfico da Figura 5.13. O gráfico representa a atuação da metodologia na linha 3, com ângulo de inserção da falta de $0^{\circ}$, a uma distância de $150 \mathrm{~km}$ da barra 2, variando a resistência e o tipo de falta. Cabe ressaltar que todas 
as situações apresentaram uma conformidade na resposta no tempo de atuação a partir da resistência de falta igual a 5 ohms.

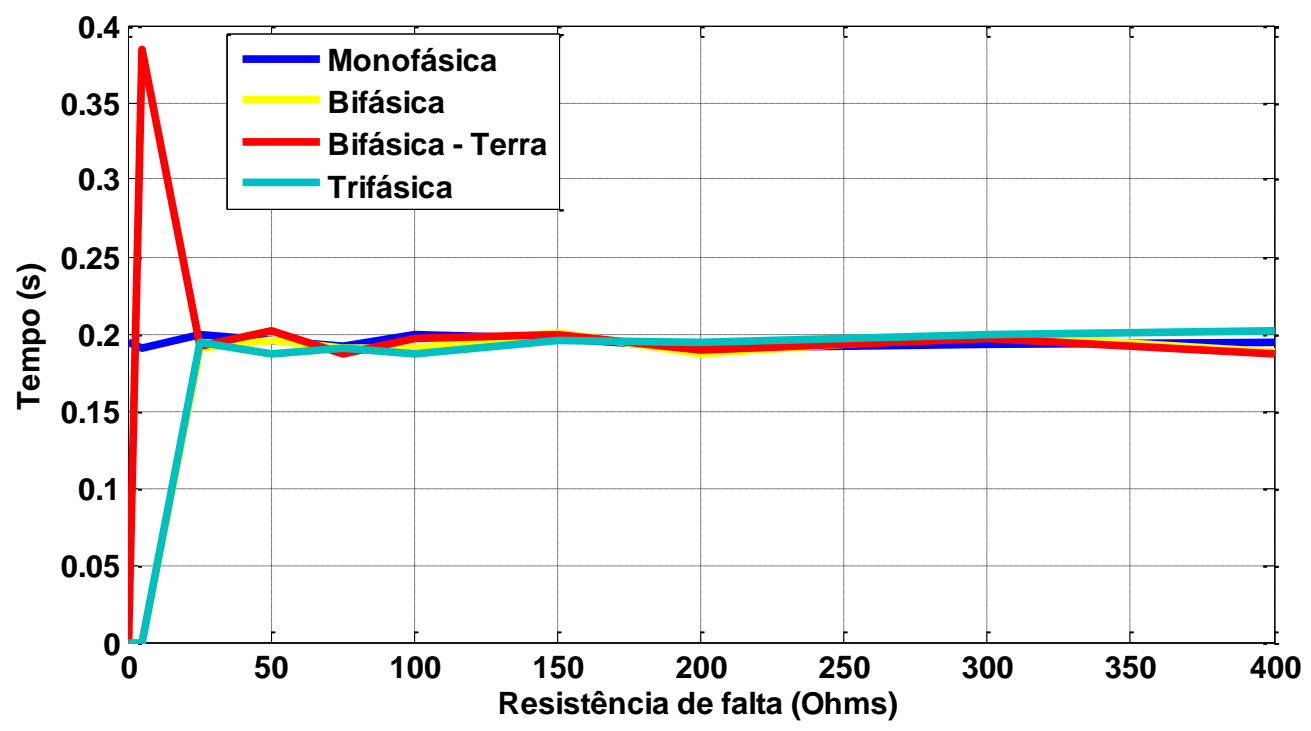

Figura .5.13 - Desempenho da metodologia da PDPL de acordo com o tipo de falta.

Na Tabela 5.3 encontram-se os tempos médios de atuação e o percentual de acerto para cada tipo de falta, utilizando para este cálculo, um total de 480 faltas para cada situação. Observando o desempenho geral da metodologia em relação à variação do tipo de falta, verifica-se que a metodologia apresenta maior dificuldade para detecção de faltas bifásicas sem o envolvimento da terra. Porém, diferentemente do desempenho frente à variação da resistência de falta, o desempenho da metodologia quanto à variação do tipo de falta se deu de forma mais uniforme. 
Tabela 5.3 - Desempenho da PDPL em relação ao tipo de falta considerado.

\begin{tabular}{ccc}
\hline \hline Tipo de falta & Tempo médio (s) & \% de acerto \\
& & \\
\hline$A-T$ & 0,203 & 93,54 \\
$B-T$ & 0,205 & 93,75 \\
$C-T$ & 0,205 & 93,75 \\
$A B-T$ & 0,198 & 86,04 \\
$B C-T$ & 0,197 & 86,04 \\
$C A-T$ & 0,198 & 86,25 \\
$A B C$ & 0,195 & 86,66 \\
$A B$ & 0,198 & 83,75 \\
$B C$ & 0,198 & 83,75 \\
$C A$ & 0,198 & 83,75 \\
\hline \hline
\end{tabular}

Para a análise do desempenho da metodologia em relação à distância, são apresentados os gráficos das Figuras 5.14 e 5.15. Ambos são resultados de faltas que ocorreram ao longo da LT3, sob uma falta trifásica, com ângulo $0^{\circ}$. Na Figura 5.14, são apresentadas as faltas cuja localização se encontra próxima à barra 2, e na Figura 5.15, as faltas mais próximas à barra 5 .

De acordo com os gráficos, a resposta da metodologia foi uniforme em relação à variação da distância, sendo que a Tabela 5.4 reforça o quão satisfatórios foram os resultados encontrados. Percebe-se também um percentual menor de acertos em relação às localizações de $95 \%$ e $90 \%$.

Outra conclusão acerca deste caso, é que a atuação da metodologia se deu de forma incorreta quando simuladas as faltas com resistência de falta muito baixa (0,001 ohms). Cabe ressaltar que o percentual de acerto e o tempo médio foram calculados considerando 600 casos de falta para cada localização. 


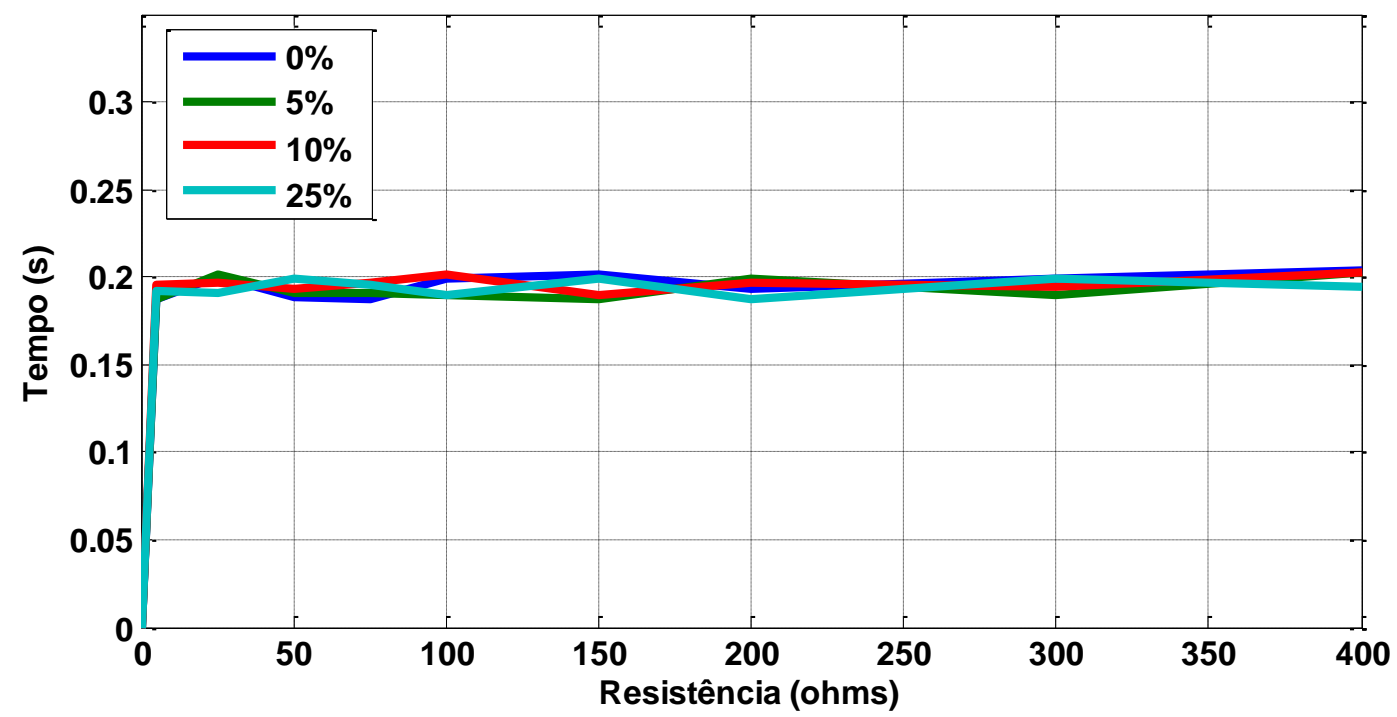

Figura 5.14 - Desempenho da metodologia da PDPL de acordo com a distância próxima à barra 2.

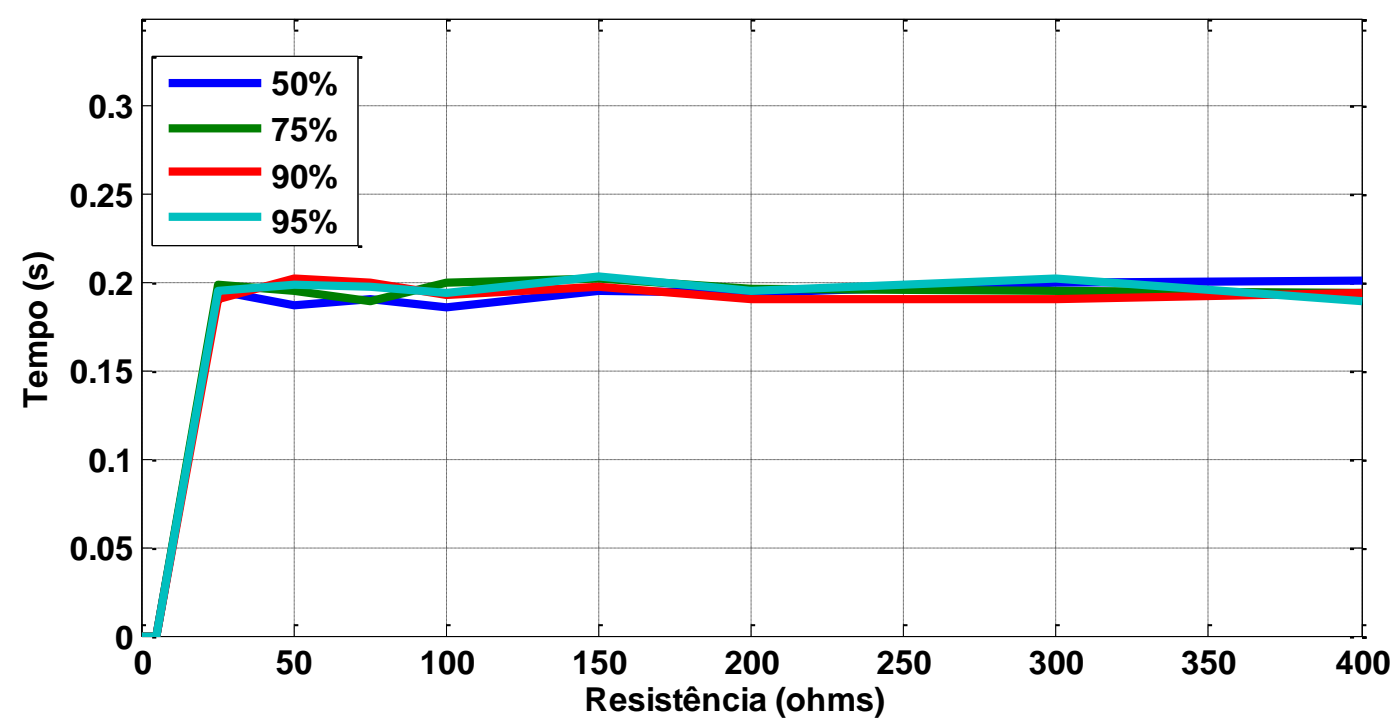

Figura 5.15 - Desempenho da metodologia da PDPL de acordo com a distância próxima à barra 5. 
Tabela 5.4 - Desempenho da PDPL em relação à localização.

\begin{tabular}{ccc}
\hline \hline \multirow{2}{*}{ Localização } & Tempo médio (s) & \% de acerto \\
\hline $0 \%$ & 0,2 & 88,5 \\
$5 \%$ & 0,199 & 90,6 \\
$10 \%$ & 0,2 & 92 \\
$25 \%$ & 0,2 & 92 \\
$50 \%$ & 0,2 & 89,6 \\
$75 \%$ & 0,197 & 84,5 \\
$90 \%$ & 0,199 & 82,3 \\
$95 \%$ & 0,201 & 82,3 \\
\hline \hline
\end{tabular}

Em seguida, a análise foi realizada para a variação do ângulo de falta. Os resultados estão sumarizados na Tabela 5.5, utilizando para o cálculo, um total de 2.400 casos de falta para cada ângulo de falta considerado. Nesta, é possível concluir que, para esta metodologia, o ângulo de incidência da falta não teve grande influência nas respostas, visto que o percentual de acerto e o tempo médio de detecção da falta foram muito próximos.

O desempenho da metodologia da PDPL frente às situações de faltas aplicadas em cada linha é contemplado na Tabela 5.6. Conforme pode ser observado, a metodologia teve mais dificuldades para encontrar erros na LT3 e na LT5. Para calcular estes valores, foram considerados 1.600 casos para cada linha de transmissão.

Tabela 5.5 - Desempenho da PDPL em relação ao ângulo de inserção da falta.

\begin{tabular}{ccc}
\hline \hline Ângulo de inserção da falta & Tempo médio (s) & \% de acerto \\
\hline $0^{\circ}$ & 0,202 & 87,79 \\
$90^{\circ}$ & 0,203 & 87,7 \\
\hline \hline
\end{tabular}


Tabela 5.6 - Desempenho da PDPL em relação à linha de transmissão onde ocorreu a falta.

\begin{tabular}{ccc}
\hline \hline Linha & Tempo médio & \% de acerto \\
& & \\
\hline 3 & 0,211 & 87,62 \\
5 & 0,209 & 83,31 \\
6 & 0,197 & 92,31 \\
\hline \hline
\end{tabular}

\subsubsection{Desempenho da Proteção Diferencial de Potência}

Para a metodologia da PDP, serão considerados os mesmos casos apresentados para a avaliação do desempenho da PDPL.

No primeiro caso, apesar de um tempo maior para atuar frente à falta com uma resistência muito baixa $(0,001$ ohms $)$, o desempenho da PDP pode ser considerado satisfatório. Pelas figuras que seguem, mostra-se que a metodologia também detectou satisfatoriamente as faltas com baixa (Figura 5.16) e com alta (Figura 5.17) resistência.

A Tabela 5.7 representa o desempenho da PDP em relação à variação da resistência de falta. Nesta, é possível observar que a metodologia detectou, com mais de $90 \%$ de acerto, em um total de 480 situações, todos os tipos de falta. 


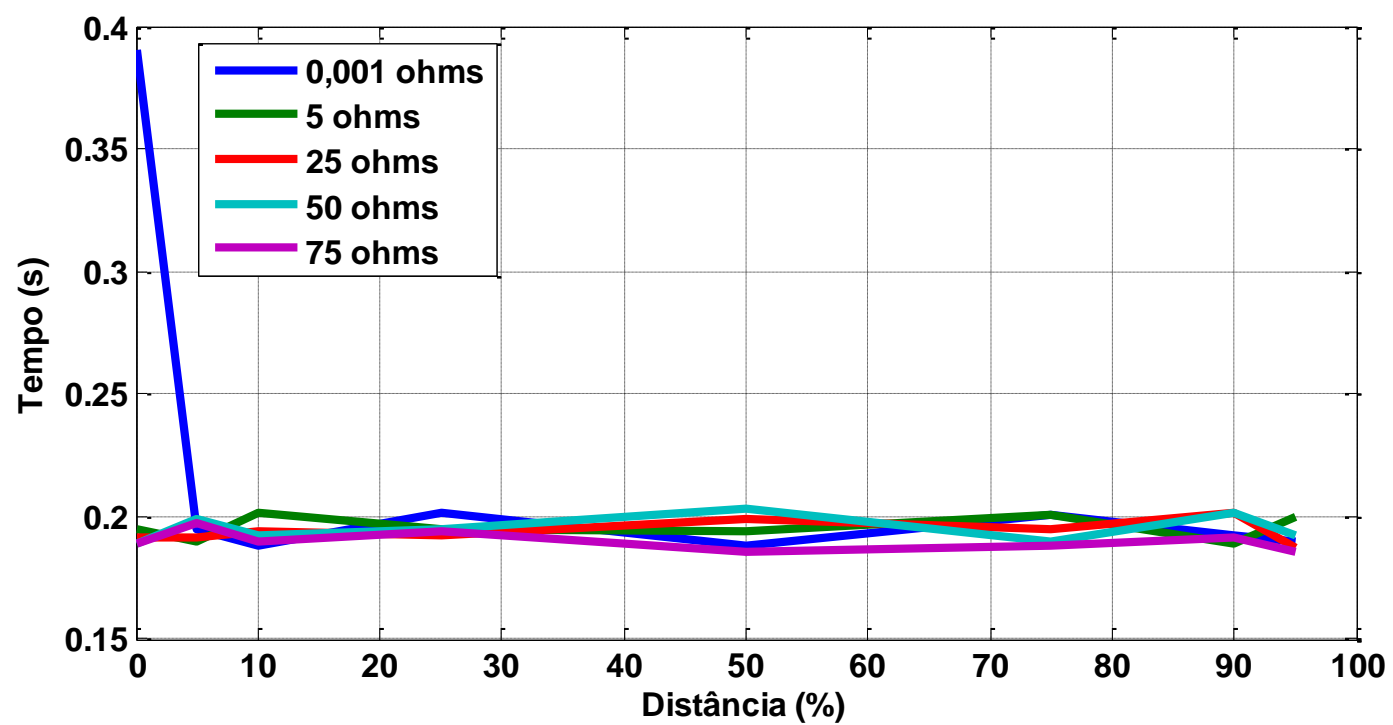

Figura 5.16 - Desempenho da metodologia da PDP para baixas resistências de falta.

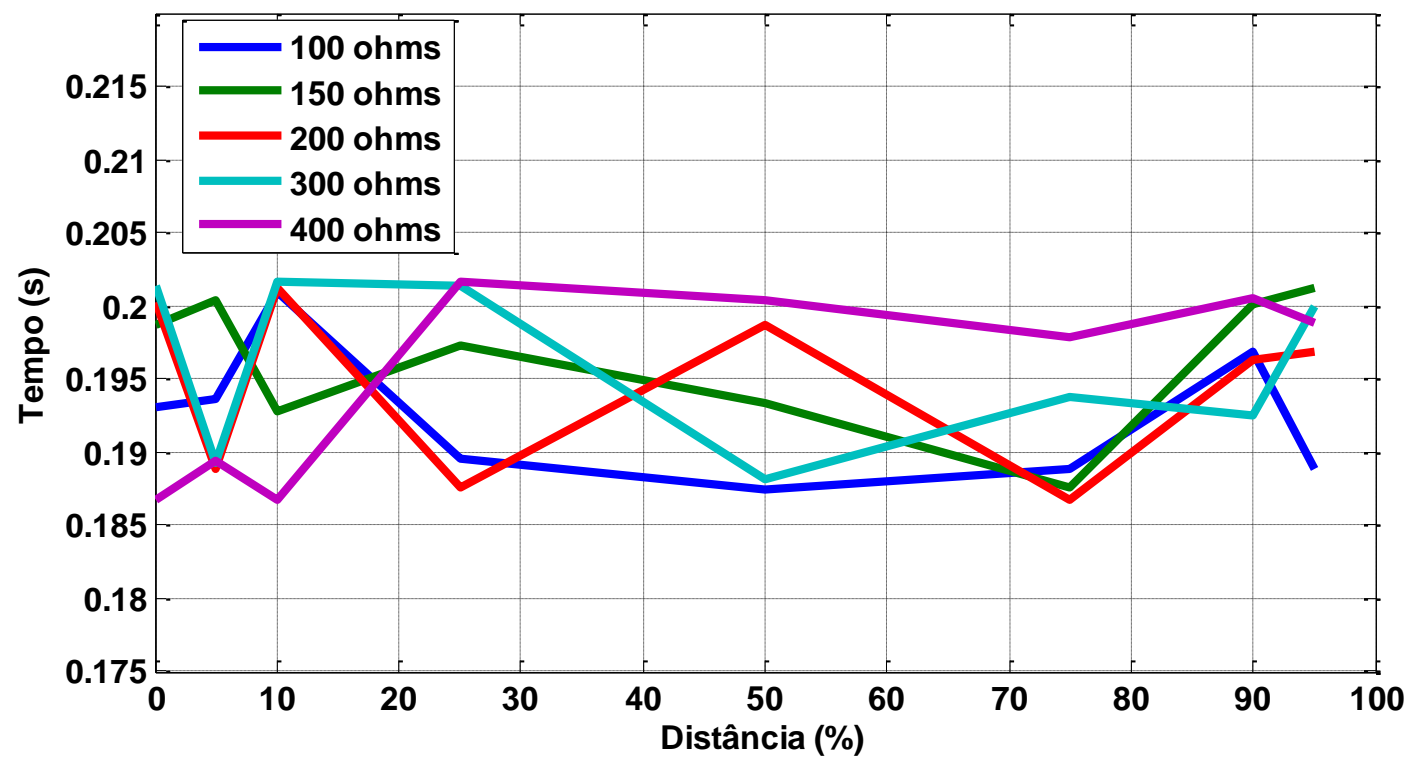

Figura 5.17 - Desempenho da metodologia da PDP para altas resistências de falta. 
Tabela 5.7 - Desempenho da PDP em relação à resistência de falta.

\begin{tabular}{ccc}
\hline \hline Resistência $(\Omega)$ & Tempo médio (s) & \% de acerto \\
& & \\
\hline 0,001 & 0,198 & 93,3 \\
5 & 0,195 & 96,04 \\
25 & 0,195 & 96,45 \\
50 & 0,195 & 98,12 \\
75 & 0,196 & 98,75 \\
100 & 0,195 & 99,4 \\
150 & 0,196 & 99,6 \\
200 & 0,196 & 100 \\
300 & 0,196 & 100 \\
400 & 0,197 & 100 \\
\hline \hline
\end{tabular}

Em relação ao desempenho quanto ao tipo de falta, através da Figura 5.18, observa-se que, para a LT3, a $150 \mathrm{~km}$ da barra 2, para todos os tipos de falta e para qualquer valor de resistência de falta, a PDP detectou satisfatoriamente as faltas aplicadas.

A Tabela 5.8 mostra que a metodologia teve um desempenho aceitável, atuando em mais de $95 \%$ para cada tipo de falta. As faltas que apresentaram mais dificuldade para detecção foram as monofásicas.

Para a avaliação de desempenho quanto à variação da distância, apresentam-se as Figuras 5.19 e 5.20. Este caso é referente às faltas trifásicas aplicadas à LT3, com ângulo de inserção de 0. Para este caso, todas as faltas foram detectadas com sucesso. A Tabela 5.9 mostra o desempenho geral da PDP em relação à variação da localização da falta. Pelo percentual de acerto, tomado com base em 480 simulações, percebe-se um desempenho uniforme para todas as distâncias consideradas. 


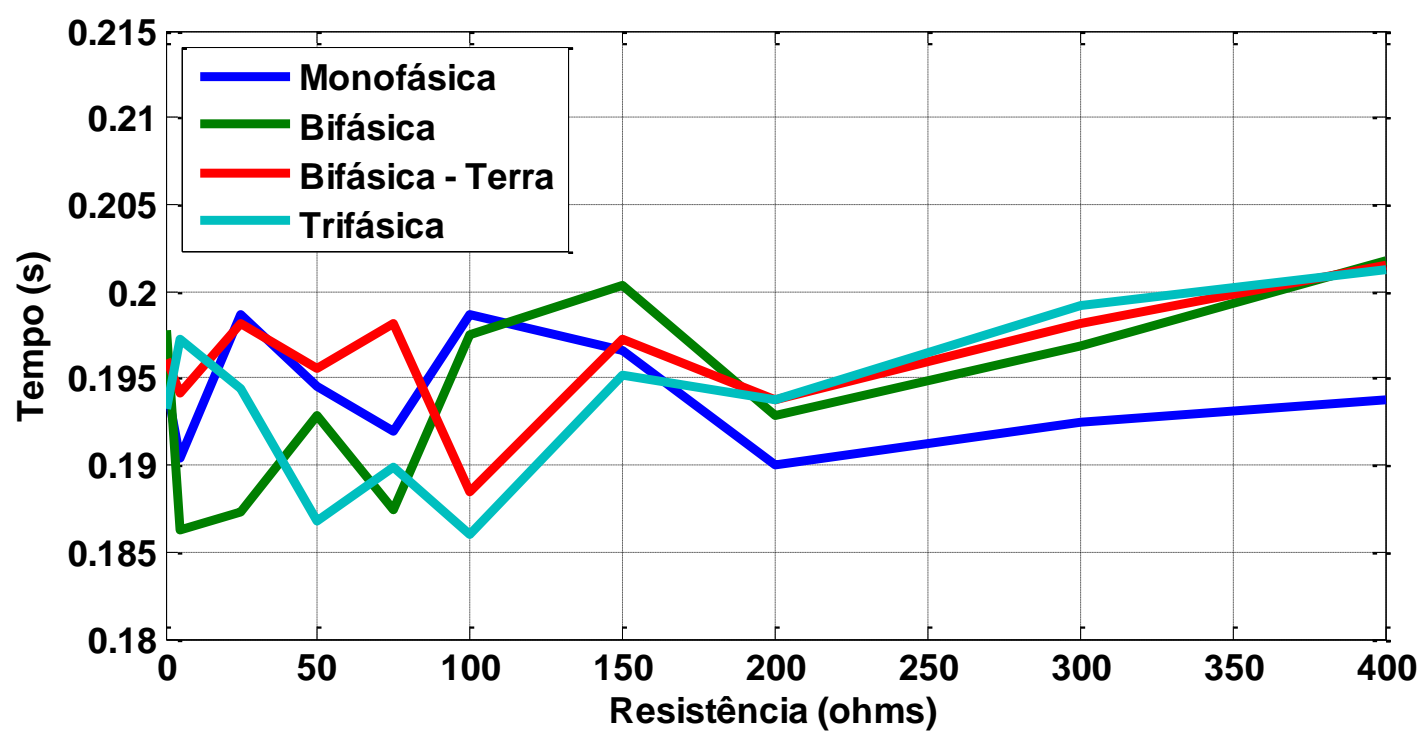

Figura 5.18 - Desempenho da metodologia da PDP de acordo com o tipo de falta.

Tabela 5.8 - Desempenho da PDP em relação ao tipo de falta.

\begin{tabular}{ccc}
\hline \hline Tipo de falta & Tempo médio (s) & \% de acerto \\
& & \\
\hline$A-T$ & 0,196 & 98,3 \\
$B-T$ & 0,197 & 97,3 \\
$C-T$ & 0,197 & 97,3 \\
$A B-T$ & 0,195 & 98,12 \\
$B C-T$ & 0,195 & 98 \\
$C A-T$ & 0,196 & 98 \\
$A B C$ & 0,194 & 99,5 \\
$A B$ & 0,196 & 97,5 \\
$B C$ & 0,197 & 98,75 \\
$C A$ & 0,197 & 99 \\
\hline \hline
\end{tabular}




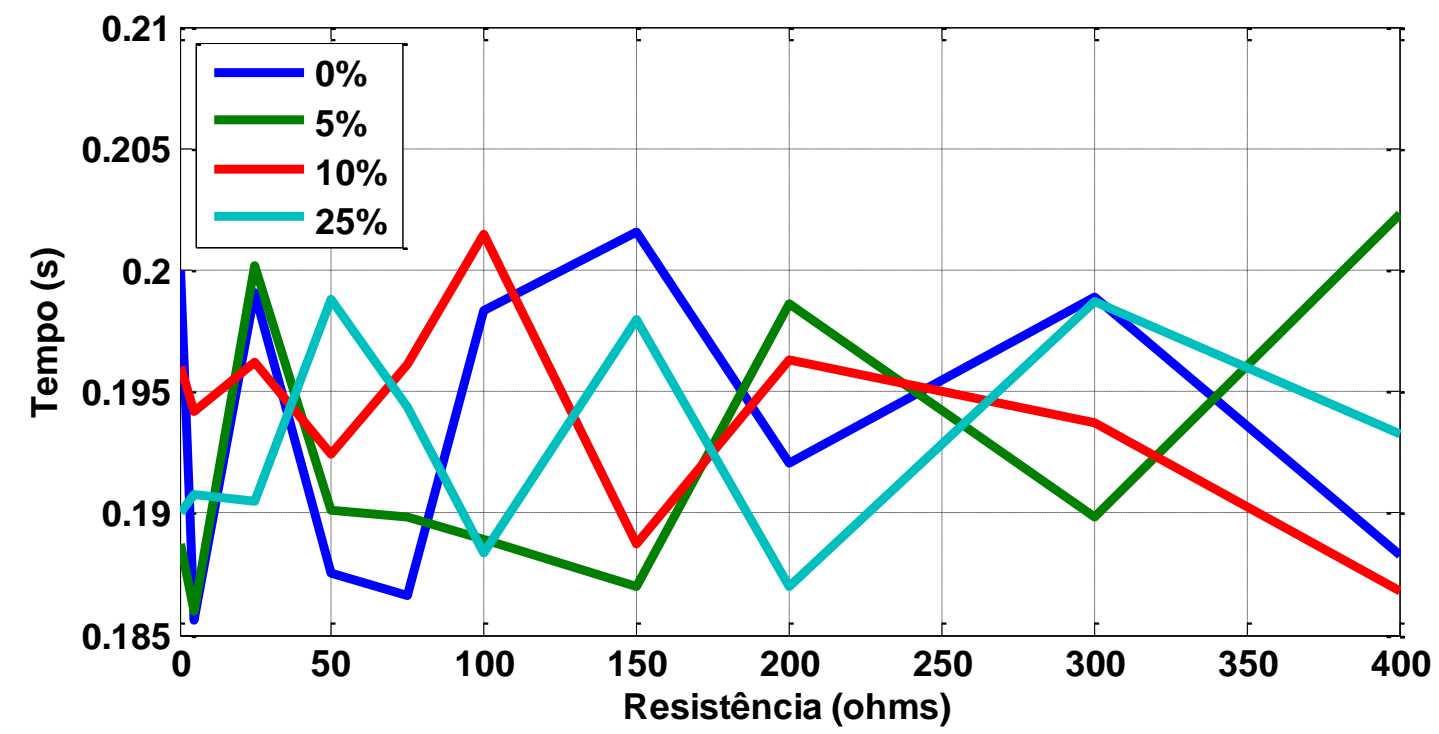

Figura 5.19 - Desempenho da metodologia da PDP de acordo com a distância de aplicação da falta.



Figura 5.20 - Desempenho da metodologia da PDP de acordo com a distância de aplicação da falta. 
Tabela 5.9 - Desempenho da PDP em relação à distância de aplicação da falta.

\begin{tabular}{ccc}
\hline \hline Distância (\%) & Tempo médio (s) & \% de acerto \\
\hline 0 & 0,198 & 97,2 \\
5 & 0,195 & 100 \\
10 & 0,195 & 100 \\
25 & 0,195 & 100 \\
50 & 0,196 & 100 \\
75 & 0,195 & 97,3 \\
90 & 0,195 & 95,6 \\
95 & 0,195 & 95 \\
\hline \hline
\end{tabular}

Assim como na metodologia da PDPL, as localizações que a metodologia de PDP mais teve dificuldade de acerto foram as correspondentes a $90 \%$ e $95 \%$, porém com um percentual de acerto maior que a primeira.

Outro parâmetro considerado nas simulações foi o ângulo de inserção da falta. Para a análise de desempenho em relação a esta variável, apresenta-se a Tabela 5.10. Com este resultado, conclui-se que não há diferença significante entre estas variáveis, mostrando que o ângulo de inserção de falta pouco influencia no desempenho desta metodologia.

Tabela 5.10 - Desempenho da PDP em relação ao ângulo de inserção da falta.

\begin{tabular}{ccc}
\hline \hline \multirow{2}{*}{ Ângulo de inserção da falta } & Tempo médio (s) & \% de acerto \\
\hline $0^{\circ}$ & 0,198 & 98,4 \\
$90^{\circ}$ & 0,196 & 98 \\
\hline \hline
\end{tabular}

Analisando todos os casos e obtendo o desempenho geral da metodologia em cada linha de transmissão, obteve-se a Tabela 5.11. Por esta conclui-se que o desempenho desta metodologia foi satisfatório, atuando em quase $100 \%$ dos casos. A linha de transmissão que a metodologia mais apresentou erros também foi a LT3, como para a PDPL, porém, com um percentual de acerto maior. 
Tabela 5.11 - Desempenho da PDP em relação à linha de transmissão onde ocorreu a falta.

\begin{tabular}{ccc}
\hline \hline Linha & Tempo médio (s) & \% de acerto \\
& & 99,8 \\
5 & 0,197 & 95,6 \\
6 & 0,195 & 99 \\
\hline \hline
\end{tabular}




\section{Conclusão}

O trabalho teve o objetivo de apresentar o desenvolvimento de um algoritmo de proteção de retaguarda de linhas de transmissão utilizando medição fasorial sincronizada, procurando contribuir com a melhoria da confiabilidade de um sistema de proteção de grandes áreas. As simulações foram realizadas a partir do RTDS®, para que, futuramente, haja a possibilidade de realizar uma simulação em malha fechada, para dar maior confiabilidade ao algoritmo.

A utilização do SMFS em um sistema real se mostra viável tecnicamente, pois o mesmo permite a aquisição dos dados de tensão e corrente de forma sincronizada de locais afastados geograficamente. Tal sincronismo oferecido pelo SMFS é um dos requisitos principais para o aumento da confiabilidade do sistema de proteção por garantir que as amostras foram colhidas no mesmo instante de tempo.

As metodologias obtiveram um desempenho satisfatório nos testes até então realizados. Observou-se durante os testes que ainda há a necessidade de um ajuste mais complexo das metodologias para que as mesmas melhorem o percentual de acerto na localização das situações de faltas apresentadas. Por outro lado, o trabalho permitiu uma análise do comportamento da potência durante as faltas, e apresentou-a como uma variável interessante a ser mais estudada, e dando bons indicativos da sua aplicação em sistemas reais.

Vale ressaltar que, de acordo com (MAEZONO et al., 2009), os valores de resistência de falta esperados para sistemas de transmissão estão ente 20 a 60 
ohms, e, portanto, considerando tal afirmação como verdade, ambas as metodologias cumprem com sucesso a performance nesta faixa de resistência de falta.

Dessa forma, os algoritmos alcançaram os resultados esperados para os testes de alta impedância, sendo útil para o objetivo proposto. A metodologia da Proteção Diferencial Potência Local (PDPL), mostrou-se uma metodologia mais simples de ser implementada, devido ao fato de não exigir um canal de comunicação robusto entre os extremos. Porém esta ainda merece ser mais bem ajustada para cobrir faltas de baixa impedância. A metodologia de Proteção Diferencial de Potência (PDP) apresentou um desempenho melhor, porém, deve-se salientar que os valores de tempo de atuação apresentados foram baseados na literatura correlata. Portanto, para a escolha da metodologia, além de se analisar as necessidades do sistema ao qual a metodologia será inserida, deve-se ainda simular o sistema de comunicação como um todo.

Outra observação a ser ressaltada, é que as duas metodologias (PDPL e PDP) podem atuar conjuntamente, assegurando uma atuação confiável da proteção implementada. As duas apresentaram capacidade de complementar uma à outra, alcançando os objetivos propostos neste trabalho, que é desenvolver metodologias confiáveis e que atuem frente às faltas de alta impedância, utilizando o SMFS. Contudo, para a eficácia desta última afirmação, seria necessária uma lógica para apontar se a falta enfrentada é de baixa ou de alta impedância.

Cabe observar que os testes foram realizados considerando as linhas com chaveamento tripolar. Para um chaveamento monopolar, as duas metodologias deverão ser adaptadas para contemplar esta situação.

Este trabalho também aponta para uma função a mais que pode ser implementada nos SMFS atuais, via as PMU já instaladas em campo. Contudo, para 
tal, deve-se observar os requisitos de comunicação da metodologia para a implementação das mesmas no sistema.

Para a continuidade dos trabalhos, sugere-se a realização da simulação em malha fechada de todo o sistema em análise. Para comprovar a eficácia das metodologias propostas, a implementação das mesmas em malha fechada para simular um sistema de proteção real, utilizando os meios de comunicação e os protocolos necessários, responderia com melhor precisão ao tempo de atuação das proteções. Esta simulação também se mostraria importante em relação aos ajustes a serem realizados.

Para a completa validação destas metodologias, seria necessário testar o comportamento das mesmas frente às várias condições de carregamento do sistema e com fontes fracas, para que se garanta a atuação das mesmas no caso de corrente de outfeed. Nessas condições, no caso de uma falta interna, a corrente flui de um dos terminais da linha protegida para a fonte, ao invés de fluir para a falha (BHALJA; MAHESHWARI, 2008).

Procurar uma alternativa para que a PDPL atue para faltas de baixa impedância é um desdobramento interessante para esta pesquisa. Como possível solução para a sensibilidade da PDPL frente à faltas de baixa impedância, tem-se a implementação da memória de tensão, que é um artificio comumente utilizado pela função de proteção de distância, que utiliza a tensão de pré-falta para o caso de perda da tensão de polarização quando ocorre uma falta com tensão próxima a zero volt (MORAIS;CARVALHO FILHO; SILVEIRA, 2012) (SCHWEITZER; ROBERTS, 2010). 


\section{Publicações}

Até o momento, parte do trabalho como apresentado já foi exposto no INDUSCON (International Conference on Industry Applications - INDUSCON 2014):

Costa, A. F. N.; Mourinho, F. A.; Oleskovicz, M. "Sistema de Medição Fasorial Sincronizado Aplicado à Proteção de Grandes Áreas de Sistemas de Transmissão", INDUSCON, Juiz de Fora, MG, 2014.

Um resumo estendido da pesquisa como apresentada, também foi submetido, e aceito na Conferência Internacional Developments in Power System Protection, que ocorrerá entre os dias 07 e 10 de março de 2016, em Edinburgh, Escócia, e ainda está em avaliação. 


\section{Referências}

ANDRADE, S. R. C. Sistemas de Medição Fasorial Sincronizada: Aplicações para Melhoria da Operação de Sistemas Elétricos de Potência. Universidade Federal de Minas Gerais. Belo Horizonte, p. 143. 2008.

ASHTON, P. M.; TAYLOR, G. A.; CARTER, A. M. Future Wide Area Monitoring Requirements for the GB Transmission System. 10th IET International Conference on AC and DC Power Transmission, Birmingham, 04-05 Dezembro 2012. 1-6.

BAHMANI, B.; JAHROMI, M. E.; RANJBAR, A. M. Optimizing the Operation of Current Differential Protection by Power Differential Relay for Three Phase Transformer. IEEE Grid and Cooperative Computing Conference (GCC), Manama, 20-22 Março 2006. 1-6.

BARROS, A. C. Detecção e Classificação de Faltas de Alta Impedância em Sistemas Elétricos de Potência Usando Lógica Fuzzy. Universidade Estadual Paulista. Ilha Solteira, p. 94. 2009. Dissertação (Mestrado).

BHALJA, B.; MAHESHWARI, R. P. New differential protection scheme for tapped transmission line. IET Generation, Transmission \& Distribution , v. 2, n. 2, p. 271279, Março 2008. ISSN: 1751-8687.

BUTTAYAK, S.; WORMPUEN, A.; PROMPARN, N.; CHARBKAEW, N.; BUNYAGUL, T. Design of Phasor Data Concentrator for Phasor Monitoring System. IEEE Conference on Sustainable Utilization and Development in Engineerinh and Technology, Kuala Lumpur, 06-09 Outubro 2012. 102-107.

CEPEL. RTDS Simulator Proposal. CEPEL, 2011. Disponivel em: <ftp://ttp.cepel.br/upload/META_Gestao/Termos_Referencia/TAC_MME_14_03_201 2/TR_CEPEL_03_2012/Lab_PMU/P877.2\%20CEPEL\%20(2\%20racks).pdf $>$. Acesso em: 04 Setembro 2014.

COURY, D. V.; OLESKOVICZ, M.; GIOVANINI, R. Proteção Digital de Sistemas Elétricos de Potência: dos Relés Eletromecânicos aos Microprocessados Inteligentes. São Carlos: EDUSP, 2007. ISBN: 978-85-85205-78-2.

DARWISH, A. H.; TAALAB, A. M. I.; AHMED, E. S.; KAWADY, T. A. Dynamic Performance Simulink-Based for the Power Differential Relay. 11th Internacional Middle East Power Systems Conference, El - Mynia, 19-21 Dezembro 2006. 476480. 
DARWISH, H. A.; TAALAB, A. M. I.; AHMED, E. S.; MALIK, O. P. Experimental Evaluation of Power Differential Relay for Transmission Line Protection. IEEE/PES Power Systems Conference and Exposition, Seatle, 15-18 Março 2009. 1-7.

DARWISH, H. A.; TAALAB, A. M. I.; AHMED, E. S. Investigation of Power Differential Concept for Line Protection. IEEE Transactions on Power Delivery, v. 20, p. 617624, Abril 2005. ISSN: 0885-8977.

DARWISH, H. A.; TAALAB, A. M. I.; AHMED, E. S. Investigation of Power Differential Concept for Line Protection. IEEE Transactions on Power Delivery, v. 20, n. 02, p. 617-624, Abril 2005. ISSN: 0885-8977.

EISSA, M. M. Ground Distance Relay Compensation Based on Fault Resistance Calculation. IEEE Transactions on Power Delivery, v. 21, n. 4, p. 1830- 1835, Outubro 2006. ISSN: 0885-8977.

EISSA, M. M.; ALLAM, A. M.; MAHFOUZ, M. M. A.; GABBAR, H.. Wireless Communication Requirements Selection according to PMUs Data Transmission Standard for Smart Grid. IEEE International Conference on Smart Grid Engineering, Oshawa, 27-29 Agosto 2012. 1-8.

EISSA, M. M.; MASOUD, M. E.; ELANWAR, M. M. M. A Novel Back Up Wide Area Protection Technique for Power Transmission Grids Using Phasor Measurement Unit. IEEE Transactions on Power Delivery, v. 25, n. 1, p. 270-278, Janeiro 2010. ISSN: 0885-8977.

GAN, Z.; BO, Z. Q.; CAUNCE, B. R. J.; MONTIGLAN, D. A New Protection Scheme for High Impedance Fault Using Adaptive Trip and Reclosure Technique. International Conference on Power System Technology, Kunming, 13-17 Outubro 2002. 295-299.

GOLSHANI, M.; TAYLOR, G. A.; PISICA, I.; ASHTON, P. Implementation of Wide Area Monitoring Systems and Laboratory-Based Deployment of PMUs. 48th International Universities Power EngineeringConference, Dublin, 2-5 Setembro 2013. 1-6.

HE, S.; SHAO, C.; XU,C.; ZHANG, R.; LIN, X.; WENG, L. Research on Summation Impedance Relay with Ability to Identify High-Resistance Ground Fault. IEEE PES Asia-Pacific Power and Energy Engineering Conference, Kowloon, 8-11 Dezembro 2013. 1-5.

HE, Z.; ZHANG, Z.; YIN, X.; WANG, H. A Novel Algorithm of Wide Area Backup Protection Based on Fault Component Comparison. International Conferenceon Power System Technology, Hangzhou, 24-28 Outubro 2010. 1-7.

IBRAHIM, D. K.; ELDIN, E. S. T.; ABOUD-ZAHAB, E. M.; SALEH, S. M. HighImpedance Fault Detection in EHV Transmission Lines. 12th Internacional MiddleEast Power System Conference , Aswan, 12-15 Março 2008. 192-199. 
IEEE. IEEE Guide for Protective Relay Applications to Transmission Lines. Institute of Electrical and Eletronics Engineers. Nova York. 2002. ISBN: 0-7381-1832$\mathrm{X}$.

IEEE POWER AND ENERGY SOCIETY. IEEE Standard for Synchrophasor Measurements for Power Systems. The Institute 0 Electrical and Eletronics Engineers. Nova York, p. 49. 2011. ISBN: 978-0-7381-6811-1.

IEEE POWER AND ENERGY SOCIETY. IEEE Guide for Phasor Data Concentrator Requirements for Power System Protection, Control, and Monitoring. Institute of Electrical and Eletronics Engineers. Nova York, p. 53. 2013. ISBN: 978-0-7381-8260-5.

INGELSSON, B.; LINDSTRÖM, P. O.; KARLSSOM, D.; RUNVICK, G.; SJODIN, J. Wide-Area Protection Against Voltage Collapse. IEEE Computer Applications in Power, v. 10, p. 30-35, Outubro 1997. ISSN ISSN: 0895-0156.

JIANG, J. A.; YANG, J. A.; LIN, Y. H.; LIU, C. W.; MA, J. C. An Adaptive PMU Based Fault Detection/Location Technique for Transmission Lines Part: I: Theory and Algorithms. IEEE Transactions on Power Delivery, v. 15, n. 2, p. 486-493, Abril 2000. ISSN:0885-8977.

JIANG, Q.; LI, X.; WANG, B.; WANG, H. PMU-Based Fault Location Using Voltage Measurements in Large Transmission Networks. IEEE Transactions on Power Delivery, v. 27, n. 3, p. 1644-1652, Junho 2012 ISSN: 0885-8977.

JIANG, S.; ANNAKAGE, U. D.; GOLE, A. M. A Plataform for Validation of FACTS Models. IEEE Transactions on Power Delivery, v. 21, n. 1, p. 484-491, Janeiro 2006. ISSN:0885-8977.

KANSAL, P.; BOSE, A. Smart Grid Communication Requirements for the High Voltage Power System. Power and Energy Society General Meeting, San Diego, 24-29 Julho 2011. 1-6.

KAWADY, T. A.; TAALAB, A. M. I.; AHMED, E. S. Dynamic Performance of the Power Differential Relay for Transmission Line Protection. International Journal of Electrical Power \& Energy Systems, v. 32, n. 5, p. 390-397, Junho 2010. ISSN doi:10.1016/j.ijepes.2009.11.004.

KHAN, R. H.; KHAN, J. Y. Wide Area PMU Communication Over a WiMAZ Network in the Smart Grid. IEEE Third International Conference on Smart Grid Communication, Tainan, 5-8 Novembro 2012. 187-192.

KHORASHADI, H. Z.; LI, Z. A Novel PMU-Based Transmission Line Protection Scheme Design. 39th North American Power Symposium, Las Cruces, 30-02 Setembro/Outrubro 2007. 13-19. 
KIM, C. H.; LEE, M. H.; AGGARWAL, R. K. Educational Use of EMTP MODELS for the Study of a Distance Relaying Algorithm for Protecting Transmission Lines. IEEE Transactions on Power Delivery, v. 15, p. 9-15, Fevereiro 2000. ISSN: 0885-8950.

LEE, J. B.; JUNG, C. H.; KIM, J. D.; BAEK, Y. K. Protective Relay Testing and Characteristic Analysis for High Impedance Faults in Transmission Lines. IEEE Power Engineering Society Summer Meeting, Edmonton, 18-22 Julho 1999. 10761081.

LIN, H.; SABAMOORTHY, S.; SKULA, S.; THORP, J.; MILI, L. A Study of Communication and Power System Infrastructure Interdependence on PMU-Based Wide Area Monitoring and Protection. Power and Energy Society General Meeting, San Diego, 22-26 Julho 2012. 1-7.

LIRA, R.; MICOCK, C.; WILSON, D.; KANG, H. PMU Performance Requirements and Validation for Closed Loop Applications. 2nd IEEE PES International Conference and Exhibition on Innovative Smart Grid Technologies, Manchester, 05-07 Dezembro 2011. 1-7.

LUO, L.; TAI, N.; YANG, G. Wide-area Protection Research in the Smart Grid. International Conference on Future Energy, Environment, and Materials, Hong Kong, 12-13 Abril 2012. 1601-1606.

MA, J., LI, J.; THORP, J. S.; ARANA, A. J.; YANG, Q.; PHADKE, A. G. A Fault Steady State Component-Based Wide Area Backup Protection Algorithm. IEEE Transactions on Smart Grid, v. 2, p. 468-475, Julho 2011. ISSN:1949-3053.

MAEZONO, P. K.; ALTMAN, E.; BRITO K.; MARIA, V. A. S. M.; MAGRIN, F. Very High-Resistance Fault on a $525 \mathrm{kV}$ Transmission Line - Case Study. Annual Conference for Protective Relay Engineers, Austin, 30-02 Março/Abril 2009. 322332.

MANTUANO FILHO, S.; SOLLERO, R. B.; MORAES, R. M. Sistemas de Medição Fasorial Princípios e Aplicações. VIII Seminário Técnico de Proteção e Controle, Rio de Janeiro, 28-01 Junho-Julho 2005.

MARTINEZ, C.; PARASHAR, M.; DYER, J.; COROAS, J. Phasor Data Requirements for Real Time Wide-Area Monitoring, Control and Protection Applications. Consortium for Electric Reliability Technology Solutions. [S.I.], p. 27. 2005.

MENEZES, A. V. A Proteção de Retaguarda para Linhas de Transmissão Aplicando Medição Fasorial Sincronizada. Universidade de São Paulo. São Carlos. 2012. Dissertação (Mestrado).

MOLAS, E. C.; SILVA, K. M. Modelagem e Simulação da Proteção Diferencial de Linhas de Transmissão no ATP. IV Simpósio Brasileiro de Sistemas Elétricos, Goiânia, 15-18 Maio 2012. 6. 
MONARO, R. M. Lógica Fuzzy Aplicada na Melhoria da Proteção Digital de Geradores. Universidade de São Paulo. São Carlos, p. 177. 2013. Tese (Doutorado).

MORAES, R. M.; HU, Y. Desafios na utilização de PMUs para Proteção e Controle em Sistemas de Potência. Seminário Técnico de Proteção e Controle, Recife, 1720 Outubro 2010.

MORAES, R. M.; VOLSKIS, H. A. R. Challenges for Large-Scale PMU Application for the Brazilian Interconected Power System. Monitoring of Power System Dynamics Performance, Saint Petersburg, 28-30 Abril 2008. 1-8.

MORAIS, M. F.; CARVALHO FILHO, J. M.; SILVEIRA, P. M. Avaliação da Proteção 67 e 21 de Interconexão entre Cogeração e Concessionária Utilizando o RTDS. Simpósio Brasileiro de Sistemas Elétricos, Goiânia, 15-18 Maio 2012.

MURTHY, C.; MISHRA, A.; GHOSH, D.; ROY, D. S.; MOHANTA, D. K. Reliability Analysis of Phasor Measurement Unit Using Hidden Markov Model. IEEE Journal Systems, v. 8, n. 4, p. 1293-1301, Maio 2014. ISSN: 1932-8184.

NAMDARI, F.; JAMALI, S.; CROSSLEY, P. A. Power Differential Based Wide Area Protection. Electric Power System Research, p. 1541-1551, Dezembro 2006. DOI: 10.1016/j.epsr.2006.10.018.

NAMDARI, F.; JAMALI, S.; CROSSLEY, P. A. Power Differential Protection as Primary Protection of Transmission Lines and Busbar. 9th International Conference on Developments in Power System Protection, Glasglow, 17-20 Março 2008. 8085.

NATIONAL COORDINATION OFFICE. GPS Applications. GPS.gov, 2014. Disponivel em: <http://www.gps.gov/applications/timing/>. Acesso em: 19 Junho 2015.

NAYAK, P. K.; PRADHAN, A. K.; BAJPAI, P. Wide-Area Measurement-Based Backup Protection for Power Network With Series Compensation. IEEE Transactions on Power Delivery, v. 29, n. 4, p. 1970-1977, Agosto 2014. ISSN: 0885-8977.

NEYESTANAKI, M. K.; RANJABAR, A. M. An Adaptive PMU-Based Wide Area Backup Protection Scheme for Power Transmission Lines. IEEE Transactions on Smart Grid, v. 06, n. 03, p. 1550-1559, Janeiro 2015. ISSN ISSN:1949-3053.

OLESKOVICZ, M. Aplicação de Redes Neurais Artificiais na Proteção de Distância. Universidade de São Paulo. São Carlos. 2001. Tese (Doutorado).

ONS. Projeto Estal: Utilização de Fasores no Sistema Interligado Nacional do ONS. Relatório 3: Aplicações das PMU e seus requisitos. Operador Nacional do Sistema. [S.I.], p. 74. 2007. 
ONS. Dados Relevantes - Operação do SIN. Site do ONS - Operador Nacional do Sistema, $2012 . \quad$ Disponivel em: <http://www.ons.org.br/biblioteca_virtual/publicacoes_operacao_sin.aspx>. Acesso em: 02 Setembro 2014.

PHADKE, A. G. Synchronized Phasor Measurements - A Historical Overview. IEEE/PES Transmission and Distribution Conference and Exhibition 2002: Asia Pacific., 6-10 Outubro 2002. 476-479.

PHADKE, A. G.; KASZTENNY, B. Synchronized Phasor and Frequency Measurement under Transient Conditions. IEEE Transactions on Power Delivery, v. 24, n. 1, p. 89-95, Janeiro 2009. ISSN:0885-8977.

PHADKE, A. G.; THORP, J. S. Computer Relaying for Power Systems. 2a ed. [S.I.]: John Wiley \& Sons Ltd, 2009. ISBN: 978-0-470-05713-1.

PHADKE, A. G.; THORP, J. S. Communication Needs for Wide Area Measurement Applications. 5th International Conference on Critical Infrastructure, Beijing, 2022 Setembro 2010. 1-7.

PHADKE, A. G.; THORP, S. J. Synchronized Phasor Measurements and Their Applications. Nova York: Springer Science, 2008. ISBN: 978-0-387-76535-8.

QUANTA TECHNOLOGY. Simulation \& Testing Capabilities Synchrophasor/WAMPAC. Quanta Technology, 2014. Disponivel em: <http://quanta-technology.com/sites/default/files/doc-

files/PMU\%20Capability\%20FINAL\%201\%2024\%2014_0.pdf>. Acesso em: 30 Junho 2015.

REASON TECNOLOGIA S.A. Multifunction Digital Fault Recorder: RPV - 310/ RPV 304. Altus Argentina, 2011. Disponivel em: <http://www.altusarg.com.ar/manuales/rpv-manual-en.pdf>. Acesso em: 27 Junho 2015.

SANTOS, A. Q.; MONARO, R. M.; COURY, D. V.; OLESKOVICZ, M.. Analysis of Load Shedding Parameters Through a New Scoring Metric System. IEEE Power and Energy Society General Meeting, Denver, Julho 2015.

SANTOS, B. P. S. Reprodução de Perturbações no Sistema Interligado Nacional a Partir de Dados de Medição Fasorial Sincronizada. Universidade do Rio de Janeiro. Rio de Janeiro, p. 110. 2013. Trabalho de Conclusão de Curso.

SARIZAWA, Y.; MYOYIN, M.; KITAMURA, K.; SUGAYA, N.; HORI, M.; TAKEUCHI, A.; SHUTO, I.; INUKAI, M. Wide-Area Current Differential Backup Protection Employing Broadband Communications and Time Transfer Systems. IEEE Transactions on Power Delivery, v. 13, p. 1046-1052, Outubro 1998. ISSN: 08858977.

SCHWEITZER, E. O.; ROBERTS, J. B. The Journal of the Realiable Power. Schweitzer Engineering Laboratories, Pullman, Julho 2010. Disponivel em: 
$<$ http://www.selinc.com.br/the_reliable_power.aspx>. Acesso em: 11 Novembro 2015.

SILVA FILHO, J. E.; BORBA, G. M. D.; RAMOS, M. A. F. Novas Aplicações Utilizando um PDC e Redes de PMUs de Baixo Custo. Seminário Técnico de Proteção e Controle, Recife, 17-20 Abril 2010.

SILVA, R. G. F. Aplicação dos Sistemas de Medição Fasorial Sincronizada na Avaliação da Estabilidade de Tensão. Universidade Federal de Minas Gerais. Belo Horizonte, p. 124. 2010. Dissertação (Mestrado).

SINGH, B.; SHARMA, N. K.; TIWARI, A. N.; VERMA, K. K.; SINGH, S. N. Applications of Phasor Measurement Units (PMUs) in Electric Power System Networks Incorporated with FACTS Controllers. International Journal of Engineering, Science and Technology, v. 3, n. 3, p. 64-82, 2011. ISSN: 21412839

SIRIWATWORASAKUL, W.; HOONCHAREON, N. Conceptual design of Wide Area Protection in Transmission System. 10th International Conference on Electrical Engineering/Eletronics, Computer, Telecommunications and Information Technology, Krabi, 15-17 Maio 2013. 1-6.

SONG, G.; CAI, X.; LI, D.; GAO, S.; SUONAN, J. A Novel Pilot Protection Principle for VSC-HVDC Cable Lines Based on Fault Component Current. Power Engineering and Automation Conference, Wuhan, 18-20 Setembro 2012. 1-4.

SUN, F.; ZHANG, M.; QI, Q.; FAN, J.; QI, J.; ZHENG, K. Analysis of Phasor Measurement Unit Signal in Wide Area Backup Protection System. 5th International Conference on Biomedical Engineering and Informatics, Chongqing, 16-18 Outubro 2012. 443-446.

TAALAB, A. M. I.; DARWISH, H. A.; AHMED, E. S. Performance of Power Differential Relay With Adaptive Setting for Line Protection. IEEE Transactions on Power Delivery, v. 22, n. 1, p. 50-58, Janeiro 2007. ISSN ISSN:0885-8977.

TAN, J. C.; CROSSLEY, P. A.; MCLAREN, P. G.; GALE, P. F.; HALL, I.; FARREL, I. Application of a Wide Area Backup Protection Expert System to Prevent Cascading Outages. IEEE Transactions on Power Delivery, v. 17, n. 2, p. 375-380, Abril 2002. ISSN 0885-8977.

TENGDIN, J.; WESTFALL, R.; STEPHAN, K. IEEE PES - Power \& Energy Society. Power System Relaying Committee, Março 1996. Disponivel em: <http://www.pespsrc.org/Reports/High_Impedance_Fault_Detection_Technology.pdf>. Acesso em: 11 Junho 2015.

THOLOMIER, D.; APOSTOLOV, A. Adaptative Protection of Tansmission Lines During Wide Area Disturbances. Power Systems Conference and Exposition, Seattle, 15-18 Março 2009. 1-7. 
VOLSKIS, H.; MANO, R.; SOLLERO, R.; MOREALE, M.; SARDINHA, C.; LIMA, L. C.; CRUZ, D.; RODRIGUES, M. A.; TIMBÓ. J. Aplicações de PMU e seu Impacto na Operação do SIN. Encontro para Debates de Assuntos de Operação, São Paulo, 09-13 Novembro 2008.

WAIKAR, D. L.; LIEW, A. C.; ELANGOVAN, S. Design,Implementation and Performance Evaluation of a New Digital Distance Relaying Algorithm. IEEE Transactions on Power Systems, v. 11, p. 448-456, Fevereiro 1996. ISSN: 08858950.

WEN, M.; CHEN, D.; YIN, X. An Energy Differential Relay for Long Transmission Lines. International Journal of Electrical Power \& Energy Systems, v. 55, p. 497502, Fevereiro 2014. ISSN doi:10.1016/j.ijepes.2013.09.035.

WEN-JING, Z.; QING-QUAN, J. Research and Simulation of an Expert System on the Wide-Area Back-up Protection System. IET 9th International Conference on Developments in Power System Protection, Glasgow, 17-20 Março 2008. 192197.

XIA, Y. Q.; DAVID, A. K.; LI, K. K. High-Resistance Faults on a Multi-Terminal Line: Analysis, Simulated Studies and an Adaptive Distance Relaying Scheme. IEEE Transactions on Power Delivery, v. 9, n. 1, p. 492-500, Janeiro 1994. ISSN: 08858977.

XU, H. M.; BI, T. S.; HUANG, S. F.; YANG, Q. X. Study on Wide Area Backup Protection to Prevent Cascading Trips Caused by Flow Transferring. IEEE PES Transmission and Distribution Conference and Exhibition, Dallas, 21-24 Maio 2006. 833-838.

XU, Z. Y.; DU, Z.. Q.; RAN, L.; WU, Y. K.; YANG, Q. X.; HE, J. L. A Current Differential Relay for a 1000-kV UHV Transmission Line. IEEE Transactions on Power Delivery, v. 22, p. 1392-1399, Julho 2007. ISSN:0885-8977.

YABE, K. Power Differential Method for Discrimination between Fault and Magnetizing Inrush Current in Transformers. IEEE Transactions on Power Delivery, v. 12, n. 03, p. 1109-1118, Julho 1997. ISSN:0885-8977.

YANG, Q. S.; MORRISON, I. F. Microprocessor-Based Algorithm for HighResistance Earth-Fault Distance a Protection. IEE Proceedings C Generation, Transmission and Distribution, v. 130, n. 6, p. 306-310, Novembro 1983. ISSN: 0143-7046.

YUEHAI, Y.; DAONANG, Z.; YINGTAO, W.; XIADONG, X.; SHIMING, X. Study on Data Transmission of RTDMS for Power Systems. The International Conference on Advanced Power System Automation and Protection , Beijing, 16-20 Outubro 2011. 2192-2195. 